\title{
EVALUATION OF FACULTY ENGAGEMENT IN PROFESSIONAL LEARNING ACTIVITIES: A MIXED-METHODS STUDY ON COMMUNICATION PROCESSES, VALUE, AND BARRIERS
}

A Dissertation
presented to
the Faculty of the Graduate School
at the University of Missouri-Columbia
In Partial Fulfillment
of the Requirements for the Degree
Doctor of Education
by by GORDON
Dr. Cynthia MacGregor, Dissertation Supervisor
DECEMBER 2018


The undersigned, appointed by the dean of the Graduate School, have examined the dissertation entitled:

EVALUATION OF FACULTY ENGAGEMENT IN PROFESSIONAL LEARNING ACTIVITIES: A MIXED-METHODS STUDY ON COMMUNICATION PROCESSES, VALUE, AND BARRIERS

Presented by Nancy Gordon, a candidate for the degree of doctor of education of educational leadership, and hereby certify that, in their opinion, it is worthy of acceptance.

\begin{tabular}{c}
\hline Professor Cynthia MacGregor \\
\hline Professor Beth Hurst \\
\hline Professor Tami Arthaud \\
\\
Professor Thomas Lane \\
\hline
\end{tabular}




\section{ACKNOWLEDGMENTS}

The pursuit of attaining my Doctor of Education and writing this dissertation has been a long journey. This could not have been done without the support of my administrators, Dr. Rachelle. Darabi and Dr. Chris Craig who understand the time required to complete the dissertation process, my advisor and dissertation chair Dr. Cynthia MacGregor whose guidance has been invaluable, and the reviews and feedback

provided by my dissertation committee members Dr. Beth Hurst, Dr. Tami Arthaud, and Dr. Thomas Lane. I would also like to thank my staff and co-workers in the Faculty Center for Teaching and Learning (FCTL), Dr. Eric Nelson and the FCTL Advisory Council, and Educational Leadership and Policy Analysis (ELPA) cohort members Dr. Michelle Branton and Dr. Lyle Foster. Each of you have walked this path with me and for that I will be forever grateful. Finally, I would like to thank the faculty at Missouri State University (MSU) that participated in this study. I could not be more blessed to be part of an amazing university community. 


\section{TABLE OF CONTENTS}

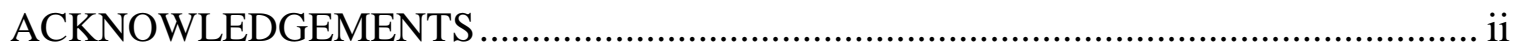

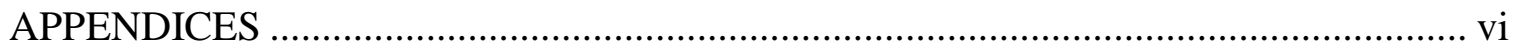

LIST OF FIGURES ...................................................................................... vii

LIST OF TABLES .......................................................................................... vii

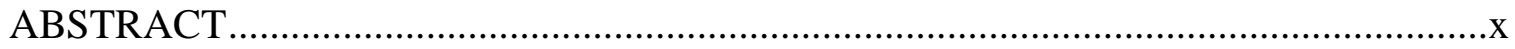

\section{CHAPTERS:}

1. INTRODUCTION TO THE DISSERTATION ................................................

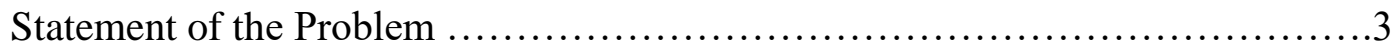

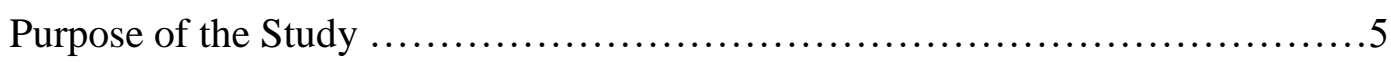

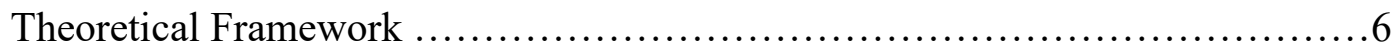

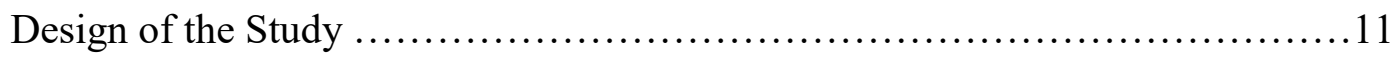

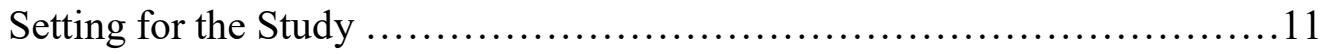

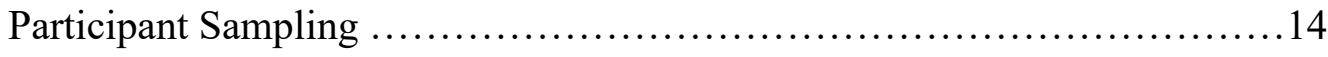

Data Collection ................................................. 14

Data Analysis .................................................... 16

Limitations, Assumptions, and Design Controls ............................ 17

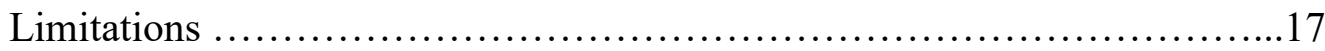

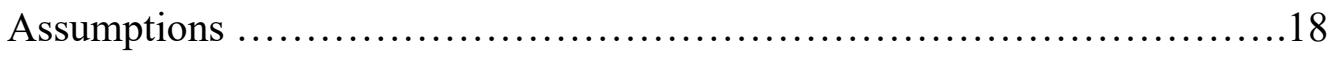

Design Controls .................................................... 18

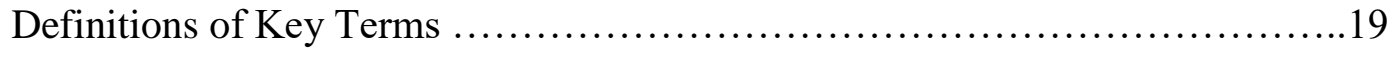

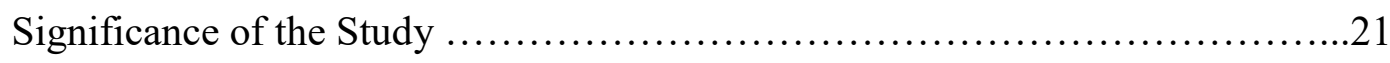

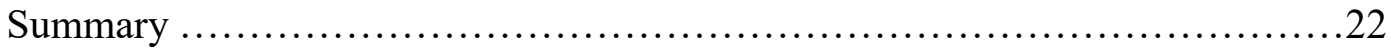




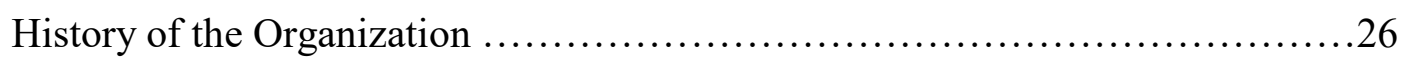

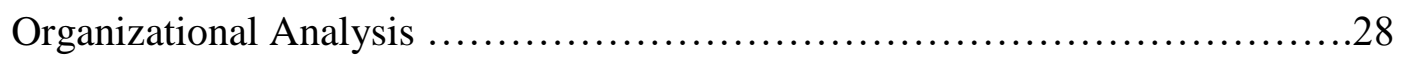

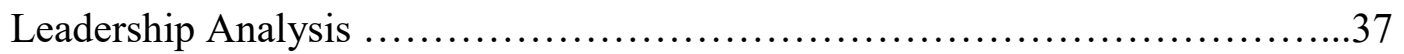

Academic Leadership ................................................. 39

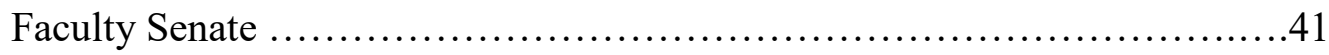

Faculty Center for Teaching and Learning $\ldots \ldots \ldots \ldots \ldots \ldots \ldots \ldots \ldots \ldots \ldots \ldots$

Implications for Research in the Practitioner Setting ........................51

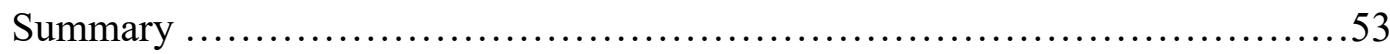

3. SCHOLARLY REVIEW FOR THE STUDY ...............................54

Faculty Development in a University Setting $\ldots \ldots \ldots \ldots \ldots \ldots \ldots \ldots \ldots \ldots \ldots \ldots \ldots 5$

Organizational Culture in Higher Education .............................60

Collaboration and Faculty Leadership ..................................67

Evaluation of Faculty Centers ......................................... 74

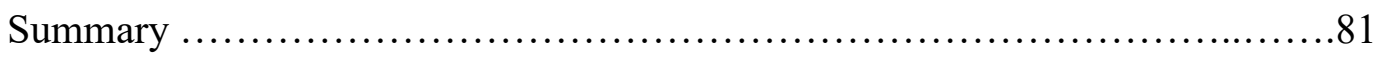

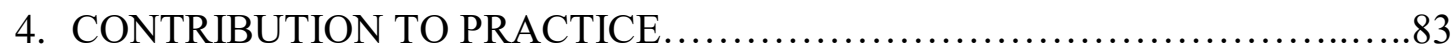

Executive Summary Report ........................................84

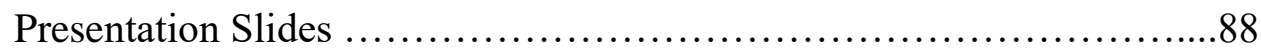

Full Technical Report..............................................98

Sampling and Data Collection Procedures ............................. 100

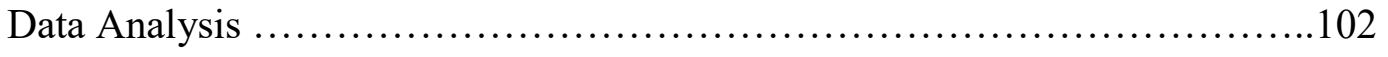

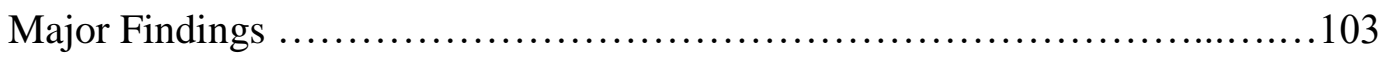

Effectiveness of Communication Processes ........................103 
Faculty Awareness of Professional Learning ........................104

Perceived Expectant Values toward Professional Learning .............106

Perceived Actual Value of Professional Learning Experience ...........110

Perceived Barriers toward Participation ..........................111

Remove Barriers to Participation ..............................., 119

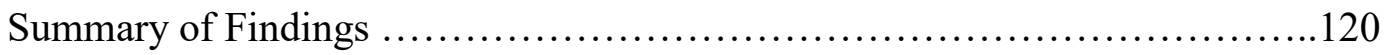

Effectiveness of Communication Processes .......................120

Perceived Values toward Professional Learning Activities ............121

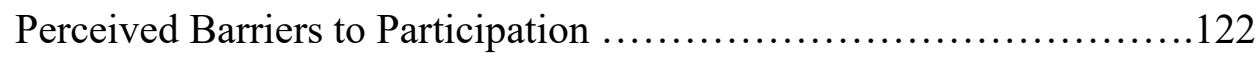

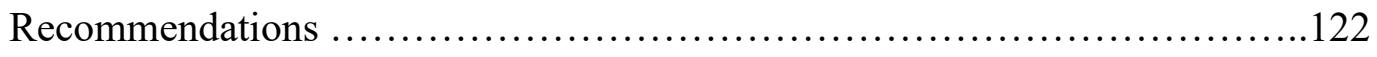

Improving Communication Processes of the Faculty Center ...........123

How to meet Faculty Members' Expectant and Actual Values ..........123

How the Faculty Center can contribute to the Removal of Barriers ......124

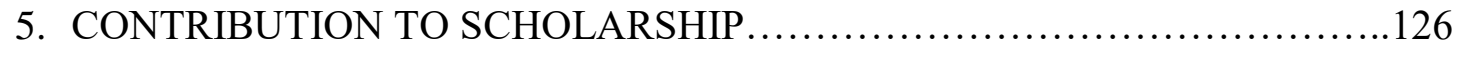

Journal Article Submission: A DEVELOPMENTAL EVALUATION OF A

FACULTY CENTER AND FACULTY ENGAGEMENT IN PROFESSIONAL

LEARNING ACTIVTIES

6. SCHOLARLY PRACTITIONER REFLECTION .......................... 151

How the Dissertation Process influenced Practice as an Educational Leader ...153

How the Dissertation Process influenced me as a Scholar ....................155

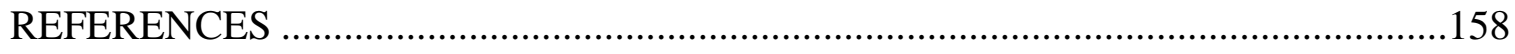




\section{APPENDICES}

A. INVITATION EMAIL AND REMINDERS ..............................................174

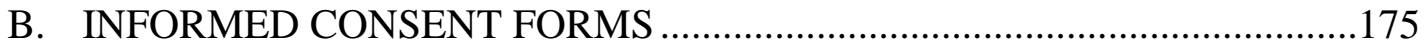

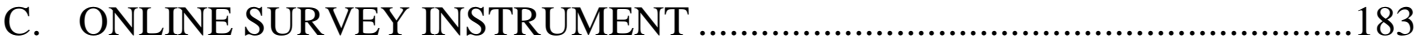

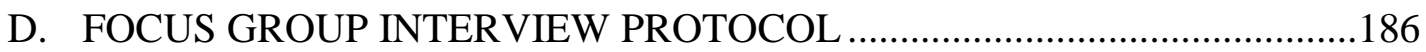

E. PERCEIVED CULTURAL AND SYSTEMS BARRIERS ..................189

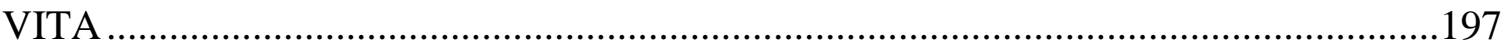




\section{LIST OF FIGURES}

Figure

Page

1. Faculty Engagement based on Expectancy-value Motivation Model...............9

2. Model of Shared Governance .................................................................... 44

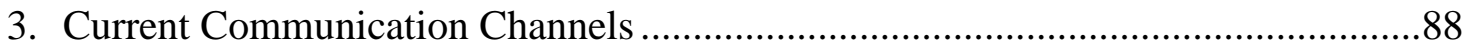




\section{LIST OF TABLES}

Table

Page

1. The CIPP Evaluation Model for Improvement and Accountability..... .10

2. A Framework of Organizational Culture .34

3. Effective Styles for Different Types of Organizational Decisions .40

4. Subcultures Defined in Terms of Relationship with the Dominant Culture.......66

5. The Evolution of Faculty Centers' Contribution and Influence..................68

6. Influence Tactics used to Influence or Create Change.........................69

7. Specific Evaluation Models, Approaches or Focus and Defining Questions........78

8. Years Teaching at the University ............................................ 101

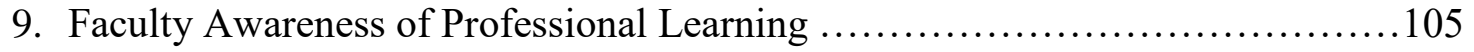

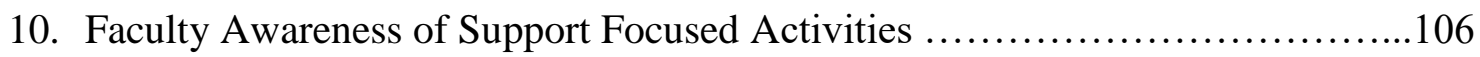

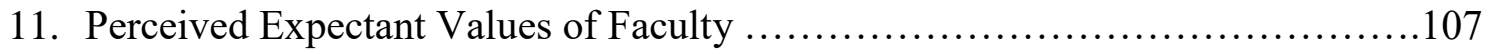

12. Faculty Perceived Expectant Values of Professional Learning Activity...........108

13. Years Teaching and Perceived Expectant Value of Inst. Technology Support....109

14. Years of Teaching and Perceived Expectant Value of MediaSite Support........110

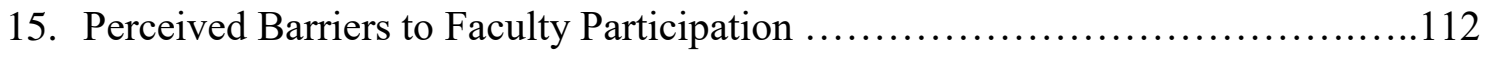

16. Years of Teaching and Relevancy of Faculty Writing Retreats...................113

17. Years of Teaching and Relevancy of Online Course Development...............113

18. Years of Teaching and Barriers for Curriculum Funding .................................115

19. Years of Teaching and Barriers for Faculty Award Program .............................115

20. Perceived Barriers to Support Focused Activities ...........................118 
21. Years of Teaching and the Classification and Frequency of Responses for Changes Needed to Remove Barriers....................................................................119 
EVALUATION OF FACULTY ENGAGEMENT IN PROFESSIONAL LEARNING ACTIVITIES: A MIXED-METHODS STUDY ON COMMUNICATION PROCESSES, VALUE, AND BARRIERS

\author{
Nancy Gordon
}

Dr. Cynthia MacGregor, Dissertation Supervisor

\begin{abstract}
This study was a developmental evaluation of a faculty center at a state funded, public non-research university focused on undergraduate and graduate degree programs that is located in the Midwest United States. The purpose of the study was to investigate effective communication processes utilized by the faculty center, faculty perceptions of value placed on professional learning activities, and perceived barriers to participate in such professional learning activities. Effective communication processes were identified as well as frequent barriers for faculty participation.
\end{abstract}


Section One:

Introduction to the Dissertation 
During a 2017 higher education symposium, a group of university presidents identified the top concerns facing higher education as excellence, access, and affordability (Pazzanese, 2017). Bok (2013) made the claim that if higher education is to flourish in our country, "educators and public officials will have to concern themselves not only with the quantity of higher education but with its quality as well" (p. 223). Bain (2004), professor and author of What the Best College Teachers Do, defined this level of excellence or quality as helping students learn in ways that make "a sustained, substantial and positive influence on how those students think, act, and feel” (p. 5). According to Shuell (1986), if the quality of education is to help students reach these outcomes, then it is the role of faculty "to get students to engage in learning activities that are likely to result in their achieving those outcomes" (p. 429).

A preliminary review of this literature supports the perspective that excellence in higher education is related to the value placed on teaching and learning (Ambrose, Bridges, DiPietro, Lovett, \& Norman, 2010; Bain, 2004, 2012; Bok, 2013; Hutchings, Huber, \& Ciccone, 2011). According to Fink (2013), if a primary purpose of higher education is to "provide high quality teaching and learning, then faculty development programs play a strategically central role in this process of continuous selftransformation" (p. 47). A problem of practice for faculty development centers is how to measure and access the value of professional learning activities. Researchers in this area have identified program evaluation issues to include a lack of time, evaluation expertise, and appropriate models for similar education programs and human services provided by faculty centers (Hines, 2017). 


\section{Statement of the Problem}

Faculty centers have traditionally offered a cafeteria of services including: individual consultations, university-wide orientations, faculty workshops, intensive programs, grants and award programs, resources and publications, and specialized services (Sorcinelli, Austin, Eddy, \& Beach, 2006). The role of faculty centers has been expanding beyond professional learning to one of integrating institutional goals and initiatives into their services and programs (Schroeder, 2011; Sorcinelli et al., 2006). This has been true of the faculty center at Missouri State University (MSU). Through specialized professional learning activities, MSU's faculty center supports the university's long-range goals of diversity and inclusion, high-impact learning practices, distance learning, and expanding instructional technology at the university.

Regardless of these innovations and changes in higher education, the core work of university faculty has essentially remained the same: teaching, research, and service. Missouri State University (MSU) is a state funded, public non-research university focused on undergraduate and graduate degree programs. It has a Carnegie classification of Community Engagement and is dedicated to the university's mission of public affairs (Carnegie Classification, 2017). Enrollment during the fall 2016 semester was over 24,000 students and more than $85 \%$ of these students were undergraduates (MSU, 2017b). Missouri State University has 747 full-time faculty and 392 part-time faculty (MSU, 2017b). The university is "committed to standards of excellence and academic integrity," providing a "high-quality education that is accessible to a broad spectrum of individuals, including those facing challenges involving distance, income, or disability," 
and promoting "diversity in all of its forms as a means to provide a wide variety of sources of knowledge and perspectives" (MSU, 2017c, p. 48).

Faculty support centers assist university faculty in meeting the changing needs of students and the university and with modifying instructional methods that promote active student engagement and deeper learning (Schroeder, 2011; Sorcinelli et al., 2006). This is often done through a variety of professional learning activities including workshops, technology training sessions, informal one-on-one meetings or consultations, communities of practice, or structured programs where a faculty member may completely redesign a course they are teaching (Schroeder, 2011).

Faculty support centers are typically positioned within the organization in such a way that they can provide programming and services for all faculty. They are staffed with professional staff and practitioners with specific areas of expertise (Hines, 2017; Schroeder, 2011). These may include instructional technologist, instructional designers, faculty, and administrators (Schroeder, 2011). Sorcinelli et al. (2006) advised that with many of the changes occurring in higher education that faculty support centers need to "preserve, clarify, and enhance the purposes of faculty development, and to network with faculty and institutional leaders to respond to institutional problems and propose constructive solutions as we meet the challenges of the new century" (p. 28). The literature informs the practitioners in this field that the role and perceived value of faculty support centers has changed over the years. In examining the role of professional learning activities at MSU, no evaluation has investigated the organizational processes that promote or impede faculty engagement in these activities. 


\section{Purpose of the Study}

During the spring of 2017, the Missouri State University (MSU) faculty center and Faculty Senate conducted a survey to collect data on faculty needs and interest in attending faculty development programming. Twenty-three percent of faculty responded that they had no interest in attending professional learning activities that were in support of teaching and university goals. While the majority of faculty indicated workload and scheduling conflicts were their primary reasons for not attending, this survey established a baseline for the value faculty place on professional learning activities offered by the faculty center and their motivation for participating in such activities.

Bolman and Deal (2013) identified four distinctive frames from which people view their world. These frames include the structural frame that focuses on structural elements within the organization, the human resource frame that focuses on people, the political frame that uses a political approach to facilitate change, and the symbolic frame that focuses on vision and inspiration to motivate and form organizations (Bolman \& Deal, 2013). Communications processes within the structural frame are focused on the transmission of facts and information. Like many professionals, faculty can be overwhelmed by the amount and immediacy of information that is communicated. As the volume of information grows attention toward managing this information is also diminished (Griffin, 2012).

The problem of practice being addressed in this study is that many faculty are unaware or uninterested in professional learning activities offered to faculty at MSU through the faculty center. The value faculty place on professional learning may depend 
on the expectant value for participating in these activities, and the communication processes that promote such activities. The central research question for this study is:

What organizational processes promote or impede faculty engagement in professional learning activities at Missouri State University?

Sub-questions include:

1. How effective are the current communication processes being utilized by the faculty center?

a. What are the communication processes that inform faculty about professional learning activities?

b. What is the level of faculty awareness of professional learning activities provided by the faculty center?

2. What are faculty perceptions of value concerning professional learning activities provided by the faculty center?

a. What are the expectant values of non-participating faculty toward professional learning activities?

b. What are the actual values of faculty participants toward such professional learning activities?

3. What are faculty perceptions of barriers to their participation in professional learning activities?

\section{Theoretical Framework}

Bolman and Deal (2013) suggested organizations provide a framework through which members of that organization make decisions, move forward, and make meaning of their actions. The structural framework exists through a hierarchy of offices and 
operates with set rules for how the organization operates and transfers knowledge and information (Bolman \& Deal, 2013). Learning organizations, as defined by Senge (1990), are organizations that are evolving from authoritarian or controlling structures into one of change. These are organizations that seek mental models, a shared vision, and use team learning and interactions in their day to day activities (Senge, 1990). Corporate organizations often undertake this type of transformation or shift in mindset in response to external influences such as a downturn in the economy, increased competition, or a changing workforce (Senge, 1990). Bok (2013) pointed out that universities are more hierarchical and slower to change, holding on to traditional curriculum frameworks and teaching methods that are perceived as dated and inadequate by many of today's students. Nonprofit organizations tend to be driven by their values and concerns about the beliefs and motivations of the individuals who make up the organization (Gill, 2010). Faculty values and motivation are important elements in understanding the culture of any university (Austin, 1990; Bok, 2013; Gappa, Austin, \& Trice, 2005; Hutchings et al., 2011). The core values of faculty are central to their commitment of educating a society of learners and their philosophy of faculty autonomy (Austin, 1990). Wergin (2001) argued that factors of motivation for faculty are closely related to their motives for entering the profession in the first place. These factors include autonomy or the freedom to grow in ways that contribute to a common good, community or belonging to a community of scholars, recognition that supports the disposition that their work is valued, and efficacy or the belief that they are making a tangible impact on their environment (Wergin, 2001). 
Faculty engagement in professional learning is likely determined by whether or not faculty recognizes the role and value of such activities within the university (Schroeder, 2011). If part of a faculty center's role is to advance the university's mission, the ability to communicate and transfer learning toward these desired outcomes is reliant on the organizational members' motivation to do so (Egan, 2008). According to Lunenburg (2010), the organizational structure within a university influences its communication patterns. Hierarchical structures tend to promote a formal flow of communication through upward and downward communication channels; while collaboration and interaction between groups demonstrates a horizontal effort to communicate (Levi, 2014; Miller, 2009). According to Richmond and McCroskey (2009), people to people or the horizontal flow of information often becomes the most important communication channels within an organization.

According to Gratz and Salem (1981), formal communications within a university must be delivered in a way that is appropriate for the purpose of the message and the organizational roles of the intended audience. The language used can easily change information into noise if it is not relevant or communicate value to the intended audience (Gratz \& Salem, 1981). Miller (2009) identified barriers to organizational communication to be information overload, embellished messages, delays in formal communications, and lack of employee trust and openness.

The study of human behavior and motivational theory are often used to identify motivators related to what an individual does or does not do at work (Herzberg, 1968/1987; Maslow, 1943; Vroom, 1964). Expectancy-value theory of motivation (Fishbein \& Ajzen, 1975) is closely linked to use and gratification theory (Blumler \& 
Katz, 1974) and used by communication researchers to study media selection based on existing beliefs rather than differing views. Expectancy-value theory (see Figure 1) predicts that a person's behavior will be determined by the level of value they place on the goal or action (Fishbein \& Ajzen, 1975). This suggests that individuals orient themselves to a situation or activity according to their own beliefs and determination of value.

\begin{tabular}{|c|c|c|c|c|c|}
\hline $\begin{array}{c}\text { Effective } \\
\text { Communication }\end{array}$ & $\begin{array}{c}\text { Expected } \\
\text { Value }\end{array}$ & Action Sought & $\begin{array}{c}\text { Decision to } \\
\text { Act }\end{array}$ & Action & $\begin{array}{c}\text { Actual } \\
\text { Value }\end{array}$ \\
\hline
\end{tabular}

Figure 1. Faculty Engagement based on Expectancy-value Motivation Model

A developmental evaluation focuses on supporting the development of innovation in a complex system or environment (Caffarella \& Daffron, 2013; Patton, 2011).

Utilizing an approach that is based on inquiry focuses on strengthening the assets being evaluated and a reflective practice that includes dialogue from participants (Patton, 2011; Preskill \& Torres, 1999). Hines (2017) reasoned that in order to evaluate the effectiveness of a university faculty center the study must be reflective and focus on structural factors of context, inputs, processes, and products. According to Patton (2011), innovation can take the form of a new program or process and a complex environment, much like a university, is characterized as having interacting and interdependent elements that are beyond central control. Patton (2011) recommended developmental evaluation an effective approach when "performative development of a potentially scalable innovation" is required (p. 22). The evaluative inquiry framework is an ongoing process for helping organizations to evaluate inquiry, reduce uncertainty, and build community (Preskill \& Torres, 1999). According to Patton (2011), "this framework begins by distinguishing beliefs from knowledge" and is an effective "in a situation where the 
action is heavily values-driven" (p. 233). Primary beliefs toward a situation are often informed by a set of values, and Patton (2011) defined a learning organization as "one that, over time, is moving more and more of the support for its actions from beliefs to knowledge" (pp. 233-234).

Evaluative Inquiry (Preskill \& Torres, 1999) and Fishbein and Ajzen's (1975) expectancy-value theory of motivation will be used as the theoretical frameworks for this study. Stufflebeam's CIPP evaluation model for program improvement (Stufflebeam \& Zhang, 2017) will be used to examine communication processes being used and to document faculty feedback on value and perceived barriers (see Table 1).

Table 1

The CIPP Evaluation Model for Improvement and Accountability

Type of Evaluation Description

Context

Evaluation of needs, problems, assets, and opportunities.

Input

Assessment of relevant approaches toward evaluation.

Process

Ongoing check of implementation and documentation of the process.

Product Measure, interpret, and judge outcomes.

Stufflebeam, 2000; Stufflebeam \& Zhang, 2017.

The CIPP evaluation model (Stufflebeam \&Zhang, 2017) is a managementoriented approach that is intended for the evaluation of service providers and valueoriented services. It provides a checklist that can be modified to include specific information needed by the researcher for decision-making purposes (Stufflebeam \& Zhang, 2017). According to Stufflebeam and Zhang (2017), this approach to program 
evaluation should be both formative and summative in order to provide knowledge and a value base for making decisions. In a developmental evaluation formative feedback can inform administrators of small changes that can be made to day-to-day operations while summative feedback can inform policymakers or those charged with making major decisions (Patton, 2018).

The developmental evaluation approach used in this study will be useful in reflecting on how the faculty center is viewed in a complex system such as Missouri State University (Patton, 2011). The evaluation of communication processes and perceived values and barriers of faculty will also provide a framework for process and program improvements. The evaluation dimensions for this study will be: communication processes; value of programs; and perceived barriers to participation.

\section{Design of the Study}

Given that this study is part of a developmental evaluation, the methodology used in the design of this study will be a mixed-methods approach that includes the collection of both quantitative and qualitative data. The methods for the study will include a faculty survey and focus group interviews of faculty who have participated and faculty who have not participated in professional learning activities at the university. In answering the research questions for this study, a convergent parallel mixed methods design will be used to compare different perspectives toward professional learning drawn from both quantitative and qualitative data (Creswell, 2014).

\section{Setting for the Study}

The setting for this study will be Missouri State University (MSU) located in Springfield, Missouri. Missouri State University is a mid-size, non-research, public 
university serving a statewide public affairs mission. Their public affairs mission characterizes how an education from Missouri State differs from that of other universities through a world view of ethical leadership, cultural competence, and community engagement (Missouri State University [MSU], 2017d). Missouri State University is the second largest university in the state of Missouri with an enrollment of over 24,000 students (MSU, 2017b). During the 2016-2017 academic year there were 743 full-time faculty; $51 \%$ of these were tenured faculty. There were also 392 part-time faculty teaching at the university (MSU, 2017b).

The academic management structure for the university is comprised of the Provost, Deputy Provost, two Associate Provosts responsible for different areas of operation, and the Academic Leadership Council (ALC). The ALC is made up of college Deans, Faculty Senate Chair and Chair-elect, members of the Provost's office, and a representative from the Department Heads Council (MSU, 2017e). This structural framework is responsible for strategic decision making defined by goals of growth, quality, or improved services (Bolman \& Deal, 2013).

Missouri State University practices shared governance through the guiding principles of fair treatment, high academic standards, rewarding exceptional achievement, and mutual respect between the university and faculty (MSU, 2017c). The Provost is the chief academic officer and is responsible for formulating policy and leading new initiatives and academic priorities for the university. The Provost office is responsible for policy related to promotion and tenure procedures as well as providing faculty development resources that support the roles of teaching, research, and service (MSU, 2017f). The Faculty Senate is responsible for the curriculum approval process for the 
university as well as providing a "representational voice of all academic departments and ranks of faculty" (MSU, 2017g, para. 1).

Missouri State University has a faculty center for teaching and learning (FCTL), which helps to support the faculty development efforts for the university. This academic support center assists faculty with the design of online and flipped instruction, and with the integration of technology into the delivery of instruction; provides classroom technology services; and offers programming related to new initiatives and academic priorities of the university. A Faculty Advisory Council guides the implementation of professional learning activities offered by the faculty center. Council members are appointed by the college deans who are members of the Academic Leadership Council. Each academic college appoints a faculty representative from their college to serve, and the council also includes an adjunct faculty representative. The FCTL Faculty Advisory Council appoints one member to serve as the FCTL Faculty Fellow and Chair of the council. The Faculty Senate Chair and Chair-elect, who are also members of the ALC, are ex-officio members of the FCTL Faculty Advisory Council. Other ex-officio members include the center's Director, the Associate Provost to whom the center reports, and the Faculty Fellows for diversity and faculty writing (MSU, 2017h). The FCTL Faculty Advisory Council membership acts as liaisons between the center and faculty, the Faculty Senate, ALC, and other groups within the academic community. Working through the human resource frame, advisory council members practice an all-channel network (Bolman \& Deal, 2013) communicating and sharing information through their connections with the university. 


\section{Participant Sampling}

Participants for this study will be a comprehensive sampling of the faculty population at Missouri State University (MSU), the site for the study. Optional demographic information that will be collected includes faculty rank, time in faculty role, and academic college. Purposeful sampling (Creswell, 2014) will be used to collect focus group data from participants who have participated in professional learning activities offered by the faculty center. Participants outside of this range will also be selected for focus group interviews to consider negative perceptions of non-participants to check against drawing easy conclusions from program review data (Seidman, 2013).

An online survey will be sent to comprehensive sampling of the target population, faculty at MSU through the Faculty Senate. Participants will be full-time faculty members and will be asked to complete a quantitative survey concerning their awareness and interest in participating in professional learning activities offered by the FCTL (see Appendix C). As part of the convergent design of this study and to maximize information about the faculty center and professional learning activities at the university (Creswell, 2014; Merriam \& Tisdell, 2016), a total of 40 full-time faculty members, who have participated in one or more FCTL activities will be invited to participate in a focus group interview (see Appendix D). The desired size of this focus group will be 10 to 12 participants (Seidman, 2013). The central theme for the focus group interview will be their expectant and actual motivational factors for participating in professional learning activities as well as perceived barriers to their participation. An additional 40 full-time faculty who have not participated in professional learning activities through the faculty center will also be asked to participate in a focus group. The desired size of this focus 
group is also 10 to 12 participants. Questions posed to this group will concern their expectant and actual motivational factors for participating in professional learning activities as well as perceived barriers to their participation (see Appendix D).

\section{Data Collection}

Data collected from faculty concerning their awareness and participation in professional learning activities provided by the faculty center will be used for answering the research questions. Evidence-based evaluation provides for rational and unbiased review of programs (Caffarella \& Daffron, 2013). Surveys are effective tools for collecting data related to policy or program needs, the evaluation of program effectiveness, and to guide future studies of a program (Fink, 2017). Web-based surveys and in person surveys and interviews will be used for data collection to increase the number of response rates and the quality of participant responses (Newcomer, Hatry, \& Wholey, 2015). Focus group interviews (see Appendix C) will be structured with openended interview questions (Seidman, 2013). Participants will have opportunities to express their opinions as a part of the interview questions (Fink, 2017).

Participation in any survey or interview associated with this study will be voluntary. The ethical guidelines established by American Educational Research Association (AERA) will be observed during this research and the personal identity and individual responses of participants will be anonymous and not recorded or shared (American Educational Research Association, 2017). Approval will be requested from the Institutional Review Board (IRB) prior to data collection and IRB guidelines will be adhered to throughout all phases of the study (Institutional Review Board, 2017). 
Participants will be informed about the purpose of the survey, why their input is being sought and how the data will be used (Seidman, 2013). They will receive an informed consent form that includes participants' rights and any potential risks for participating or not participating, possible benefits, confidentiality of records, dissemination of survey results, and contact information (Seidman, 2013). In-person interviews will last no more than one hour, and participants will be asked if they can be contacted for clarification or follow-up questions.

The web-based survey will be created using Qualtrics software. The entry page of the survey will serve as an informed consent form providing participants the choice of whether or not to participate. Participants will be informed of an estimated amount of time needed to complete the in-person or web-based survey (Fink, 2017). Participants responding to the web-based survey will have ten days to respond. A reminder email will be sent after five days reminding them that the survey will soon close.

\section{Data Analysis}

The context for this study will be multiple case studies and interviews (Merriam \& Tisdell, 2016) from faculty. Comparing the qualitative data of faculty expectancyvalue to actual value of experiences will provide credibility and trustworthiness to the study (Merriam \& Tisdell, 2016; Onwuegbuzie \& Johnson, 2006). A convergent parallel design (Creswell, 2014) will be used to compare findings from the quantitative and qualitative data sources. Results from the quantitative and qualitative data will be merged and compared to frame a viewpoint of the value faculty place on professional learning activities and perceived barriers to participating in such activities. Whether or not a faculty member has participated in professional learning activities offered through 
the faculty center will be a categorical variable and responses from these two focus groups will be compared in the data analysis.

\section{Limitations, Assumptions, and Design Controls}

A mixed-methods research study for the developmental evaluation of a faculty support center will provide cultural relevance for quantitative data and a more in-depth understanding of participants' viewpoints within the context of the study (Creswell, 2014). To ensure data validation and accurate findings based on quantitative and qualitative data collected through this study, the following limitations, assumptions, and design controls will be addressed.

\section{Limitations}

A limitation to this program review is its dependency on self-reported user data and the possible small sample size based on voluntary responses. Another limitation to self-report data is the limited distribution of participant sampling in terms of age, gender, ethnicity, faculty rank, and length of service with the university. Unknown participant biases or predispositions toward the university, administrators, or the faculty center may also serve as a limitation to this study.

Researcher bias in the interpretation of findings is another potential limitation for this evaluation since the researcher is the director of the faculty center. Confirmation bias is the predisposition to interpret information in such a way that it will confirm preexisting beliefs and prejudices (Patton, 2018). While developmental forms of evaluation overlap with evaluative inquiry, it is the ongoing process of evaluative inquiry that supports continual and circular learning avoiding predisposed or unwarranted conclusions (Preskill \& Torres, 1999). 


\section{Assumptions}

According to Patton (2018), embedding explicit assumptions into the research design allows for the opportunity to identify and examine participant assumptions and potential biases. The researcher has identified the following assumptions concerning this developmental program review of the faculty center at Missouri State University. First that faculty will choose to respond to the request to participate in the survey or focus group interviews. It is also a rational assumption that faculty will have a sincere interest for participating in a review of the faculty center and respond to inquiries honestly and without bias. An assumption of the participants in this study might be that feedback they provide will not impact any possible changes or improvements.

It is an assumption of the researcher that a mixed-methods approach will contribute multiple perspectives providing a deeper understanding of the problem (Creswell, 2014). Another assumption of the researcher is that qualitative data collected through actual experiences of faculty will help to explain quantitative results of the study. It is also an assumption that this developmental evaluation will become part of a larger program review for this support unit.

\section{Design Controls}

A convergent parallel mixed methods approach analyzing data collected through focus group interviews and surveys will provide a more comprehensive analysis of the problem being studied. Multiple stakeholders will be invited to take part in the study and data analysis will be constructed according to faculty status, years of service and whether or not they have previously participated in professional learning activities offered by the faculty center. The research design will be supported through evaluative inquiry, 
developmental program evaluation, and expectancy-value motivation (Fishbein \& Ajzen, 1975; Preskill \& Torres, 1999; Patton, 2011).

\section{Definitions of Key Terms}

For the purposes of this program review, the following terms and definitions will be used. Specific terminologies will be further defined in the context of this paper to clarify meaning and purpose as it relates to this study.

\section{Academic Culture}

The academic culture of an institution is determined by the influential factors of how members of a university, or those outside the university "perceive the purposes and appropriate operations of academic institutions, and how they believe they themselves should interact with these institutions" (Bergquist \& Pawlak, 2008, p. 1).

\section{Communication Channel}

A communication channel is the means by which information is carried from one individual or department to another within the organization. The flow of information can be downward, upward, or a horizontal exchange (Richmond \& McCroskey, 2009).

\section{Developmental Evaluation}

Developmental evaluation is an approach toward program review or evaluation that "supports innovation development to guide adaptation to emergent and dynamic realities in complex environments" (Patton, 2011, p. 1).

\section{Evaluation Model}

An evaluation model is the framework or an organized view of how a "evaluator conceptualizes and describes the evaluation process" (Madaus \& Kellaghan, 2000, p. 20). 


\section{Evaluative Inquiry}

Evaluative inquiry is a "collective action of dialogue, reflection, asking questions, and identifying and clarifying individuals' values, beliefs, assumptions, and knowledge" which "results in learning about significant organizational issues" (Preskill \& Torres, 1999, p. 3).

\section{Faculty Career Stages}

Early career faculty are identified as "those individuals within the first seven years of their faculty appointments or those who have not yet been awarded tenure" (Gillespie \& Robertson, 2010, p. 364). Midcareer is typically described as the timeframe between "five to twenty or so years post-tenure" (Gillespie \& Robertson, 2010, p. 371). Later-career faculty are those "within ten or twelve years of retirement" (Gillespie \& Robertson, 2010, p. 374).

\section{Faculty Center}

Faculty center is a universal term used to describe "a centralized unit with dedicated staff that is budgeted by the institution to offer a range of faculty development programs" serving the "entire institution, or a substantial segment of it, in a variety of ways" (Sorcinelli et al., 2006, p. 36). Faculty centers may also be referred to as academic development centers (Gillespie \& Robertson, 2010), and centers for teaching and learning (Hines, 2017).

\section{Organizational Communication}

Organizational communication is "the process by which individuals stimulate meaning in the minds of other individuals" through the sharing of information within "the context of a formal organization" (Richmond \& McCroskey, 2009, p. 20). 


\section{Professional Learning Activity}

Professional learning is any activity "faculty development, professional development, organizational development, and the scholarship of teaching and learning" (Gillespie \& Robertson, 2010) that "seeks to modify the attitudes, skills, and behavior of faculty members toward greater competence and effectiveness in meeting student needs, their own needs, and the needs of the institution" (Francis, 1975, p. 720).

\section{Referent Power}

Referent power is personal power that is independent from other sources of power such as authority or expertise. Leaders who use referent power are described as individuals that expand their influence through charisma, vision, or other characteristics that people admire (Bolman \& Deal, 2013).

\section{Value}

Value is the personal or organizational regard that something has worth or usefulness:

(a) Expectancy value suggests that a person's behavior will be determined by the level of value placed on the situation or action (Fishbein \& Ajzen, 1975).

(b) Actual value is the benefit or consequence for the behavioral performance (Fishbein \& Ajzen, 1975).

\section{Significance of the Study}

Missouri State University (MSU), like many mid-size non-research public universities, has invested human and financial resources to support academic faculty and for the advancement of the university's mission. Professional development and faculty support services are some of these resources (Schroeder, 2011). 
Ideally, faculty centers are effective program units influencing academic culture of the university and supporting faculty in their role of teaching. An examination of the implementation and practices of professional learning activities at MSU will assist this university's understanding of the value that faculty place on professional learning. It will also assist the faculty center in understanding what motivates faculty to participate in professional learning activities. The findings of this study will also inform other midsize, non-research, public universities on these practices and how they might be applied to their faculty centers.

\section{Summary}

This study will serve as a developmental evaluation examining processes followed by the faculty center at Missouri State University for the purposes of program improvement. The research question, "what organizational processes promote or impede faculty engagement in professional learning" will help academic leaders explore critical issues that support the academic mission of the university and apply newly formed knowledge much like a learning organization. Evaluative inquiry (Preskill \& Torres, 1999) and Fishbein and Ajzen's (1975) expectancy-value theory of motivation will be used as the theoretical frameworks for this developmental program evaluation. Stufflebeam's CIPP evaluation model for program improvement will guide the process evaluation of this study (Stufflebeam \& Zhang, 2017).

A convergent parallel mixed-methods design will provide an evaluative approach for evaluating communication processes and multiple perspectives resulting in a deeper understanding of faculty's expectant and actual values toward professional learning activities and their perceived barriers for participating in such activities. Implications and 
findings from this study will also assist Missouri State University with decision making in regard to communication processes and the appropriate language of messages sent to faculty that support expectant value of professional learning activities provided by the faculty center. 
Section Two:

Practitioner Setting for the Study 
The value placed on teaching by faculty and the academic administration has a positive impact on student learning experiences (Bain, 2004; Kuh, Kinzie, Schuh, \& Whitt, 2005/2010; McKeachie \& Svinicki, 2011/2014; Shulman, 2004). According to Shulman (2004), valuing teaching as a scholarship of practice is analogous to how historical normal schools prepared the "most prestigious of professionals, the highest level of scholar, the teacher" (p. 197). In support of this practice, many universities provide services through a faculty center or other academic units that demonstrates value and support of all teaching faculty at the university (Austin, 2010).

The setting for this study will be Missouri State University (MSU), which is a public, comprehensive university system. The main campus, located in Springfield, Missouri, is the second largest university in the state of Missouri with an enrollment of over 24,000 students (Missouri State University [MSU], 2017b). Missouri State University serves a statewide public affairs mission focusing on ethical leadership, cultural competence, and community engagement (MSU, 2017d).

The MSU campuses are structured to address specific educational needs of the populations they serve. The Springfield campus is a selective admissions teaching and research institution offering undergraduate and graduate educational. The West Plains campus is an accredited open admissions campus offering two-year degrees. The China campus is a cooperative agreement with Liaoning Normal University in Dalian, China offering associate's degrees accredited by the West Plains campus and Bachelor of Arts degrees accredited by the main campus. A research facility located in Mountain Grove provides support for the Missouri fruit industry (MSU, 2017b). MSU also serves an 
access and outreach mission delivering academic programming through outreach locations in area high schools and through distance learning.

This section will examine the setting for this study, which is the faculty center at Missouri State University. A brief history of the university will be discussed along with an organizational and leadership analysis of the current leadership structure. Implications for research in a practitioner setting and how it relates to the research questions for this study will also be discussed.

\section{History of Organization}

Missouri State University (MSU) was founded in 1905 as a State Normal School (Missouri State University [MSU], 2017i). The primary role as a state normal school was to prepare teachers for the public school systems in the southwest region of Missouri and in 1919 the school became known as Southwest Missouri State Teachers College (MSU, 2017i). In 1945 the name was changed to Southwest Missouri State College to demonstrate the school's progression from a teachers college to one of liberal arts and science education (MSU, 2017i).

Southwest Missouri State College became as a university during the early 1970s recognizing a growing institution with a diverse number of undergraduate programs and the establishment of a graduate college (MSU, 2017i). In 1995 the Missouri General Assembly designated the university with a statewide public affairs mission (MSU, 2017i). The public affairs mission focused on ethical leadership, cultural competence, and community engagement, and was intended to be a primary way in which an educational experience from Southwest Missouri State University (SMSU) would differ from that of other universities. 
In 2002, an Academic Development Center (ADC) was established at the university in accordance with the university's 2000-2006 long-range plan (Sell, 2004). The ADC was part of the Teaching Academy Campus Program initiated by the Carnegie Foundation for the Advancement of Teaching and the American Association for Higher Education (Sell, 2004). This program recommended four different models for establishing an on-campus teaching academy: 1) an interdisciplinary academy for teaching and learning, 2) a teaching and learning academy that focused on preparing graduate students, 3) a technology-centered teaching academy, and 4) a distributed model where support resources are decentralized and programming responsibilities resided within programs, departments, or colleges (Shulman, 2010). The ADC at SMSU functioned as an interdisciplinary academy furthering the value of teaching at the university, serving full-time faculty and academic administrators, and engaging a "substantial portion of the faculty (at least 30\%) in one or more sponsored activities each year" (Sell, 2004).

The Missouri General Assembly granted another name change in 2005 and the university became known as Missouri State University with an enrollment of over 20,000, higher admission standards, and a growing number of graduate programs (MSU, 2017i). The director of the ADC remained in that position until 2008, at which time the center was reorganized into a mixed-model academy offering interdisciplinary programming on teaching and learning, technology support, and support with assessment and research. The center was renamed the Faculty Center for Teaching and Learning (FCTL) and led by a tenured faculty member from the psychology department. In 2012 the director resigned and the center was again reorganized. This time the focus of the 
center included teaching through technology, developing courses for online and blended modalities, and the support of faculty seeking to improve their teaching practices. Today the direction and activities of the FCTL are directed by a Faculty Advisory Council which is representative of all the colleges at the university. The center is staffed with practitioners that have backgrounds in curriculum development, educational technology, and adult education. Professional staff in the FCTL work with faculty and academic administrators across the campus in a conceptual structure that is similar to other universities; responding to institutional problems and deepening the teaching mission of the university (Sorcinelli et al., 2006). In addition, Faculty Fellows contribute to university initiatives that are related to teaching and learning and also facilitate the professional learning activities delivered through the faculty center.

\section{Organizational Analysis}

An organizational analysis provides insight into how an organization is structured and how they function in their day to day operations. Bolman and Deal (2013) suggested that organizations provide a framework through which members of that organization make decisions, move forward, and make meaning of their actions. This section will provide an organizational analysis of Missouri State University (MSU) using Bolman and Deal's four frame model: structural, human resource, political, and symbolic. Perspectives from other scholars and theorists will also be used supporting this analysis.

The overarching mission of the university is directed by the Board of Governors and the President serves as the chief executive officer responsible for the operations of the university. The President chairs the Administrative Council which is made up of central administrators that are responsible for developing and implementing the goals and 
priorities of the university. Administrators serving on this council include Chief of Staff and assistant to the president for governmental relations, Vice Presidents for research, economic development and international programs, university advancement, administrative services, marketing and communications, student affairs, Chancellor of the West Plains campus, the academic Provost, a college Dean representative, Director of Athletics, General Legal Counsel, Chief Information Officer, Chief Diversity Officer, Chief Financial Officer, Director of Internal Audit and Compliance, and the Secretary to the Board of Governors (MSU, 2017j). The divisional structure of the Administrative Council functions as top down management making major decisions for the university (Bolman \& Deal, 2013). These include administrative policies, facility planning, budget and fiscal planning, and resource management for the university.

The academic management structure is comprised of the Provost, Deputy Provost, two Associate Provosts responsible for different areas of operation, and the Academic Leadership Council (ALC). The ALC is made up of college Deans, Faculty Senate Chair and Chair-elect, members of the Provost's office, and a representative from the Department Heads Council. This structural framework is responsible for strategic decision making that is defined by goals such as growth, quality, or improved services (Bolman \& Deal, 2013).

Missouri State University has a unique identity serving a statewide public affairs mission that focuses on ethical leadership, cultural competence, and community engagement. There is much symbolism in higher education including a school mascot, homecoming celebrations, and graduation ceremonies complete with cap and gown. The designation of a public affairs university is an essential profile in MSU's symbolic frame. 
This symbolism can be seen on MSU's Make Your Missouri Statement webpage, which highlights the accomplishments of students and graduates that have put public affairs into practice through their careers, volunteerism, or other means (MSU, 2017k).

Strategic decisions are concerned with the accomplishment of defined goals such as growth, quality, or improved services (Bolman \& Deal, 2013). The strategic goals outlined in the university's 2000-2006 long-range plan provided direction for the establishment of an Academic Development Center (ADC) to oversee all faculty development efforts and included a performance measure that at least 30 percent of the faculty participate in ADC-sponsored activities each year (Sell, 2004). The ADC was under the direction of the Office of Academic Affairs and served as a liaison with the academic library, the center for assessment, distance learning and instructional technology, the graduate college, and human resources in areas of faculty development that supported faculty in the design and development of courses and the improvement of teaching and learning. From the very conception of establishing a faculty development unit, it functioned within a loosely coupled system (Weick, 1978/1983), void of any formal authority or defined regulations and procedures. Specific performance measures were defined but the ADC was loosely connected with other organizational units. Loosely coupled organizations are made up of largely self-functioning subsystems and, according to Weick (1978/1983), are good systems for localized adaptation meaning that one group can adapt to their local environment without changing the entire system.

Rituals and symbols are central formalities in higher education; freshman orientation, Greek rush week, homecoming, the university mascot, Pomp and Circumstance playing at graduation are important sacraments of the college experience. 
Formal procedures unique to higher education; governing boards, shared governance, tenure, and professor emeritus are integrated into organizational meaning and draw "on social and cultural anthropology, treats organizations as temples, tribes, theaters, or carnivals" (Bolman \& Deal, 2013, p. 16). The Faculty Center for Teaching and Learning (FCTL) at Missouri State University (MSU) can be viewed as having its own rituals and symbols. These include a Faculty Advisory Council that oversees professional learning activities, an annual signature event that is open to all faculty, and faculty grants and awards that recognizes the culture of teaching excellence at Missouri State.

According to Bolman and Deal (2013), viewing organizations through the symbolic lens, "interprets and illuminates the basic issues of meaning and belief that make symbols so powerful” (p. 247). The symbolic frame can clarify an organizational issue that is "far different from canons of rationality, certainty, and linearity" (Bolman \& Deal, 2013, p. 247). Characteristics of an organization operating through a symbolic frame are: what happens is not as important as what it means, events have different meanings depending on the interpretation of the individual, the process followed is often times more important than what was actually accomplished, and organizational culture is what unites individuals to accomplish the intended outcomes (Bolman \& Deal, 2013).

Cultures are achieved through shared experiences and sensemaking (Weick, 1995). A shared meaning of an experience is difficult to define; but, according to Weick (1995), individuals share stories about common experiences that then frame a shared meaning or how they think about what is happening. Cultures within an organization are formed through identities associated with a group and multiple cultural contexts can exist simultaneously within the same organization (Austin, 1990; Bess \& Dee, 2008a; Tierney, 
2008; Weick, 1995). Kuh and Whitt (1988) defined the culture of higher education as "the collective, mutually shaping patterns of norms, values, practices, beliefs, and assumptions that guide the behavior of individuals and groups in an institute of higher education and provide a frame of reference within which to interpret the meaning of events and actions" (pp. 12-13).

Bess and Dee (2008a) looked at the relationship between organizational culture and organizational effectiveness in higher education. Bergquist (1992) identified four cultures in higher education: collegial, or a culture of shared decision making; managerial, a culture based on rules and hierarchy; developmental, culture of promoting human growth and professional development; and negotiating which is a culture characterized by conflict, compromise, and bargaining. Bergquist and Pawlak (2008) expanded the original four cultures to include the virtual culture or a global perspective of open, shared, and responsive educational systems; and the tangible culture finding meaning in roots, community, and spiritual grounding. In addition to Bergquist's Four Cultures of the Academy (1992); Bess and Dee identified additional cultural frameworks that occur in colleges and universities. These include anarchical, a culture defined by illdefined goals that are often in conflict or competition with other goals; adhocracy, a culture where decision-making is often ad-hoc; and market, or a culture of placing a high priority on customer satisfaction and promoting change through market analysis (Bess \& Dee, 2008a). Higher education organizations often demonstrate a blend of cultures providing intersections for subcultures within the same organization (Bergquist, 1992, Bergquist \& Pawlak, 2008; Bess \& Dee, 2008a; Tierney, 2008). However, subcultures 
that are in conflict with one another are likely to impede the effectiveness of the organization (Bess \& Dee, 2008a).

When culture is viewed from a social constructionist viewpoint, there are multiple perspectives of reality and varying layers of values and assumptions that are being made across the organization (Bess \& Dee, 2008a). A subculture is "the culture of a subsystem within a larger system" (Bess \& Dee, 2008a, p. 382), and differences of perspectives and experiences of these groups make subcultures a normal component of any organizational culture (Austin, 1990). An example of this in higher education might be the assumptions and beliefs that different groups such as student affairs, academic support, faculty, and the administration hold toward issues like student retention or sexual violence on campuses. Austin (1990) proposed that the culture of higher education was formed out of the collegial model but that bureaucratic structures and external demands for accountability have diminished faculty participation in organizational decisions, increased faculty workloads, and created constraints on faculty autonomy. The MSU Faculty Senate is a subsystem of the university system and believes this shift to be true making its 2017-2018 platform one of "clarifying faculty voice in university decisionmaking" (MSU, 2017g, para. 2).

Tierney $(1988,2008)$, provided a working framework from which to view culture within a university to overcome organizational problems. Viewing organizational culture allows practitioners to understand and "consider why different groups in the organization have varying perceptions about institutional performance" (Tierney, 2008, p. 27). This framework (see Table 2) examines cultural concepts of the organization which will lead to a deeper analysis of organizational culture. 
Table 2

A Framework of Organizational Culture

\begin{tabular}{ll}
\hline \multicolumn{1}{c}{ Cultural Concepts } & Questions to Evaluate \\
\hline Environment: & What is the attitude toward the environment? Hostile? \\
& How is it defined? Is it used as a basis for decisions? \\
Mission: & How are new members socialized? What do you need to \\
Socialization: & Whow to excel in this organization? \\
& Who has it? How is it disseminated? \\
Information: & How are decisions made? What strategies are used? Who \\
Strategy: & What does the organization expect from its leaders? Who \\
Leadership: & are the leaders? Are there formal and informal leaders?
\end{tabular}

Tierney, 1988, 2008.

According to Austin (1990), features of a university that influence its organizational culture include the mission and goals of the university, its curricular structure and academic standards, the governance structure and administrator's leadership style, the attributes of the student body and faculty members, student-faculty relations, the size and geographical location of the university, and the physical environment of the institution. The university's mission is a "particularly important element, affecting recruitment processes, socialization of new faculty, tasks faculty must fulfill, and performance standards" (Austin, 1990, p. 66). 
Missouri State University's mission statement is prominently placed on the university's website:

Missouri State University is a comprehensive institute offering undergraduate and graduate programs, including the professional doctorate. The university educates students to be global citizen scholars committed to public affairs. (Missouri State University [MSU], 20171)

Values of the university include:

- Student-centered learning environment;

- Excellent teaching;

- Knowledge, research, and creative activity;

- Integrity;

- Inclusiveness and an environment of respect;

- Continuous improvement;

- Innovation and entrepreneurial spirit;

- Collaboration and partnerships;

- Pride in and celebration of achievements;

- Responsible and transparent stewardship (MSU, 2017k).

The role of faculty is paramount to any college or university and the MSU Faculty Handbook (MSU, 2017c) states that the first obligation of faculty is to "provide quality learning experiences" in the teaching of undergraduate and graduate students (p. 18). Tenured and tenure-track faculty are expected to pursue research or "engage in scholarship related to their discipline or profession" and to also pursue service activities that utilize the "diverse and specialized talents of the faculty" and "represent a 
collaborative effort for the common good" (MSU, 2017c, pp. 18-19). Collegiality is defined as a community of scholars focused on the university's general mission and public affairs focus (MSU, 2017c) and are included in all areas of teaching, scholarship, and service (AAUP, 2016). Academic support units at the university provide "direct service to the University's programs of teaching, scholarship, research, creativity activity and public service" (MSU, 2017c, p. 19).

A faculty center's position within the university is often defined as one of neutrality and separation (Schroeder, 2011). According to Schroeder (2011), in order to provide services in support of instructional improvement, centers have developed strategies to attract faculty voluntarily with innovative programs and positioned themselves as "neutral service providers that functioned outside of promotion, tenure, and merit systems" (p. 28). This approach often results in uncertainty and ambiguity in regard to the faculty center's role in faculty development work (Schroeder, 2011). Schroeder stated that unless a faculty center's mission statement, program reviews, and ongoing professional development reflect the organizational development needs of the university, that their formal role will not be institutionalized or sought out by faculty. At MSU, the mission statement for their Faculty Center for Teaching and Learning (FCTL) is listed on the university website:

The Faculty Center for Teaching and Learning is committed to applying researchbased principles of pedagogy, instructional design, and integration of technology to encourage active student engagement and deep learning. The FCTL supports the professional development of faculty and staff, and the equipping of classrooms with learning-centered technology. Firmly rooted in the sciences of 
learning and cognition, instructional design and multimedia learning, the FCTL strives to promote a culture of active learning and assessment. (MSU, 2017m) The FCTL provides programming in support of performance improvement areas identified by faculty and administrative committees during the university's long-range planning processes. These include faculty programs on high-impact learning practices, diversity and inclusion, and universal design for learning. Faculty participation in these programs are voluntary and not required for the purposes of promotion, tenure, or merit. The FCTL is located in the academic library on the main campus and hosts many of the professional learning activities in this space. Larger events such as the annual Showcase on Teaching and Learning is held in the student union and supported by conference services at the university. Being housed in the academic library is an appropriate location considering the unit's mission and the academic climate of the university.

New faculty at the university are socialized through the new faculty orientation program and their home college. In addition, the university provides an annual orientation meeting for all per-course or part-time faculty. The FCTL works with the provost's office on the coordination of both these activities and provides resources and programming to assist new full-time and part-time faculty with their transition to the university. The FCTL's role participating in the new faculty and per-course orientation has grown since its reorganization in 2012. The FCTL's role in the socialization of faculty supports a developmental culture of a university.

\section{Leadership Analysis}

Leadership and administrative structures are cultural concepts that influence the culture of a university. According to Austin (1990), the administrative and governance 
roles of a university are responsible for shaping the organizational culture and faculty behavior. In higher education it is a common practice for university administrators, faculty senate, task forces or other governing committees to contribute to the development of policy and institutional initiatives (Schroeder, 2011).

In collegial cultures, decisions are less centralized and faculty experience more autonomy with less restrictions or formal rules (Austin, 1990). A more managerial or bureaucratic culture provides for more central decision making and a work environment that is more structured in regard to teaching loads and schedules (Austin, 1990). Missouri State University's (MSU) fourth president, Leland Traywick served in his office from 1961-1964 and introduced the cultural concept of shared governance which continues to be in practice at the university (MSU, 2017i). This governance philosophy is written into many of the administrative job descriptions and it is clearly stated in the university's policy library that faculty "who are responsible for teaching, scholarship, research, creative activity, and service .. .shall have such organization and exercise such delegated authority ... of shared governance permitted by law" (MSU, 2017n). The constitution of faculty states that the Faculty Senate "provide a forum for discussing matters of concern to the Faculty and to inform all segments of the academic community of the Faculty Senate's concerns, findings, and action” (MSU, 2017o, p. 5).

The university's long-range plan, Implementing the Vision is one of the planning processes that is the responsibility of both administrative and academic leaders at the university (MSU, 2017p). This planning document places institutional value on faculty and student learning through its language of academic traditions at the university (MSU, 2017q) and key performance indicators that focus on faculty and the quality of student 
learning (MSU, 2017r). Strategic priorities include the commitment that all students "experience a challenging learning environment that fosters intellectual growth" and a "student-centered learning environment promoting and supporting academic excellence" (MSU, 2017s, para. 11). Even with these priorities, the key performance indicators or measurable outcomes do not measure the value of teaching and its impact on the student learning experience. Instead the measurable outcomes concerning faculty include maintaining a low student to faculty ratio, increasing the number of faculty by rank, increasing salary compensations, and increasing faculty diversity by race/ethnicity and gender (MSU, 2017t).

\section{Academic Leadership}

The Provost is the chief academic administrator at Missouri State University (MSU) serving directly under the university president. Academic officers who report to the provost include the deputy provost, the associate provost for student development and public affairs, the associate provost for access and outreach, the associate provost and dean of the graduate college, director of the honors college, and the deans of the seven academic colleges and dean of the library (MSU, 2017f). The academic policy and decision making group for the university is the Academic Leadership Council. The council is made up of the college Deans, Faculty Senate Chair and Chair-elect, members of the Provost's office, and a representative from the Department Heads Council (MSU, 2017f).

The provost and the ALC are responsible for both long-term and short-term planning as well as decision-making that is focused on academic policy and procedure. Information utilization and decision-making styles are important components for 
effective decision making in higher education (Bess \& Dee, 2008b). Driver's (1983) decision style model is comprised of four dimensions of decision making and two dimensions of information complexity influencing different types of decisions in different environments. Organizations may be information-rich or information-poor and the solutions generated by their decision-makers can be uni-focused on one right answer or multi-focused with more than one option (Bess \& Dee, 2008b). Long-range or strategic planning utilizes information rich conditions and hierarchical decision-making (see Table $3)$.

Table 3

Effective Styles for Different Types of Organizational Decisions.

Effective Style Type of Organizational Decision

\begin{tabular}{ll}
\hline Hierarchical & Information-rich and uni-focused solution. \\
Decisive & May be information rich or poor. Uni-focused. \\
Integrative: & Information-rich and multi-focused. \\
Flexible & May be information rich or poor. Multi-focused.
\end{tabular}

Driver, 1983; Bess \& Dee, 2008b.

Situational leadership advocates that leaders adapt to a particular situation in their decision making as well as the development level of their followers (Northouse, 2016). The ALC follows situational leadership when responding to external influences such as state funding cuts. Another common leadership practice in higher education is path-goal leadership (Northouse, 2016). Path-goal leadership focuses on "the relationship between the leader's style and the characteristics of the followers and the organizational setting" (Northouse, 2016, p. 115). According to Northouse (2016), path-goal leadership behaviors include directive, supportive, participative, and achievement- oriented. Similar 
to situational leadership; Path-goal leaders choose a style that meets the needs of workers and the work to be done (Helland \& Winston, 2005; Northouse, 2016). This leadership approach advocates motivation by defining goals, clarifying a path, removing obstacles, and providing support (Helland \& Winston, 2005; Northouse, 2016).

The provost and the ALC facilitates path-goal leadership through the long-range plan and the university's guiding principles. While the key areas outlined in the longrange plan are rather broad and somewhat ambiguous; university governance practices include participative leadership to provide greater clarity and the identification of key performance indicators for how outcomes will be accessed.

While day-to-day operational decisions tend to be decisive; these decisions may be made under information-rich or information-poor conditions (Bess \& Dee, 2008b). Integrative decisions rely on much information and are usually used to create several solutions or even strategic goals. This decision-making style is commonly utilized by the provost and the ALC in continuous and participatory planning. Brainstorming and improvisation are both types of flexible decision-making (see Table 3). University administrators and governing bodies tend to use hierarchical and decisive decisionmaking styles deciding on policy and procedures, while non-administrative units focus more on integrative and flexible decision-making styles (Bess \& Dee, 2008b).

\section{Faculty Senate}

Shared governance at Missouri State University (MSU) recognizes the "interdependence of governing boards, administration, faculty, staff, and students" (MSU, 2017o, p. 5). The purpose of the Faculty Senate is to "provide a forum for discussing matters of concern to the Faculty and to inform all segments of the academic 
community of the Faculty Senate's concerns, findings, and actions" (MSU, 2017o, p. 5).

Officers of the Faculty Senate include the chair, chair-elect, and secretary. The voting membership is made up of senate officers, senators which are comprised of one representative from each of the academic departments, and one representative from each of the faculty classifications and ranks: instructors; clinical faculty; assistant professors; associate professors; and full or distinguished professors (MSU, 2017g).

Responsibilities of the Faculty Senate Chair:

- Preside at all senate sessions and supervise all functions of the Faculty Senate;

- Appoint members to the standing committees of the Faculty Senate;

- Organize and appoint ad-hoc committees as necessary;

- Represent faculty to the administration and the Board of Governors;

- Convey all Faculty Senate actions and resolutions to the Board of Governors;

- Attend sessions of any college council as an ex-officio member;

- Review judicial review committee decisions and determine if faculty bylaws revisions are needed. (MSU, 2017o, pp. 9-10)

"The responsibility for dealing with curricular matters is assigned to the faculty of the university by the Board of Governors" and the Faculty Senate reviews and approves all curricular proposals (MSU, 2017o, p. 41). Curricular proposals then become Faculty Senate Actions and are subject to approval and implementation by the university colleges and administrators (MSU, 2017o, p. 41). This type of hierarchy recognizes where authority lies, connects interdependent boards, and reduces the number of communication channels needed to transfer actions (Bess, 1988). 
The collegial governance model is grounded in the principle of a community of scholars and advocates for full participation of all members of the academic community, or at least faculty (Baldridge, 1971). It emphasizes the professional's ability to make decisions and the need to be free from organizational restraints. Baldridge (1971) suggested that viewing the university as a collegium is a useful balance of power when institutions have grown into large bureaucratic systems where students feel lost; but that "they tend to gloss over many essential aspects of the university's structure and processes" (p. 7).

The value that an individual places on these structures and processes could be dependent on their position within the organization. As early as 1947, Parsons (as cited in Baldridge, 1971) brought attention to the difference between official competence, which comes from one's official place in the organization, and technical competence or one's ability to perform a specific duty. Faculty are professionals whose influence is based on their knowledge and reputation in the academic community rather than their hierarchal position in the organization.

According to Bess (1988), structural designs are intended to meet the organization's need for information exchanges. In a hierarchy structure the channels for communications are few and limited in its capacity for information sharing (Bess, 1988) disseminating primarily decisions, actions, and issues. While Bess viewed university structures from the standpoint of information and power; Taylor (2013) suggested that academic engagement in shared governance is important to avoid discipline or collegecentric thinking and the alienation from larger university goals and objectives. Many educators believe that collaborative but decisive leadership is extremely important during 
times of uncertainty or change in higher education (Bahls, 2014). Bahls (2014) suggested that if faculty cannot effectively govern themselves, they will be too fragmented or even dysfunctional to share in the governance of an institution. Faculty that are able to unify and take strong collective actions can help move beyond shared governance to shared responsibility (Bahls, 2014).

A central theme of shared governance is mutual respect between the academic and governing bodies (Taylor, 2013). A model of shared governance in higher education (see Figure 2) includes an executive body that is accountable for the administrative and financial solvency of the university while the faculty senate is the authority on academic matters (Taylor, 2013). In such a system, each body interacts with the other in "mutual cooperation in which the official supremacy of either body would seldom be exercised" (Taylor, 2013, p. 88).

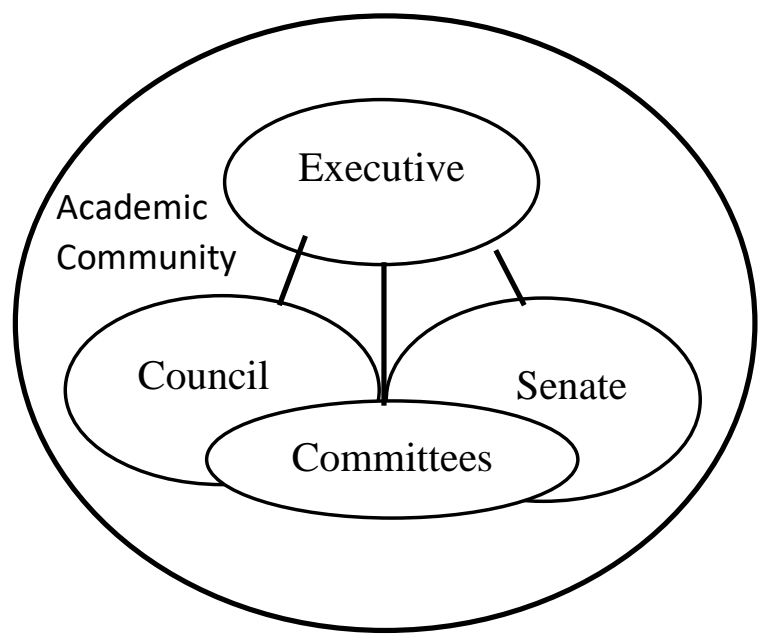

Figure 2. Model of Shared Governance (Taylor, 2013)

According to Bess (1988), belief is an important element in order for different bodies within a university to interact with collegiality. "In a collegial organization faculty must believe in the system because they cannot be privy to all knowledge required 
for decisions" (Bess, 1988, p. 90). Organizational structures within a university have a tendency to become bureaucratic when their source of power comes from authority (Bess, 1988). The common structures of shared governance such as faculty senate, staff senate, and student government provide for the distribution of power; but when power is highly concentrated and systems are tightly regulated, an overbounded system can occur resulting in a more political than collegial environment (Bolman \& Deal, 2013). During times of uncertainty, distrust in the academic administration, or authority-compliance management, the faculty senate's influence becomes more bureaucratic than collegial (Bergquist \& Pawlak, 2008; Bess, 1988; Bess \& Dee, 2008b; Bolman \& Deal, 2013; Northhouse, 2016; Tierney, 2008).

Braskamp and Wergin (2008) proposed that "academic leadership is not just for designated leaders but is a responsibility of all members of the academic community" (Introduction, par. 2). The leadership style these authors describe as inside-out leadership is finding your life's vocation and then acting from a sense of purpose to lead through your vocation (Braskamp \& Wergin, 2008). Inside-out leadership is based on the principles of transformational leadership and Mezirow's (2009) theory of transformative learning. Strengths of transformational leadership include advocating change for others, practicing leadership as a process that occurs between the leader and followers, and focusing on followers' needs, values, and beliefs (Northouse, 2016). Inside-out leadership is more than a commitment to leadership but rather taking action that is based on a calling or commitment to your vocation (Braskamp \& Wergin, 2008). Braskamp and Wergin described leading with vocation as "giving voice to others, building relationships, and recognizing - and rewarding - the contributions of others" it requires 
leaders to "not only discover their own vocations but also inspire others to find theirs" (Leading with vocation, para. 1).

The Faculty Senate Chair demonstrates a commitment to collegial governance that is shaped by a community of scholars. The belief that academic leadership is the responsibility of all members of the academic community is supported through the following statement found in A Message from the Faculty Senate Chair; "Faculty members have expertise in all areas relevant to the success of an organization" (MSU, 2017g, para. 2). Inside-out leadership (Braskamp \& Wergin, 2008) is also evidenced in this same message through the statement "my platform to improve faculty voice in university decision making is to improve the products that emerge from Faculty Senate investigation and debate" (MSU, 2017g, para. 6).

\section{Faculty Center for Teaching and Learning}

The Faculty Center for Teaching and Learning (FCTL) has a Faculty Advisory Council that oversees professional development activities of the center and serves as liaisons between the FCTL and the academic community. The college deans appoint a faculty representative from their college to serve on this council. This type of representation ensures that the interests and needs of each college is considered when planning faculty development activities. Advisory council members function as FCTL contacts within their college and also assist with programming and mentoring opportunities. Through this level of faculty representation and participation, the faculty center is promoting a developmental culture and a cross-curricular collegial sub-culture (Beach, Sorcinelli, Austin, \& Rivard, 2016; Bergquist \& Pawlak, 2008; Bess \& Dee, 2008b; Schroeder, 2011; Tierney, 2008). 
The FCTL Faculty Advisory Council is led by the FCTL Faculty Fellow. This is a faculty leadership position with referent power that is grounded by a reputation as a tenured faculty member and shared values and beliefs held by the organization (Bolman \& Deal, 2013; Sashkin, 2006). The Faculty Fellows are selected by the Faculty Advisory Council to serve a three-year term for which they receive a course release or faculty stipend paid by the FCTL.

Northouse (2016) quantified that the principles of path-goal leadership can be used by leaders at all levels in an organization. The FCTL Faculty Advisory Council demonstrates achievement-oriented behaviors through a participatory process aligning professional learning activities and faculty awards with the goals of the university's longrange plan (Northouse, 2016). The Faculty Fellows select research areas to pursue during their term that aligns with shared values and beliefs of faculty and the university (Bolman \& Deal, 2013; Sashkin, 2006). The current Faculty Fellow pursued accessible learning as an area of research and served on the President's Council, contributed to policy, and provided programming to faculty on Universal Design for Learning (UDL) pedagogy as a way to create more accessible and inclusive learning experiences for all students. Sharing expert and tacit knowledge through scholarship has allowed the Faculty Fellow to positively influence faculty, practices at the university, the collegiality power of the faculty center (Beach et al., 2016; Bess \& Dee, 2008b; Schroeder, 2011; Von Krogh, Nonaka, \& Rechsteiner, 2012).

Through their work, the FCTL Faculty Fellows are demonstrating a practical approach toward authentic leadership (George, Sims, McLean, \& Mayer, 2011; Northouse, 2016). This is evidenced by 1) a sense of purpose, 2) strong values toward 
accessible learning, 3) ability to build trusting relationships with the administration and faculty, 4) ability to act on their values, and 5) passion toward their chosen mission (George et al., 2011; Northouse, 2016). Austin and Trice (2016) supported core principles that the work of faculty is essential to academic excellence and the university's effectiveness "creating new knowledge, supporting and facilitating student learning, and applying cutting-edge knowledge to the vexing problems confronting society" (p. 59). The FCTL Faculty Fellows are also demonstrating scholarship to their practice through Boyer's (1990/2016) expanded perception of scholarship that includes the scholarship of integration making co-curricular connections and the scholarship of application influencing policy and how new knowledge is applied.

A transformational or transforming leader "motivates followers to perform beyond expectations by creating an awareness of the importance of mission" (Sashkin, 2006, p. 3). The FCTL Faculty Fellow demonstrated transformational leadership by setting examples of good practice in their own teaching practices and giving meaning to shared assumptions and beliefs faculty held toward accessible learning and UDL. These transformations were accomplished through mutual respect and the shared responsibility of faculty pursuing a common good (Gappa et al., 2005; Northouse, 2016; Sashkin, 2006). In addition to mutual respect, the FCTL Faculty Fellow demonstrated essential elements of collegiality, autonomy, and professional growth toward these transformational changes (Gappa et al., 2005).

The FCTL has a managing director who is responsible for supervising staff, program planning, and the day-to-day operations of the center. This role is a staff practitioner that works collaboratively with the academic administration, the Faculty 
Fellows, the advisory council, and other committees, councils and ad hoc work groups that they have been appointed. Schroder's (2011) research on the organizational development role of faculty centers quantified institutional collaborations, relationships, and partnerships as being essential elements in influential leadership of faculty centers. In order to be a change agent, Preskill and Brookfield (2009), advised leaders to create opportunities for contributions to the community as a whole. The director of the center is collaborative encouraging the open sharing of information which promotes learning and the creation of new ideas (Preskill \& Brookfield, 2009).

Change agents can directly or indirectly influence change within an organization. Rogers' (2003) diffusion of innovations theory is primarily used for investigating the adoption of technology in education; but, this model can also be used to view how change agents function within organizations. Rogers proposed that there are four elements to the change process: the innovation or new idea, communication channels, time, and the social system. Education technologists typically use this change model when implementing system-wide technology changes. Their role is often integrated into the culture of the organization having a certain level of power or "the ability to influence others or to bring about change" (Merriam \& Bierema, 2014, p. 241).

The FCTL director collaborates with a variety of groups on campus, but the position reports to the academic administration of the university. The director performs an annual review of all activities and this report is provided to the center's Faculty Advisory Council, academic leadership, and the Faculty Senate. Influences of leaders are often accomplished without any authority or formal power (Bolman \& Deal, 2013). 
Leaders influence through their status as an expert, through leading by example, or through a network of people.

The FCTL supports faculty and the university on a variety of initiatives such as online course development, universal design for learning, and high-impact practices. In order to create change around these initiatives, the director champions change efforts that will potentially transform the organization (Ettling, 2012). According to Ettling (2012), "practitioners of transformative learning theory have a predisposition to educate for change" (p. 536). The FCTL director, along with the Faculty Fellow, are motivated by change and encourage collaboration to make sense of changes and provide frameworks of shared values and beliefs (Mezirow, 2009; Northouse, 2016; Preskill \& Brookfield, 2009; Weick, 1995).

Gill (2010) proposed that some of the reasons institutions of education are not learning organizations is because of ineffective and passive leadership. The director focuses on getting faculty input, evaluating professional learning activities, and sharing information with faculty through the communication channels that are available at the university. Learning is encouraged in all activities and the advisory council and faculty have a voice to provide input, share ideas, or discuss issues. Through this type of sharing the director is attempting to build trust which "results in a decision that the entire team can support" (Gill, 2010, p. 96). Part of the director's reasoning for practicing this collaborative approach is to seek out diverse opinions and feedback in hopes of creating “opportunities for unimagined initiatives" (Preskill \& Brookfield, 2009, p. 25). 


\section{Implications for Research in the Practitioner Setting}

The horizontal and vertical structures of a university create clusters of tightly and loosely coupled units within that organization (Ingersoll, 1993; Keeling, Underhile, \& Wall, 2007; Weick, 1978/1983). The Administrative Council and the Faculty Senate at Missouri State University (MSU) function as tightly coupled units responsible for the strategic management of the university. The strategic management of an organization involves the ongoing activities that focus on responding to the internal and external influences on the organization (Athapaththu, 2016). This includes the Administrative Council's role in formulating a budget and allocating resources to the Faculty Senate's role in the formal curricular process of the university. The faculty center at MSU is a loosely coupled unit meaning that it has autonomy and rational input into the professional learning activities it provides, but it also has a decentralized distribution of power when it comes to resources and influence (Ingersoll, 1993). An example of this is when the faculty center collects input from faculty to develop a new program but then must communicate with faculty through the college deans about the availability of the program. The deans have the designated authority and centralized power to communicate with the faculty in their college. According to Weick (1978/1983), loose coupling results in the type of connections that are either marginalized, ignored, or suppressed by the bureaucratic power of an organization. The organizational identity of the faculty center by those with centralized power also impacts the center's ability to effectively function within the university. According to Haslam, Postmes, and Ellemers (2003), organizational identity enables organizational behavior such as effective communication, interrelationships, planning, and leadership. 
Prior research has be conducted on the role of a university faculty center and how these centers should connect with the faculty body (Hines, 2017; Schroeder, 2011; Sorcinelli et al., 2006). There has also been considerable research on the specific areas of expertise that a faculty center can bring to a university (Schroeder, 2011; Sorcinelli et al., 2006). However, such a review and an analysis of these practices has not been conducted at MSU.

The low response rate to the faculty survey conducted by the Faculty Senate and the faculty center, along with the number of faculty who indicated no interest in programs that support teaching or university goals, may be an indication that the faculty center is not connecting with faculty. The implications for conducting this study in the practitioner setting is to address the problem of how the faculty center at MSU can best support the academic endeavors of the faculty body. This study will specifically address the research questions: (1) how effective are the current communication processes being utilized by the faculty center; (2) what are faculty perceptions of value concerning professional learning activities provided by the faculty center; and (3) what are faculty perceptions of barriers to their participation in professional learning activities?

The findings from this study will be disseminated to all stakeholders in a format that is appropriate to their role in the organization. The complete program evaluation report will be shared with direct administrators of the faculty center, the FCTL Faculty Advisory Council, faculty center staff, and the Faculty Senate. An executive summary will be provided to the Board of Governors to inform them of the completed study, findings, and any recommendations. 


\section{Summary}

This section reviewed the history of Missouri State University and provided an organizational analysis of the university. Through the nature higher education, universities can evolve into loosely coupled systems where faculty, staff, and administrators maintain separate identities and form multiple cultural contexts within the same organization (Austin, 1990; Bess \& Dee, 2008a; Kuh and Whitt, 1988; Tierney, 2008; Weick, 1995). This section introduced the concept of how university culture and faculty values toward the faculty center can impact its contributions to organizational development at the university. A leadership analysis of academic leadership, faculty senate, and the faculty center also revealed differing values and management styles of these three organizational areas. The academic administration is more tightly coupled while the Faculty Senate is driven by a sense of purpose and advocating change for others. Working with multiple stakeholders, the faculty center focuses on authentic leadership and its ability to build trusting relationships with administrators and faculty. The organizational role of a faculty support unit is to broaden institutional initiatives around the context of teaching and learning (Schroeder, 2011). The faculty center at Missouri State supports a variety of initiatives working collaborative with others providing a framework of shared values and beliefs (Fishbein \& Ajzen, 1975; Mezirow, 2009; Northouse, 2016; Preskill \& Brookfield, 2009). Findings from this study will help the faculty center determine how processes are being used to connect faculty with professional learning activities. 
Section Three:

Scholarly Review for the Study 
This section will provide a scholarly review of existing research that pertains to the evaluation of faculty centers and the problem of practice being addressed in this study. To answer the question of how the faculty engagement in professional learning activities at Missouri State University it is important to understand what faculty value and the organizational work processes that connect faculty with the faculty center. The scholarly review will specifically examine faculty development in a university setting, organizational culture in higher education, collaboration and faculty leadership within the university organization, and evaluation models and methods for evaluating faculty centers.

\section{Faculty Development in a University Setting}

The growth of federal funding during the 1960s provided support for expanding the research efforts of American universities; this included opportunities for faculty release time and sabbaticals (Schroeder, 2011). These earlier practices of sabbatical work were primarily for the purposes of faculty development (Schroeder, 2011). As a more efficient approach to faculty development, universities began to create faculty support centers to assist faculty with modifying instructional methods that promoted active student engagement and deeper learning (Sorcinelli et al., 2006). This type of support was provided through various professional learning activities including workshops, technology trainings, informal one-on-one meetings or consultations, communities of practice, or structured programs where a faculty member would completely redesign a course they are teaching (Sorcinelli et al., 2006).

The history of faculty development is rooted in earlier educational reform was driven by social and economic unrest during the 1950s and 1960s. The student rights 
movement impacted higher education when students demanded more control over what they were learning and the desire for ethnic and social justice issues to be discussed in academic settings (Ouellett, 2010). Student expectations were for college curriculum to be more relevant to their experiences, concerns, and aspirations for the future. These reforms continued through the 1970s when faculty members began to advocate for recognition and rewards that focused on excellence in teaching (Ouellett, 2010). Earlier researchers such as Francis (1975), defined faculty development as "a process which seeks to modify the attitudes, skills, and behavior of faculty members toward greater competence and effectiveness in meeting student needs, their own needs, and the needs of the institution" (p. 720).

Faculty development has traditionally played a supportive role in assisting faculty with responding to internal changes within a university (Sorcinelli et al., 2006). Changes in student expectations and competition from for-profits have resulted in public universities developing distance learning programs and online education (Gappa et al., 2005; Pazzanese, 2017). This has increased the need for services to help with the development of online courses and to prepare faculty for teaching online (Gappa et al., 2005). Economic constraints and growing enrollments have driven the need to offer more general education courses, and the number of classes being taught by adjunct faculty has continued to rise (Gappa et al., 2005; Pazzanese, 2017). These changes have augmented the need to support faculty (Gappa et al., 2005; Schroeder, 2011). As nonresearch universities attempt to distinguish themselves through their mission, servicelearning, diversity goals, increased access and student success; the responsibilities of 
faculty are effected by new institutional initiatives and organizational change (Schroeder, 2011).

Sorcinelli et al. (2006) classified the evolution of faculty development into four distinct eras: scholar, teacher, developer, and learner. During the age of the scholar, which comprised the 1950s and early 1960s, faculty development focused on the development of scholarly expertise as indicated by research success and publication rates (Sorcinelli et al., 2006). The age of the teacher focused on teaching effectiveness during the mid-1960s through the 1970s (Sorcinelli et al., 2006). Sorcinelli et al. (2006) described the willingness for experimentation with new approaches to teaching and technology in the 1980s as the age of the developer. Interest in learning theory and student-centered pedagogies such as active engagement, collaborative learning, and inquiry-based learning during the 1990 s was referred to as the age of the learner (Sorcinelli et al., 2006).

Faculty centers have traditionally offered professional learning activities that included individual consultations, university-wide orientations, faculty workshops, and grant and award programs (Sorcinelli et al., 2006). The role of faculty centers have expanded beyond professional learning to one of integrating institutional goals and initiatives into their services and programs (Schroeder, 2011; Sorcinelli et al., 2006). Through specialized services and programs, faculty centers are supporting the strategic goals of the university which may include the assessment of student learning outcomes, distance learning, multiculturalism and diversity related to teaching, and course and curriculum reform (Beach et al., 2016). 
In order to support diverse programming, faculty support centers are often staffed by practitioners with specific areas of expertise (Hines, 2017; Schroeder, 2011). This may include instructional technologist, instructional designers, faculty, and administrators (Schroeder, 2011). Sorcinelli et al. (2006) proposed that the field of faculty development has entered into an era they called the age of the networker. They recommended that faculty support centers "preserve, clarify, and enhance the purposes of faculty development, and to network with faculty and institutional leaders to respond to institutional problems and propose constructive solutions as we meet the challenges of the new century" (Sorcinelli et al., 2006, p. 28).

In 2016, Beach, Sorcinelli, Austin, and Rivard advanced their research and identified institutional differences in faculty development structures. According to data collected from four-year comprehensive universities, the number of faculty centers increased from $51 \%$ to $59 \%$ during their 10-year study (Beach et al., 2016). During this timeframe, the number of centralized faculty centers at research and doctoral universities did not change, indicating that $70 \%$ of these campuses had centralized faculty development programs (Beach et al., 2016). The structural model of an individual being responsible for faculty development remained prevalent at $33 \%$ of the comprehensive universities while the use of faculty committees to coordinate faculty development declined. (Beach et al., 2016). Beach's et al. most recent research indicated that faculty development has become more centralized in the university setting.

When it comes to the day to day practices of the faculty support center, Hines (2017) argued that many centers lack an evaluation mindset and have a weak infrastructure in terms of resources and workflow allocations. In meeting the needs of a 
growing university they also have an ever-expanding menu of offerings, unclear goals and short-aimed missions, and often times an inappropriate evaluation framework (Hines, 2017). Program evaluation can help determine the value of various programs or the need for improvement (Caffarella \& Daffron, 2013; Hines, 2017). Evaluation data can also be shared with administrators and other stakeholders to demonstrate value and provide evidence for resource requests (Hines, 2017).

Research shows that the role faculty development in a university setting has changed over time depending on the needs of the university, changing student expectations and external factors that are impacting higher education (Ouellett, 2010; Schroeder, 2011; Sorcinelli et al., 2006). Services offered by faculty centers have also changed depending on the needs and desires of faculty to participate in such programming (Gappa et al., 2005; Sorcinelli et al., 2006). Beach et al (2016) advanced this earlier research examining the organizational structures of faculty centers finding that faculty development has become a more centralized process within the university setting. A significant consideration of this evolutional history is what Hines (2017) described as short-aimed missions and a lack of adequate resources and workflow allocations.

The role of faculty development in a university setting has changed from that of supporting sabbatical work to supporting the university as a learning organization and meeting individual needs and desires of faculty engaged in professional learning activities. Even with the changing focus of faculty development the purpose of higher education has remained the same and that is to provide high quality teaching and learning. If professional learning activities within a university are to support these efforts 
then faculty centers should "play a strategically central role in this process" (Fink, 2013, p. 47).

\section{Organizational Culture in Higher Education}

Bolman and Deal (2013) suggested that organizations provide a framework through which members of that organization make decisions, move forward, and make meaning of their actions. The symbolic lens is used to view how individuals use organizational symbols and culture to make sense of uncertainty and other ambiguities in their environment (Bolman \& Deal, 2013). A university is a large organization and considering many of the challenges facing higher education, the symbolic framework is a useful organizational lens for examining these issues (Bolman \& Deal, 2013; Pazzanese, 2017).

Learning organizations, as defined by Senge (1990), are organizations that are evolving from authoritarian or controlling structures into one of change. These are organizations that are seeking mental models, a shared vision, and team learning in their day to day activities (Senge, 1990). Corporate organizations often undertake this type of transformation or shift in mindset in response to external influences such as a downturn in the economy, increased competition, or a changing workforce (Senge, 1990). Bok (2013) points out that universities have been much slower to change holding on to traditional curriculum frameworks and teaching methods that are perceived dated and inadequate by many of today's students.

Institutions of public education are complex organizations. Regardless of their research mission; a university functions as a large organization made up of diverse individuals, an array of departments, technologies, and goals. Universities are open 
systems (Bolman \& Deal, 2013) that affect and are affected by an ever changing environment. There is also an enormous amount of symbolism (Bolman \& Deal, 2013) within a university. Traditions, ceremonies, and rituals are revealed through the university mascot, freshman week, and even graduation. It is the organizational symbols and culture that exemplifies the values of an organization (Bolman \& Deal, 2013). The difference between goals and values is that an organization's identity is communicated through their values (Bolman \& Deal, 2013). According to Bolman and Deal (2013), vision frames an organization's sense of purpose and its image for the future.

In addition to these academic values, the organizational culture of a university is defined by its mission and goals, leadership and governance structures, academic standards, student and faculty characteristics, as well as the size of the university and its geographical location (Austin, 1990). The designation of a non-research or teaching university is a contributing factor to how faculty spend their time and also shapes the culture of the university. There are a growing number of external factors that influence the culture of today's public universities. These influences include public perceptions, economic factors, student expectations when entering college, increased competition from for-profits schools, and government policy and regulations (Austin, 1990; Bok, 2013).

Decision making within the university organization differs from that of a business where the flow of decisions follows the organizational chart including input from multiple departments such as product design, manufacturing engineers, and marketing. While faculty voice is clear in determining curriculum, evaluation standards for teaching, and all matters of concern to the faculty; they do not have formal influence into certain 
types of decision such as setting budget priorities or the management of university resources (Bok, 2013; Tierney, 2008). According to Tierney (2008), the decision-making path within a university is often ambiguous when faculty governing bodies seek their own issues to pursue and these vary from one year to the next. This often results to hours of discussion without reaching a decision during the one-year tenure of the senate chair (Tierney, 2008). Weick's (1995) theory of sensemaking in organizations emphasized that "people who do things together should build strong cultures, even if they fail to share a common interpretation of what they did" (p. 189). Tierney (2008) argued that "the manner in which groups communicate with one another highlights underlying cultural beliefs within the organization" (p. 121). The organizational culture of a university determines the role of faculty in formal and informal influences to university governance (Tierney, 2008).

Bergquist and Pawlak (2008) argued that the advocacy and developmental cultures of a university are in direct conflict with one another. When faculty become marginalized and distrust the collegial culture of shared decision making, those grounded in the managerial culture based on rules and hierarchy may consider an advocacy culture to be a source of influence and power (Bergquist \& Pawlak, 2008). According to Bergquist and Pawlak (2008), in universities practicing collective bargaining, developmental activities are often distrusted and seen as an administrative ploy. "Advocacy and developmental cultures grew out of a reaction against a dominant force" and both must "come together to formulate common plans and integrate complementary assumptions about influence and change in higher education" (Berquist, 2008, p. 128). Bergquist and Pawlak argued that if these two cultures could not work together they 
would "fail to provide needed corrections to the dominant collegial and managerial cultures" of a university (p. 129).

The challenges facing higher education today are similar to those of earlier decades. According to Gappa, Austin and Trice (2005), four significant movements have made a significant impact on the traditional American university. The first of these are external pressures such as cuts in funding, increased accountability, ever changing technologies, the rapid expansion of specialized disciplines/degrees, and a more diverse student body in terms of age, ethnicity, educational backgrounds, and student expectations (Gappa et al. 2005). The second movement, according to Gappa et al. (2005), is the growing number of part-time faculty and non-tenure track faculty. These appointments often lack opportunities for professional growth and the ability to feel a part of the collegial community which are essential components of work satisfaction and productivity (Gappa et al., 2005). These researchers described a third movement being the changing faculty demographics in American universities (Gappa et al., 2005). According to Gappa et al. (2005), women and a more diverse academic workforce in terms of race and ethnicity are changing the traditional image of the white male professor. A more diverse faculty body also includes needs that are somewhat different than their white male peers (Gappa et al., 2005). The fourth impact changing the organizational culture of American universities (Gappa et al., 2005) are the new faculty members that are entering these institutions. Younger faculty members have certain expectations about the workforce, which includes balancing work with other responsibilities that are important to them (Gappa et al., 2005). 
Higher education, much like a nonprofit organization, tends to be driven by values, concerns for the common good, and the beliefs and motivations of the individuals who make up the organization (Gappa et al., 2005; Gill, 2010, Sashkin, 2006, Wergin, 2001). Regardless of these external impacts, the core work of faculty has essentially remained the same; scholarship, teaching, research, and service (Boyer, 1990/2016). The core values of faculty are to educate a society of learners and to their commitment of faculty autonomy (Austin, 1990). Faculty values and motivation are important elements in understanding the organizational culture and the role of the faculty center in that university (Austin, 1990; Bok, 2013; Gappa et al., 2005; Hutchings et al., 2011). According to Schroeder (2011), the value that a faculty center contributes to its university is likely determined by whether or not faculty recognize the value and role of the center.

Senge (1990) described a learning organization as an organization that is seeking change. An organizational culture that limits open communication and reflection creates a culture of nonlearning (Gill, 2010). Higher education is often perceived as operating in silos or unwilling to collaborate across the organization. Academic culture focuses on the values of good work educating a society and faculty autonomy (Austin, 1990). This provides the organizational context for academic freedom or the freedom for faculty "to write and think as one chooses, to prepare one's courses as one thinks best, to organize one's life and schedule one's time with minimal oversight and direction" (Bok, 2013, p. 379). The academic values of a university mold the norms for faculty to function and fulfill these responsibilities (Gappa et al., 2005).

Mental models are the shared thought constructs that shape how people view their world (Senge, 1990). Human beings interrupt things differently and learn different things 
from different stimuli or data; but it is the shared experiences that provide the opportunities to create shared meaning (Bess \& Dee, 2008b; Senge, 1990; Weick, 1995). According to Weick (1995), when people share actions, activities, and conversations they are making sense of their experiences and it is this "shared meaning" that becomes "the glue of organizational culture" (p. 188). Organizational culture is created through the processes of interpersonal communication and sensemaking, which both are often beyond managerial control (Bess \& Dee, 2008a; Weick, 1995).

The social constructionist view of organizational culture recognizes that "multiple interpretations of reality and multiple layers of values and assumptions" exist within the same organization (Bess \& Dee, 2008a, p. 382). According to Bess and Dee (2008a), these are not shared universally across the organization but rather certain realities, values, and assumptions are held among different subcultures within the organization. These subcultures represent different units or groups of people within the organization. Bess and Dee (2008a) researched the differences between faculty and administrative subcultures as a way to view subcultural divisions within a university. They found that since administrators are responsible for the financial, legal, and managerial issues, that they tend to value clarity, continuity, and accountability to external influences (Bess \& Dee, 2008a). The administrative subculture values utilitarian methods while the faculty subculture values collegial communication and expects to participate in organizational decision-making, specifically in the areas of curriculum and research (Bergquist \& Pawlak, 2008; Bess \& Dee, 2008a; Tierney, 2008). Faculty value the principles of tenure and academic freedom, which reflects a predilection for preservation and autonomy for the professoriate (Bergquist \& Pawlak, 2008; Bess \& Dee, 2008a; Bok, 2013). 
Bess and Dee (2008a) argued that different values between the administrative and faculty subcultures can manifest into conflict and distrust between the two groups. This can result in structural divisions and subcultures that are defined by their connectedness with the dominant values of the organization (Bess \& Dee, 2008a). Hatch and Cunliffe (2013) identified three subcultures and their connections with the dominant cultures and values of the academic organization (see Table 4). Subcultures that have a value system separate from the dominant culture or are in conflict with the dominant culture are likely to inhibit the effectiveness of the organization (Bess \& Dee, 2008a). Therefore, it is the role of organizational leaders, wherever they are situated in the organization, to promote dialogue among the different subcultures building common values and establishing shared commitments for continued development of the organization (Bess \& Dee, 2008a).

Table 4

Subcultures Defined in Terms of Relationship with the Dominant Culture.

\begin{tabular}{ll}
\hline Subculture & Connection with the Dominant Culture and Values \\
\hline Enhancing Subculture & $\begin{array}{l}\text { Strongly supports the dominant values of the university } \\
\text { (e.g., Faculty Senate). } \\
\text { Values are in conflict with the dominant culture (e.g., } \\
\text { Counterculture }\end{array}$ \\
& $\begin{array}{l}\text { Student or Faculty coalition protesting administrative } \\
\text { decisions). }\end{array}$ \\
Orthogonal Subculture & Subculture with a value system that is disconnected from \\
the dominant culture and values (e.g., faculty subculture \\
that does not interact with high-level administrators).
\end{tabular}

Hatch \& Cunliffe, 2013. 
Public universities are large complex organizations made up of diverse individuals, different colleges and departments, and various units providing an array of products and services. The culture of a university is framed by its mission, governance structures, academic standards, and student and faculty characteristics (Austin, 1990). Tierney (2008) provided research on how the cultural beliefs within a university affect its decision-making ability and determine the role of faculty in formal and informal influences of power. The lack of open communications creates a culture of nonlearning (Gill, 2010) promoting the concept of operating in silos or an unwillingness to collaborate within the organization. Research from Bess and Dee (2008a) focused on the differences between faculty and administrative subcultures as a way to view subcultural divisions between faculty and administrators. These divisions can manifest into conflict and distrust forming subcultures that are defined by their disassociation with common goals and values of the university.

\section{Collaboration and Faculty Leadership}

Higher education is similar to other organizations in that all organizational members, including administration, academic leaders, faculty, and managerial staff, have several sources of power (Bess \& Dee, 2008b; Bolman \& Deal, 2013). Bolman and Deal (2013) identified six bases of power: 1) legitimate or position, 2) reward, 3) coercive, 4) information and expert power, 5) reputation, and 6) personal or referent power. An important extension of referent power is the power of influence or the ability of an individual to use different tactics in different situations to change attitudes, behaviors, strategic direction, and values (Bess \& Dee, 2008b; Bolman \& Deal, 2013; Northouse, 2016). Influence can be upward when followers attempt to influence those in positions 
of power, downward when the administration or others in authority attempt to influence their followers, or even lateral among peers (Bess \& Dee, 2008b; Yukl \& Falbe, 1990). The downward influence of "executive sponsor, organisational structures and historical precedent" have contributed to the silo mentality of a university compartmentalizing faculty centers into providing designated services (Debowski, 2017). Faculty centers should transition from the age of the networker described by Sorcinelli (2006) to the age of influence (see Table 5) defined by Debowski (2017).

According to Beach et al. (2016) and Schroeder (2011), faculty centers utilize professional staff, advisory committees, and other collective capacity in order to influence faculty and the academic administration on many of the complex challenges facing the university. Schroeder (2011) argued that in order for faculty centers to serve as change agents, they must collectively bring expertise as organizational developers into their operational strategies and tactics.

Table 5

The Evolution of Faculty Centers' Contribution and Influence.

\begin{tabular}{|c|c|c|}
\hline Age of ... & Timeframe & Importance \\
\hline The scholar & $1950 \mathrm{~s}-$ early $1960 \mathrm{~s}$ & $\begin{array}{l}\text { Established sabbaticals and other practices } \\
\text { designed to improve scholarly competence. }\end{array}$ \\
\hline The teacher & Mid 1960s - 1970s & Focused on improving college teaching. \\
\hline The developer & $1980 \mathrm{~s}$ & $\begin{array}{l}\text { Addressed curricular issues and assisting } \\
\text { faculty at different career stages. }\end{array}$ \\
\hline The learner & $1990 \mathrm{~s}$ & $\begin{array}{l}\text { Created multiple venues for faculty } \\
\text { development that focused on teaching and } \\
\text { learning. }\end{array}$ \\
\hline
\end{tabular}


The networker 2000s

Influence
Present
Redefined the purpose of faculty development and responded to institutional change (e.g. online teaching).

Collaborate with faculty and academic leaders to build capacity and enhance university functioning.

Debowski, 2017; Schroeder, 2011; Sorcinelli et al., 2006.

Bauer and Erdogan (2009) described nine commonly used tactics when exerting influence for the purpose of creating change or other desired outcomes (see Table 6). Table 6

Influence Tactics used to Influence or Create Change. Influence Tactic Example of Desired Outcome/Change

\begin{tabular}{|c|c|}
\hline Rational Persuasion & $\begin{array}{l}\text { Use facts, data, and logical arguments to convince others } \\
\text { your point of view. }\end{array}$ \\
\hline Inspirational Appeal & Focus on values and emotions to gain support for an idea. \\
\hline Consultation & $\begin{array}{l}\text { Engage others in the process of making the decision or } \\
\text { proposing policy, strategy, or change. }\end{array}$ \\
\hline Ingratiation & $\begin{array}{l}\text { Help others to feel good about themselves or to think } \\
\text { favorably before asking them to do something. }\end{array}$ \\
\hline Personal Appeal & Help to feel positive about helping because they like you. \\
\hline Exchange & Give-and-take where you do something for each other. \\
\hline Coalition & $\begin{array}{l}\text { When a group of individuals work together toward a } \\
\text { common goal to influence others. }\end{array}$ \\
\hline Pressure & Insisting that someone does something you want or else. \\
\hline Legitimating & Downward influence based on legitimate power. \\
\hline
\end{tabular}
Bauer \& Erdogan, 2009, p. 304. 
While different tactics or a mix of tactics can be applied to downward, upward, or lateral influence, Yukl and Falbe (1990) found that certain tactics were used more frequently than others regardless of being used by authority, followers, or peers. Consultation and rational persuasion were found to be used the most frequently to influence and create change within an organization (Yukl \& Falbe, 1990). Trust is an important condition in order for effective influence to take place. Rational persuasion based on facts and data is not effective if a level of distrust exists; while inspirational and emotional appeals are effective if the individual is perceived as authentic and charismatic (Bess \& Dee, 2008b; Kouzes \& Posner, 2002; Northouse, 2016). Leaders who use influence effectively understand that "trust is key" and also "make use of people's expertise and abilities" (Kouzes \& Posner, 2002, p. 247).

According to Kouzes and Posner (2002), when leaders display an openness to influence they are building trust that allows their followers to be more open to their influence. Transformational leaders build trust with their followers by "being predictable or reliable, even in situations that are uncertain" (Northouse, 2016, p. 173).

Transforming leaders, as well as authentic leadership, focuses on using values and purpose to create shared meanings that help shape their organization (George et al., 2011; Morrill, 2010; Northouse, 2016). Individuals who take an authentic approach to leadership understand their purpose, have strong values about what is the right thing to do, build trusting relationships, demonstrate the self-discipline to act on their values, and are passionate about their role and lead from the heart (George et al., 2011; Northouse, 2016). 
Collaborative leaders build relationships between individuals in their organization and work toward a common goal by sharing responsibility, authority, and accountability for the final results (Chrislip \& Larson, 1994; Kouzes \& Posner, 2002; Northouse, 2016). Chrislip and Larson (1994) described collaborative leaders as individuals that are not in authority roles but are able to leverage individual strengths within the organization to create collective outcomes. Collaborative leaders initiate a process of mutual influence where "the boundaries between leaders and followers are fluid and flexible" (Bess \& Dee, 2008b, p. 869). These type of leaders are trustworthy individuals that are skilled at seeking out and nurturing relationships, building agreement abound a collective vision, articulating and communicating that vision, and networking within and across different divisions to build support for the vision and the collaborative way of working toward the results (Chrislip \& Larson, 1994). This leadership style is credited with strengthening employee involvement and contributing to significant organizational improvements (Bess \& Dee, 2008b; Kouzes \& Posner, 2002). Kouzes and Posner (2002) describe these leaders as those who "enlarge people's sphere of influence" (p. 306).

The organizational culture of a university is more complex than other organizations largely in part of the intellectual nature and academic structure of departments, disciplines and colleges (Bess \& Dee, 2008a; Bok, 2013; Tierney, 2008; Weick, 1978/1983). Administrators and faculty may identify with the same academic and intellectual values but differ in their ideas on how to address institutional effectiveness, economic challenges, and the decision-making processes at the university (Kuo, 2009). The belief of the individual versus the organization creates a culture of 
distrust and fragmentation with diminishing employee involvement and increased bureaucracies (Bess \& Dee, 2008a; Kuo, 2009).

The fragmented nature that exists in many university processes is viewed as disjointed structures or unclear paths of governance and hierarchical structures of committees and councils that are not used or perhaps even necessary (Bess \& Dee, 2008a; Bok, 2013; Mallon, 2004). While external influences might drive a common perception for university governance to alter its structure and formal processes much like a business; Kezar (2004) concluded that "leadership, trust, and relationships supersede structures and processes in effective decision making" in the university governance system (p. 44). According to Kuo (2009), the "relationships between academic staff and administrators could be strengthened if each side would endeavor to recognize and support each other's priorities and principles" (p. 49).

Kezar and Lester (2011) examined grassroots leadership among faculty and staff with no formal positions of authority at five separate institutions. These individuals were "operating from the bottom up, and are interested in and pursue organizational changes that often challenge the status quo of the institution" (Kezar \& Lester, 2011, p. 8). A research study on faculty leadership at the University of Maryland found evidence of grassroots faculty leadership working in collaboration with administration on institutional change (Perry, 2014). Perry (2014) found that faculty were more likely to utilize group interaction strategies to promote open-communication and the transparency of information that aligned with the academic culture. These group interactions are much like the communities of practice that support learning organizations and academic culture within a university setting (Gill, 2010; Wenger, 1999). 
Faculty leaders do not need a position of authority to play a key role in the development of the university organization (Walsh \& Kahn, 2010). The "capacity to transfer learning back into the academic workplace is strongly contingent on supportive supervisors and leaders, cultures and colleagues" and also dependent upon a "learning community that publicly advocates learning and professional enhancement" to be an important role of its faculty leaders (Debowski, 2017, p. 322). Wong (2006) described the healthy organizational culture for collaboration and faculty-led leadership to be progressive-adaptive, purpose-driven, community-oriented, and people-centered.

Research on leadership styles has shown collaborative leaders to be those that operate outside a position of authority and focus on relationship building in order to achieve a common goal (Chrislip \& Larson, 1994). This type of power and influence can be exerted from multiple levels of an organization (Bess \& Dee, 2008b; Bolman \& Deal, 2013). Yukl and Falbe (1990) researched the differences in downward, lateral, and upward influence tactics and found consultation and rational persuasion to be the most frequently used. Kouzes and Posner (2002) advocated that when leaders display an openness to influence that they are building trust that allows their followers to be more open to influence. Through their scholarly work, faculty often utilize communities of practice to engage peers and promote open-communications (Perry, 2014; Wenger, 1999). Walsh and Kahn (2010) upheld the idea that faculty leaders do not need a position of authority to influence the organizational development of the university. This type of support inspires an academic culture that is similar to that of a learning organization encouraging organizational development and change (Gill, 2010). 


\section{Evaluation of Faculty Centers}

A developmental evaluation can serve as an effective program study when the review is taking place in a highly dynamic environment that is adapting to changing circumstances (Caffarella \& Daffron, 2013; Patton, 2011). As program developers, most faculty centers tend to evaluate the work of their center by measuring the number of participants or the satisfaction level at the end of a workshop event (Chism \& Szabo, 1997; Gillespie \& Robertson, 2010, Kirkpatrick \& Kirkpatrick, 2006). With increased requests for accountability and accreditation standards in higher education, many faculty center directors began to relate the assessment of student learning to faculty development efforts (Carriveau, 2010; Condon, Iverson, Manduca, Rutz, \& Willett, 2016; Gibbs \& Coffey, 2004; Sorcinelli et al., 2006). According to Schroeder (2011), faculty centers should access their organizational role in the university by reviewing the center's vision statement and becoming involved in institutional initiatives beyond the traditional instructional development programming. Beach et al. (2016) argued that faculty centers are entering the age of evidence focused on assessing "the quality and impact of the programs they offer and how they disseminate the results of that assessment" (p. 108).

A review of the literature on the models and approaches for program and educational evaluation suggests a number of questions that researchers should consider when selecting an evaluation model. A focused evaluation built around a set number of objectives for a defined group of stakeholders is a time efficient and cost-effective way to examine return-on-investment questions (Fitzpatrick, Sanders, \& Worthen, 2004) while a formative evaluation designed to collect different information to improve outcomes of an educational program (Dick, Carey, \& Carey, 2008). Wang (2009) characterized 
educational evaluation models into three classifications, each focusing on a different area of program review; management-oriented evaluations, outcome-based evaluations, and training effectiveness models. Madaus and Kellaghan (2000) recommended when choosing an evaluation model that the researcher consider the evaluation questions to be addressed and then "pick and choose features from various models that can provide the best evidence to answer questions about the project" (p. 25).

Evaluation models such as Hines' (2017) four-phase program evaluation model is a model that is unique to faculty centers and designed to assess capacity, curricular conceptualization, evaluation planning, and plan implementation. Hines (2017) studied the evaluation practices of 53 faculty centers and developed an evaluation model based on the structural foundation of Stufflebeam's CIPP model (Stufflebeam \& Zhang, 2017). The Hines (2017) model attempts to contrast initial and intermediate results with the intended results of the program. Much like the approach of the CIPP evaluation model (Stufflebeam \& Zhang, 2017), Hines (2017) advocates that the purpose of conducting a program evaluation is to make decisions concerning the value of various programs, determine areas of improvement, and to share these results with administrators in an effort to document contributions and justify resource requests.

Goal-free evaluations are an evaluative approach that is focused on the actual impact, including any side effects, rather than the prescribed outcomes (Preskill \& RussEft, 2005). Outcomes-based evaluation models (Wang, 2009) and behavioral objectives approaches to evaluation (Preskill \& Russ-Eft, 2005) focus on the degree to which the objectives, product, or processes of a program have been achieved. Expertise or 
accreditation models are another type of outcomes-based evaluation based on expert opinion to determine the quality of the program (Preskill \& Russ-Eft, 2005).

Responsive evaluation approaches are formative in nature, calling on the researchers to be responsive to the information needs of stakeholders, while participatory or collaborative evaluations engage stakeholders in the evaluation process and the analysis of evaluation data for decision-making purposes (Preskill \& Russ-Eft, 2005; Wang, 2009; Yin, 2000). Kirkpatrick and Kirkpatrick (2006) and Guskey (2000) relied primarily on participant responses as an approach to evaluating professional development. These models can be used for both formative and summative evaluations. Kirkpatrick's (2006) four-level model focused on training outcomes based on the four levels of reactions, learning, behavior, and results (Kirkpatrick \& Kirkpatrick, 2006). Through responsive evaluation and student assessment data, Geskey (2000) expanded upon Kirpatrick's (2006) model as an educational program evaluation to assess how teachers applied new knowledge and skills to improve student learning outcomes.

Large scale studies on the participation in faculty development confirms existing data that faculty consistently self-report increased learning that aligned with the intended program goals (Sorcinelli et al., 2006; Beach et al., 2016). Gibbs and Coffey (2004) researched these perceived changes over time using student data from the Student Evaluation of Educational Quality questionnaire (SEEQ), faculty self-ratings from the Approaches to Teaching Inventory scale (ATI), and the analysis of surface and deeplearning approaches toward teaching using scores from the 'Good Teaching' scale of the Module Experience Questionnaire (MEQ). Focusing on the extent to which faculty adopt a student-centered approach toward teaching after participating in faculty development 
activities, Gibbs and Coffey provided evidence that adopting a student-centered approach in their teaching practices have a positive impact on improved student learning. Condon et al. (2016) conducted multiyear studies at a small liberal arts college in Minnesota and at Washington State, a large land-grant university, and despite the differences in these two settings they found the same relationship between faculty development and improved student outcomes. Findings in their research also indicated that the benefits of faculty development are cumulative throughout the faculty members' career (Condon et al., 2016). The focus of this study looked at how valuing faculty development created a generative culture of teaching and learning and "enhances self-motivated, individual faculty learning, and supports faculty experimentation in their courses" (Condon et al., 2016. p. 121).

The assessment and impact of faculty development on the organization has been one way that faculty centers have shown value in supporting learning and assisting institutions of higher education to become learning organizations (Fink, 2013). However; faculty centers have begun to shift from the single service business model of providing teaching consultations to improve student learning to one that supports faculty and the university in responding to significant changes that are occurring in higher education (Schroeder, 2011). Through the evaluation of a faculty center it is important to "identify and promote the value they provide to various stakeholders" and have a better understanding of how they "can cocreate it (value) with various stakeholder groups" (Schumann, Peters, \& Olsen, 2013, p. 21). Chalmers and Gardiner (2015) recommended that program evaluation be designed around the principles of relevance, rigor, context, and reliability. According to Hines (2017), a contextual model of evaluation must take 
into account "the situational factors influencing the operations of the center, including its infrastructure, management, curriculum, and institutional learning culture" (p. 90).

Caffarella and Daffron's (2013) interactive model for program planning and evaluation provides for the ability to focus on features and potential issues that may arise when carrying out adult learning programs. They recommended using a developmental evaluation approach when addressing problems with no real answers, transitioning a program into a different context; and when rapid-responses are needed to address a particular problem (Caffarella \& Daffron, 2013). To provide answers and inform the researcher, Patton (2011) argued that the approaches used in a developmental evaluation should be properly aligned with the complexity of the problem and the complexity of any proposed solutions (see Table 7). Patton developed the utilization-focused evaluation model and argued that program evaluation should be done with a specific group of users in mind; and in order to be a useful evaluation, that stakeholders should be involved in many, if not all, phases of the evaluation.

Table 7

Specific Evaluation Models, Approaches or Focus and Defining Questions

Model, Approach, or Focus $\quad$ Questions to be Answered

\begin{tabular}{ll}
\hline Accountability focus & $\begin{array}{l}\text { Have resources been appropriately used to } \\
\text { accomplish the intended outcomes? }\end{array}$ \\
Attitude focus & $\begin{array}{l}\text { What changes in attitudes or opinions have } \\
\text { occurred as a result of participation in the program? }\end{array}$ \\
Behavioral focus & $\begin{array}{l}\text { What changes in behaviors or actions can be } \\
\text { observed as a result of participation in the program? }\end{array}$ \\
Balance-focused approach & $\begin{array}{l}\text { What are the various viewpoints that exist about } \\
\text { this program? }\end{array}$
\end{tabular}


Expertise/accreditation focus

Four-level model

Formative evaluation

Impact focus

Mission focus

Knowledge focus

Management-focused

Organizational learning

Outcomes-focused evaluation

Participatory/collaborative

Personnel evaluation

Process evaluation

Responsive evaluation

Success case method

Utilization-focused evaluation
How would practitioners in the field rate this program?

Is the program, product, or process reaching its objectives?

How can the program be improved?

What are the direct and indirect program effects on the larger community?

How does the department/program support the overall mission of the organization?

What do participants know as a result of participation in the program?

What data do managers need to know to improve the program?

What are the information and learning needs of individuals, teams, and the organization?

What are the effects of the program? To what extent are intended outcomes being met

What information do stakeholders need to know to better understand the program?

How effective are staff in performing assigned work and accomplishing goals?

What are the strengths and weaknesses of day-today operations? How are program processes perceived by stakeholders? How can processes be improved?

What does the program look like to different people?

What is really happening

What information is needed and wanted by decision makers and other stakeholders?

Kirkpatrick \& Kirkpatrick, 2006; Patton, 1981, 2011; Preskill \& Russ-Eft, 2005; Preskill \& Torres, 1999.

Preskill and Torres (1999) argued that evaluation could be used as a catalyst for organizational learning. They viewed evaluation as a social activity where issues are 
constructed and acted on by members of the organizational community (Preskill \& Torres, 1999). This organizational learning approach is ongoing, integrated into work practices, and provides a way of sharing or storytelling (Brinkerhoff, 2003, 2005; Preskill $\&$ Torres, 1999). A success case approach to evaluation focuses on the practice of defining and sharing successful outcomes and success cases (Brinkerhoff, 2003, 2005; Krueger \& Casey, 2015; Newcomer et al., 2015). This approach is useful in documenting stories of impact and helping members of the community to understand the factors that contributed to or impeded this impact (Brinkerhoff, 2003, 2005).

Hines (2017) proposed that faculty centers are faced with five crucial obstacles when it came to the integration of evaluative practices: (1) a misguided mindset of what should be evaluated; (2) a weak infrastructure to operationalize evaluations; (3) illconceived programs and a growing menu of offerings without a curricular design, (4) fuzzy goals that are focused on processes not product, and (5) a non-defined evaluation framework. Through an investigation of evaluation practices and challenges at 53 faculty centers, Hines field-tested a four-phase program evaluation model that was designed to assess capacity, curricular conceptualization, evaluation planning, and the implementation of the evaluation plan. Hines' evaluation model is unique in that it is designed specifically for faculty centers and it also takes into consideration contextual factors impacting the operations of the center including its management, infrastructure, curricular design of programming, and the learning culture of the university.

Program evaluation provides critical information about the needs and desires of participants, the processes used to provide programming, and also information that determines if the intended outcomes have been met. Faculty centers are charged with 
designing curriculum to meet faculty development needs but oftentimes the assessment of their programming is designed to measure participant reaction or satisfaction (Fink, 2013). There are numerous educational evaluation models, approaches, and focuses each looking at collecting different information for the purposes of program improvement or reform. As demands for accountability continue to grow throughout education, faculty centers have entered the age of evidence and are more focused on showing relational assessments of faculty development and student outcomes (Beach et al., 2016). A gap in this research that is just starting to be addressed is the evaluation of a faculty center within the context of their university including its management, structure, processes, and learning culture of the university. Patton (2011) argued that developmental evaluations should align with the complexity of the problem or the setting where the problem is occurring.

\section{Summary}

Research shows that the role faculty centers has changed over time depending on the needs of the university education (Ouellett, 2010; Schroeder, 2011; Sorcinelli et al., 2006). Regardless of these changes, faculty development has become a more centralized process within the university setting (Schroeder, 2011) but a significant consideration remains that most faculty centers have short-aimed missions and a lack of adequate resources and workflow allocations (Hines, 2017). Tierney (2008) provided research on how the cultural beliefs within a university affect its decision-making ability and determine the role of faculty in formal and informal influences of power. Bess and Dee (2008a) advised that the cultural divide between faculty and administrators can manifest into conflict and distrust defined by their disassociation with common goals and values of 
the university. In their role as organizational developers, faculty centers work collaborative with administration and faculty. These units utilize professional staff, advisory committees, and other collective means to influence faculty and the academic administration on many of the complex challenges facing the university (Beach et al., 2016; Schroeder, 2011). However, fragmented processes can create an unclear path and hierarchical structures that become a hindrance and serve no real purpose (Bess \& Dee, 2008a; Bok, 2013; Mallon, 2004).

Most faculty centers tend to evaluate the work by measuring the number of participants and the satisfaction level of participants (Gillespie \& Robertson, 2010, Kirkpatrick \& Kirkpatrick, 2006; Chism \& Szabo, 1997). Program evaluation models such as Stufflebeam $(2000,2017)$ and Hines' $(2017)$ examine processes used in the implementation of professional learning. The evaluation of processes also helps to identify and promote value having a better understanding of how to co-create value with various stakeholders (Schumann et al., 2013). Stufflebeam's CIPP evaluation model for program improvement and accountability (Stufflebeam \& Zhang, 2017) reviews processes to help managers make decisions on the procedural design and implementation of professional learning activities provided by faculty centers. 
Section Four:

\section{Contribution to Practice}




\section{EVALUATION OF FACULTY ENGAGEMENT IN PROFESSIONAL LEARNING ACTIVITIES: A MIXED-METHODS STUDY ON COMMUNICATION PROCESSES, VALUE, AND BARRIERS}

EXECUTIVE SUMMARY REPORT

\section{Presented to:}

Academic Administrator's Assembly

Academic Leadership Council

FCTL Advisory Council 
The role of the faculty center has expanded beyond the solitary mission of providing faculty development to one that supports the university's strategic goals and key performance indicators through professional learning activities (Schroeder, 2011; Sorcinelli, Austin, Eddy, \& Beach, 2006).

\section{Problem of Practice:}

A faculty survey conducted at Missouri State University during the spring of 2017, indicated that $23 \%$ of faculty had no interest in professional learning activities that supported teaching and university goals.

This study was a developmental evaluation of the faculty center to investigate the question, "what organizational processes promote or impede faculty engagement in professional learning activities at Missouri State University?"

\section{Methods of Analysis:}

This study focused on the structural factors of context, inputs, processes, and products of the faculty center (Hines, 2017). A framework of evaluative inquiry identified areas of improvement and included a reflective dialogue of faculty experiences (Patton, 2011; Preskill \& Torres, 1999).

An online survey was sent to 753 fulltime and 370 part-time faculty; a total of 139 responded for an $18 \%$ response rate.
$>$ A random sampling of faculty who had participate and who had not participated in professional learning activities were invited to participate in a focus group. Eight faculty participated in these focus group interviews.

\section{Major Findings:}

\section{Effectiveness of communication processes}

Communication channels that inform faculty of upcoming professional learning activities

$$
\begin{array}{ll}
\text { Inside Missouri State } & 29 \% \\
\text { What's Happening } & 25 \%
\end{array}
$$

A faculty who had not participated professional learning activities responded, "If an email is addressed to me personally it tends to hold my attention longer. Individual notes to faculty that say I want you to know about this, is something I'd be more likely to read."

\section{Perceptions of value toward professional learning activities}

Faculty indicated these activities were very or extremely valuable

$\begin{array}{ll}\text { Public Forums and Writing Retreats } & 45 \% \\ \text { Support for Online Teaching } & 63 \% \\ \text { Support for Instructional Technology } & 68 \%\end{array}$


Positive experiences included: impressive level of support when learning a new technology; nice tips from staff; showed me some tools I could use; and wouldn't be able to teach effectively without training and guidance provided by the faculty center.

While most comments were positive, the diversity workshops received positive and negative comments: not helpful in terms of real strategies to incorporate in the classroom.

\section{Perceived barriers toward participation}

Cultural Barriers

Lack of incentives to attend

Workload

Not tied to promotion and tenue

\section{System Barriers}

Scheduling

Location

Cultural barriers are those that cannot be changed by a single unit like the faculty center.

System barriers like scheduling and delivery modalities can be controlled by the faculty center.

\section{Recommendations for the Faculty Center for Teaching and Learning}

1. Ways to improve communication processes of the faculty center:

- Use appropriate language that will support relevancy and expectant values.

- Target faculty groups with specific information about professional learning activities.

- Use mail merge features to send batch emails that are personalized for each recipient.

2. How best to meet faculty expectant and actual values:

- $\quad$ Align and promote professional learning activities to different stages of teaching careers.

- Use success stories and testimonials from participants to market professional learning activities to future participants.

3. How the Faculty Center can contribute to the removal of barriers:

- Develop online and just-in-time resources to increase the availability of professional learning.

- Create a faculty lab with computer workstations and collaborative furniture where faculty can learn new technologies and engage in course development work.

\section{Further Considerations for University Administration}

1. Form a strategic committee to investigate how professional learning might be aligned to the university's promotion and tenure processes.

2. Reassign time/space or incentives for faculty to participate in professional learning. 


\section{References}

Patton, M. Q. (2011). Developmental evaluation: Applying complexity concepts to enhance innovation and use. New York, NY: Guilford.

Preskill, H. S., \& Torres, R. T. (1999). Evaluative inquiry for learning in organizations. Thousand Oaks, CA: Sage.

Schroeder, C. M. (2011). Coming in from the margins: Faculty development's emerging organizational development role in institutional change. Sterling, VA: Stylus Publishing.

Sorcinelli, M. D., Austin, A. E., Eddy, P. L., \& Beach, A. L. (2006). Creating the future of faculty development: Learning from the past, understanding the present. Bolton, MA: Anker Publishing. 


\section{Presentation Slides}

\section{Evaluation of Faculty Engagement in Professional Learning Activities}

A Mixed-Methods Study on Communication

Processes, Value, and Barriers

Nancy Gordon

\section{Statement of the Problem}

- Faculty Senate 2016 survey indicated that many faculty at Missouri State University are unaware or uninterested in professional learning activities offered to faculty through the faculty center. 


\section{Research Question}

What organizational processes promote or impede faculty engagement in professional learning activities at Missouri State University?

Sub-questions include:

1. How effective are the current communication processes being utilized by the faculty center?

a. What are the communication processes that inform faculty about professional learning activities?

b. What is the level of faculty awareness of professional learning activities provided by the faculty center?

\section{Research Question}

What organizational processes promote or impede faculty engagement in professional learning activities at Missouri State University?

Sub-questions include:

2. What are faculty perceptions of value concerning professional learning activities provided by the faculty center?

a. What are expectant values of non-participants toward such professional learning activities?

b. What is the actual values of faculty participants toward such professional learning activities?

3. What are faculty perceptions of barriers to their participation in professional learning activities? 


\section{Research Methodology}

- Setting for the Study: Missouri State University

- A mid-sized, non-research, public university located in the Midwest

- Theoretical Framework

- Evaluative Inquiry (Preskill \& Torres, 1999);

- Expectancy-Value Theory of Motivation (Fishbein \& Aizen, 1975);

- CIPP Evaluation Model (Stufflebeam \& Zhang, 2017)

- Scholarly Review

- Faculty Development; Organizational Culture; Collaboration and Faculty Leadership; Evaluation Models and Methods for Evaluating Faculty Centers

\section{Study conducted Spring 2018}

- A mixed-methods approach to developmental evaluation for process improvement

- Faculty Survey

- Collect data concerning their awareness and participation in professional learning activities provided by the faculty center

- Focus Groups

- Faculty who have participated - actual-value of their experience

- Faculty who have not participated-expect-value of their experience 


\section{Major Findings: Communication Processes}

- Most effective communication channels

- Inside MissouriState weekly newsletter-29\%

- What's Happening monthly emails - $25 \%$

- Other communication channels

- Communique $-12 \%$

- Colleagues $-10 \%$

- Dept. Head-8\%

- Web-8\%

- University Calendar - 6\%

- Other $-2 \%$

\section{Major Findings: Communication Processes}

Faculty Awareness of Professional Learning Activities

\begin{tabular}{lcccc}
\hline & Never heard of it & I've heard of it & Familiar with this & Have participated \\
\hline Showcase & $1 \%$ & $9 \%$ & $17 \%$ & $73 \%$ \\
\hline Online Boot Camp & $9 \%$ & $24 \%$ & $41 \%$ & $26 \%$ \\
\hline Diversity Scholars & $8 \%$ & $31 \%$ & $38 \%$ & $23 \%$ \\
\hline Faculty Writing & $4 \%$ & $23 \%$ & $51 \%$ & $22 \%$ \\
Curriculum Grants & $13 \%$ & $31 \%$ & $39 \%$ & $17 \%$ \\
\hline Teaching Awards & $5 \%$ & $37 \%$ & $46 \%$ & $12 \%$ \\
\hline Accessibility Inst. & $31 \%$ & $27 \%$ & $35 \%$ & $7 \%$ \\
\hline
\end{tabular}




\section{Major Findings: Communication Processes}

Perceived relevancy of messages:

- "if an email is addressed to me personally it tends to hold my attention longer"

- "individual notes that say 'I want you to know about this' is something I'd be more likely to read"

Major Findings: Value of professional learning activities

Expectant values toward professional learning activities

\begin{tabular}{|l|l|}
\hline Professional Learning Activity & Dominant Perceived Value
\end{tabular}

Faculty Recognition

Extremely/Very valuable

Online Teaching Support

Very valuable

Grant Funding

Very valuable

UDL (accessibility)

Very valuable

Technology Support

Very valuable

MediaSite Studio

Very valuable

Public Forum

Somewhat valuable

Diversity Workshops

Somewhat valuable

Faculty Writing

Somewhat valuable 


\section{Major Findings: Value of professional learning activities}

Perceived value of actual experiences:

"impressive level of support when learning a new technology"

"nice tips from staff"

"showed me some tools I could use"

"wouldn't be able to teach effectively without training and guidance provided by the faculty center"

\section{Major Findings: Perceived barriers to participation}

Identification of cultural and system barriers to participation

\section{\begin{tabular}{|l|l}
\hline Cultural Barriers & System Barriers \\
\hline
\end{tabular}}

Lack of incentives to attend Scheduling

Workload Location

Not tied to promotion and tenure 


\section{Recommendations for the FCTL}

\section{Ways to improve communication processes:}

1. Use language that supports relevancy and expectant values.

2. Target faculty groups with specific information about professional learning activities.

3. Use mail merge features to send batch emails that are personalized for each recipients.

4. Explore other communication channels such; e.g. academic building's e-bulletin boards.

\section{Recommendations for the FCTL}

\section{How to best meet faculty expectant and actual values:}

1. Align and promote professional learning activities to different stages of teaching careers.

2. Use success stories and testimonials from participants to market professional learning activities to future participants. 


\section{Recommendations for the FCTL}

How the Faculty Center can contribute to the removal of barriers:

1. Develop online and just-in-time resources to increase the availability of professional learning.

2. Create a faculty lab with computer workstations and collaborative furniture where faculty can learn new technologies and engage in course development work.

\section{Considerations for University Administration}

1. Form a strategic committee to investigate how professional learning might be aligned to the university's promotion and tenure processes.

2. Reassign time/space or incentives for faculty to participate in professional learning. 


\section{Contribution to Practice}

- Presentation of Research Findings

- Academic Administrator's Assembly

- Academic Leadership Council

- FCTL Advisory Council

\section{Contribution to Scholarship}

- Scholarly Journals

- To Improve the Academy: A Journal of Educational Development

- Studies in Educational Evaluation 


\section{Future Research}

- Continued evaluation of improvements made as a result of this study.

- Evaluative study of additional ways to promote professional learning activities at the annual Showcase. 
EVALUATION OF FACULTY ENGAGEMENT IN PROFESSIONAL LEARNING ACTIVITIES: A MIXED-METHODS STUDY ON COMMUNICATION PROCESSES, VALUE, AND BARRIERS

FULL TECHNICAL REPORT 
During the spring of 2017, the Faculty Center for Teaching and Learning (FCTL) and the Faculty Senate conducted a survey to collect data on faculty needs and interest in attending faculty development programming. Twenty-three percent of faculty responded that they had no interest in attending professional learning activities that were in support of teaching and university goals. While the majority of faculty indicated workload and scheduling conflicts were their primary reasons for not attending, this survey established a baseline for the value faculty place on professional learning activities offered by the faculty center and their motivation for participating in such activities.

A developmental evaluation was conducted by the FCTL the following fall to further explore these initial findings. The problem of practice addressed was that many faculty were unaware or uninterested in professional learning activities being offered to faculty through the faculty center. The value faculty place on professional learning may depend on the expectant value for participating in these activities, and the communication processes that promote such activities. Questions central to this evaluation were:

What organizational processes promote or impede faculty engagement in professional learning activities at Missouri State University?

Sub-questions include:

1. How effective are the current communication processes being utilized by the faculty center?

a. What are the communication processes that inform faculty about professional learning activities?

b. What is the level of faculty awareness of professional learning activities provided by the faculty center? 
2. What are faculty perceptions of value concerning professional learning activities provided by the faculty center?

a. What are the expectant values of non-participating faculty toward professional learning activities?

b. What are the actual values of faculty participants toward such professional learning activities?

3. What are faculty perceptions of barriers to their participation in professional learning activities?

\section{Sampling and Data Collection Procedures}

An online survey was sent to 753 full-time and 370 part-time faculty teaching at Missouri State University (MSU) through communication channels administered by the Faculty Senate. A total of 139 faculty responded to the online survey for an $18 \%$ response rate. The participants who completed the survey represented a cross-section of faculty ranks including full-time and part-time faculty. Of the 139 participants, there were 51 Assistant Professors, 21 Associate Professors, 35 Professors, 31 instructors or part-time faculty, and one undisclosed. The participants also provided a diverse representation of years teaching at the university (see Table 8) representing early, mid, and later-career faculty (Gillespie \& Robertson, 2010). 
Table 8

Years Teaching at the University

\begin{tabular}{llc}
\hline Number of years teaching & Percent of Participant Sampling & $N$ \\
\hline$<1$ year & $9 \%$ & 13 \\
$1-5$ years & $34 \%$ & 47 \\
$6-15$ years & $30 \%$ & 42 \\
$16-20$ years & $10 \%$ & 14 \\
More than 20 years & $17 \%$ & 23 \\
\hline
\end{tabular}

Note. These percentages are based on the total of 139 respondents to the online survey.

The survey was developed to investigate effective communication processes utilized by the faculty center, faculty perceptions of value placed on professional learning activities, and perceived barriers to participate in such professional learning activities. The survey provided both quantitative and qualitative data using Likert-scale question types as well as open-response questions. Before administering the survey, it was validated for content and usability by faculty members of the faculty center's advisory council.

Using registration data housed in the university's professional learning management system, a random sampling of 40 faculty who had participated in more than one event facilitated by the faculty center, was invited to participate in a focus group interview. Out of the 40 faculty invited to participate, seven participants attended the focus group discussion. Those in attendance represented a cross-section of faculty ranks including full-time and part-time faculty. The focus group consisted of one Assistant Professor, three Professors, and three instructors or part-time faculty. Two of these faculty had been teaching at the university for 1 to 5 years, two had been teaching 6 to 15 
years, and three of these faculty had been teaching at the university for more than 20 years. The focus group interviews provided qualitative data responding to questions developed to investigate effective communication processes utilized by the faculty center, perceptions of value placed on professional learning activities, and perceived barriers to participate in such professional learning activities.

Professional learning registration data was compared to faculty distribution lists for each college to come up with a random sampling of 40 faculty who had not participated in professional learning activities facilitated by the faculty center. This group of 40 faculty were then invited to participate in a second focus group interview. Of the 40 subjects invited, five faculty contacted the researcher to say they would participate but could not attend the scheduled focus group meeting. These five participants included one Professor, one Associate Professor, and three part-time instructors. These individuals were then invited to participate in a phone interview to be scheduled for a date and time of their choosing. One participant, a professor who had been teaching at the university for 7 years, agreed to a one-on-one interview and the other four did not respond.

\section{Data Analysis}

The survey data was downloaded and imported into SPSS where descriptive statistics were used to analyze the quantitative data (Wright \& London, 2013). The openresponse questions from the survey and the focus group interviews were coded and analyzed by categorizing statements and then identifying thematic connections within and among the responses (Seidman, 2013). The analysis of both quantitative and qualitative data allowed the researcher to have a better understanding of the findings and an increased confidence of the overall validity of the study (Creswell, 2014). 


\section{Major Findings}

\section{Effectiveness of Communication Processes}

The first research question focused on the effectiveness of the current communication processes being utilized by the faculty center. When asked which university communication channels faculty used to inform themselves about upcoming professional learning activities, $29 \%$ of the respondents indicated the weekly university enewsletter Inside Missouri State was how they heard of these events and 25\% responded that they learned about them from the monthly What's Happening email sent by the faculty center (see Figure 3). Both of these communication tools are delivered through the university's email system.

\section{Current Communication Channels}

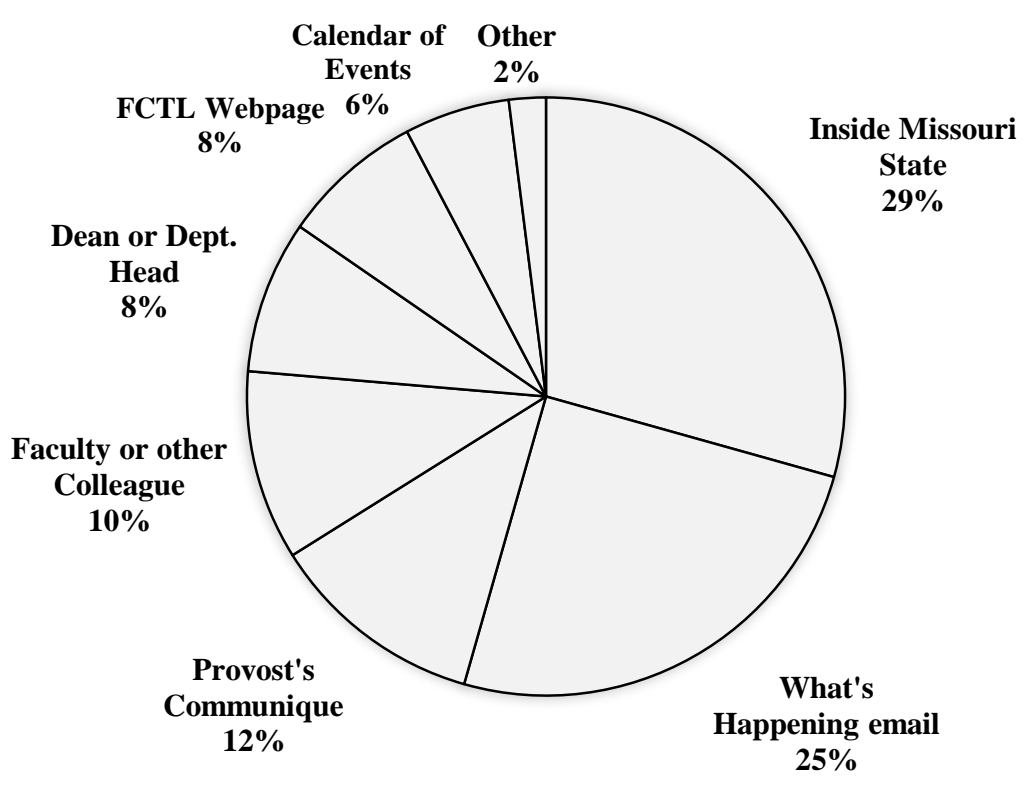

Figure 3. This graph represents faculty responses concerning how they are informed of professional learning activities.

One faculty member in the focus group said that email "may not be the most effective because we are bombarded and it gets lost." They went on to say that they were 
"most likely to notice email if from someone you know, I pay attention to the emails that my department head forwards." While this may be the most effective communication channel for this faculty member, only $8 \%$ of those responding to the survey indicated that they learned of professional learning activities from emails forwarded by their dean or department head. Faculty that selected "Other" as a response specified they learned of professional learning activities through emails they had received, although they did not indicate from where the email originated, and from faculty orientations or other meetings. One of the research subjects who had not participated in professional learning activities facilitated by the faculty center stated, "If an email is addressed to me personally it tends to hold my attention longer. Individual notes to faculty that say 'I want you to know about this' is something I'd be more likely to read." Another research subject stated that they would like to see an increase in social media presence for the faculty center.

\section{Faculty Awareness of Professional Learning}

To answer the question concerning effective communication processes, faculty awareness of professional learning activities was examined. Participants were asked to rank their awareness of twelve professional learning activities facilitated by the faculty center. These activities included a public forum to share teaching practices (the annual Showcase on Teaching and Learning), one day and week-long workshops (diversity, accessibility, and course design workshops), as well as teaching awards and faculty funding opportunities. Awareness of these activities were ranked using the Likert scale (1) have never heard of it, (2) somewhat familiar, (3) I am familiar with this, or (4) I have attended or participated in this activity. 
Table 9

Faculty Awareness of Professional Learning

\begin{tabular}{rcccc}
\hline & Never heard of it & I've heard of it & I'm familiar with this & I have participated \\
\cline { 2 - 5 } - Showcase & $1 \%$ & $9 \%$ & $17 \%$ & $73 \%$ \\
Online Boot Camps & $9 \%$ & $24 \%$ & $41 \%$ & $26 \%$ \\
Diversity Scholars & $8 \%$ & $31 \%$ & $38 \%$ & $23 \%$ \\
Faculty Writing & $4 \%$ & $23 \%$ & $51 \%$ & $22 \%$ \\
Curriculum Grants & $13 \%$ & $31 \%$ & $39 \%$ & $17 \%$ \\
- & $5 \%$ & $37 \%$ & $46 \%$ & $12 \%$ \\
Teaching Awards & $31 \%$ & $27 \%$ & $35 \%$ & $7 \%$ \\
\hline
\end{tabular}

Participants were most aware of Showcase; 73\% of those responding to the survey had previously attended this activity (see Table 9). The Showcase on Teaching and Learning is the longest standing event organized by the faculty and has been held every year since the center was established in 2002 . The activity that participants were least aware, the accessibility institute, is a newer offering held less than three years. Thirtyone percent of those responding to the survey had never heard of this professional learning activity. The curriculum grants and teaching awards are competitive activities with fewer than eight proposals or nominations submitted annually for each of these activities. Seventy percent of those responding to the survey had either heard or were familiar with this grant program and $83 \%$ had either heard of or were familiar with the teaching awards. 
Table 10

Faculty Awareness of Support Focused Activities

\begin{tabular}{rcccc}
\hline & Never heard of it & I've heard of it & I'm familiar with this & I have participated \\
\cline { 2 - 5 } - Instructional Technology & $6 \%$ & $30 \%$ & $37 \%$ & $27 \%$ \\
Online Teaching & $8 \%$ & $24 \%$ & $42 \%$ & $26 \%$ \\
MediaSite (video lectures) & $30 \%$ & $24 \%$ & $25 \%$ & $21 \%$ \\
UDL (accessibility) & $12 \%$ & $29 \%$ & $42 \%$ & $17 \%$ \\
Support for Teaching & $14 \%$ & $35 \%$ & $37 \%$ & $14 \%$ \\
\hline
\end{tabular}

Examining faculty awareness of support focused professional learning activities; faculty are aware of these support services (see Table 10) even though they are not actively communicated outside of the faculty center's website, public forums, and within the context of other workshops and activities. Fourteen percent or less of the respondents were not aware of support available for online teaching, instructional technology, teaching, or accessibility issues. Support services most utilized by participants were those that supported: online teaching with $26 \%$ that have participated; instructional technology with 27\% that have participated; and MediaSite video lectures with $21 \%$ that have participated. Faculty awareness of support focused activities was reiterated by qualitative data from the focus groups when one participant stated "I like the personal contact" and "will continue to seek out one-on-one help."

\section{Perceived Expectant Values toward Professional Learning}

To answer the second research question examining faculty perception of value toward professional learning activities provided by the faculty center, participants were asked to rank their expectant value using a Likert scale of (1) not at all valuable, (2) somewhat valuable, (3) very valuable, or (4) extremely valuable. Professional learning activities included in the study were public forums to share teaching practices, one day 
and week-long workshops, support for online teaching and instructional technology, and faculty recognition and funding opportunities (see Table 11).

Table 11

Perceived Expectant Values of Faculty

\begin{tabular}{rcccc}
\hline & Not as all & Somewhat & Very & Extremely \\
\cline { 2 - 5 } Grant Funding & $6 \%$ & $18 \%$ & $40 \%$ & $36 \%$ \\
Faculty Recognition & $9 \%$ & $25 \%$ & $33 \%$ & $33 \%$ \\
Faculty Writing & $23 \%$ & $32 \%$ & $22 \%$ & $23 \%$ \\
MediaSite Studio & $14 \%$ & $32 \%$ & $32 \%$ & $22 \%$ \\
Instructional Technology & $8 \%$ & $23 \%$ & $48 \%$ & $21 \%$ \\
Online Teaching & $12 \%$ & $24 \%$ & $41 \%$ & $21 \%$ \\
Diversity Workshops & $14 \%$ & $40 \%$ & $31 \%$ & $15 \%$ \\
UDL (accessibility) & $7 \%$ & $37 \%$ & $42 \%$ & $14 \%$ \\
Public Forums & $10 \%$ & $45 \%$ & $35 \%$ & $10 \%$ \\
\hline
\end{tabular}

Expectant values of faculty toward professional learning activities were comparatively positive. Forty-five percent of faculty perceived public forums and retreats for faculty writing to be very or extremely valuable. Support for online teaching and using instructional technology was also perceived valuable; $63 \%$ perceived support for online teaching to be very or extremely valuable and $68 \%$ perceived support for using instructional technology to be very or extremely valuable.

To further examine which of these professional learning activities and support services were perceived to be of most value, basic frequencies of expectant values were calculated using SPSS. The valid percentage of responses were analyzed to determine the dominant perceived value for that professional learning activity (see Table 12). Activities with equal frequency distribution across two different values are represented with having two dominant perceived values. 
Table 12

Faculty Perceived Expectant Values of Professional Learning Activity

\begin{tabular}{ll}
\hline PL Activity & Dominant Perceived Value \\
\hline Faculty Recognition & Very valuable/Extremely valuable \\
Online Teaching Support & Very valuable \\
Grant Funding & Very valuable \\
UDL (accessibility) & Very valuable \\
Inst. Technology Support & Very valuable \\
MediaSite Studio & Very valuable \\
Public Forum & Somewhat valuable \\
Diversity Workshops & Somewhat valuable \\
Faculty Writing & Somewhat valuable \\
\hline
\end{tabular}

A comparison of the perceived expectant values of faculty participating in this study points to the most dominant perceived value for any of the items was faculty recognition, very valuable/extremely valuable, while public forums for distinguishing teaching practices and research of those practices was ranked as somewhat valuable. Another finding of this analysis indicates that professional learning activities focused on diversity, one of the university's strategic initiatives supporting its mission (MSU, 2017i), was perceived as somewhat valuable by the participants in this study.

To further analyze and clarify the relationship between the ordinal variables years of teaching and perceived expectant value of instructional technology support, the 
categories of years of teaching were first collapsed and recoded to avoid small cells, and then a crosstabulation was created (see Table 13).

Table 13

Years of Teaching and Perceived Expectant Value of Inst. Technology Support

\begin{tabular}{|c|c|c|c|c|c|}
\hline & & \multicolumn{4}{|c|}{ Categories for years of teaching } \\
\hline & & $<1+1-5$ yrs. & $6-15 \mathrm{yrs}$. & $16-20+>20$ yrs. & Total \\
\hline \multirow[t]{2}{*}{ Not at all valuable } & Count & 4 & 2 & 5 & 11 \\
\hline & Expected Count & 4.7 & 3.3 & 2.9 & 11.0 \\
\hline \multirow[t]{2}{*}{ Somewhat valuable } & Count & 17 & 6 & 9 & 32 \\
\hline & Expected Count & 13.8 & 9.7 & 8.5 & 32.0 \\
\hline \multirow[t]{2}{*}{ Very valuable } & Count & 31 & 21 & 15 & 67 \\
\hline & Expected Count & 28.9 & 20.2 & 17.8 & 67.0 \\
\hline \multirow[t]{2}{*}{ Extremely valuable } & Count & 8 & 13 & 8 & 29 \\
\hline & Expected Count & 12.5 & 8.8 & 7.7 & 29.0 \\
\hline \multirow[t]{2}{*}{ Total } & Count & 60 & 42 & 37 & 139 \\
\hline & Expected Count & 60.0 & 42.0 & 37.0 & 139.0 \\
\hline
\end{tabular}

A Chi-square test was then calculated to compare years of teaching and the perceived expectant value of instructional technology. The Pearson Chi-square test indicated no significant difference in years of teaching and perceived expectant value of support for instructional technology, $X^{2}(1, n=139)=8.584, p=.198$.

To further analyze and clarify the relationship between the ordinal variables years of teaching and perceived expectant value of MediaSite support, the categories of years of teaching were first collapsed and recoded to avoid small cells, and then a crosstabulation was created (see Table 14). 
Table 14

Years of Teaching and Perceived Expectant Value of MediaSite Support

\begin{tabular}{|c|c|c|c|c|c|}
\hline \multirow{4}{*}{ Not at all valuable } & \multirow[b]{3}{*}{ Count } & \multicolumn{3}{|c|}{ Categories for years of teaching } & \multirow[b]{2}{*}{ Total } \\
\hline & & \multirow{2}{*}{$\begin{array}{r}<1+1-5 \mathrm{yrs} . \\
7\end{array}$} & \multirow{2}{*}{ 6-15 yrs. } & \multirow{2}{*}{$\begin{array}{r}16-20+>20 \text { yrs. } \\
7\end{array}$} & \\
\hline & & & & & 19 \\
\hline & Expected Count & 8.2 & 5.7 & 5.1 & 19.0 \\
\hline \multirow[t]{2}{*}{ Somewhat valuable } & Count & 25 & 11 & 8 & 44 \\
\hline & Expected Count & 19.0 & 13.3 & 11.7 & 44.0 \\
\hline \multirow[t]{2}{*}{ Very valuable } & Count & 19 & 14 & 12 & 45 \\
\hline & Expected Count & 19.4 & 13.6 & 12.0 & 45.0 \\
\hline \multirow[t]{2}{*}{ Extremely valuable } & Count & 9 & 12 & 10 & 31 \\
\hline & Expected Count & 13.4 & 9.4 & 8.3 & 31.0 \\
\hline \multirow[t]{2}{*}{ Total } & Count & 60 & 42 & 37 & 139 \\
\hline & Expected Count & 60.0 & 42.0 & 37.0 & 139.0 \\
\hline
\end{tabular}

A Chi-square test was then calculated to compare years of teaching and the perceived expectant value of support for MediaSite video production. The Pearson Chi-square test indicated no significant difference in years of teaching and perceived expectant value of MediaSite support, $X^{2}(1, n=139)=7.057, p=.316$.

\section{Perceived Actual Value of Professional Learning Experience}

Qualitative data from the focus group and the online survey was categorized and coded as actual value received through participation in professional learning activities.

The actual value of these experiences was classified as support, impact/outcome, community, efficiency of time, or recognition. Experience statements were then coded as plus or minus to indicate whether it represented a positive (+) or negative (-) experience.

Faculty experiences were overall positive when commenting on support they had received; "impressive level of support when learning a new technology," "nice tips from staff," and "showed me some tools I could use." Experiences of impact or outcome were 
primarily positive statements of actual value received that helped faculty to improve their teaching, adopt formative assessment strategies, create and use of grading rubrics, universal design for learning, and online instruction. One subject commented that they "wouldn't be able to teach effectively without training and guidance provided by the faculty center."

The evaluative inquiry of this study has provided a process for collecting and utilizing faculty voices as a means of evaluation and organizational learning (Preskill \& Torres, 1999). This is evidenced by contrasting experiences of participants that attended the same professional learning activity. One of these was a diversity workshop sponsored by the faculty center and facilitated by a diversity fellow from the office of diversity and inclusion. A faculty member who participated in this activity remarked that they had modeled activities from the workshop into their own teaching. Another faculty member contributed a negative actual value of this same professional learning activity stating that it had "not been helpful in terms of real strategies to incorporate in the classroom."

\section{Perceived Barriers toward Participation}

The final research question examined perceived barriers to faculty participation in professional learning activities. Participants ranked perceived barriers to participating in professional learning activities offered through the faculty center by using a Likert scale of (1) too busy, (2) not relevant to me, (3) scheduling conflicts, (4) not encouraged to participate, (5) unaware of this activity, and (6) no barriers. They were also able to writein other possible barriers as open responses. Descriptive statistics were sorted to provide an overview of barriers for professional learning activities delivered as a public forum or Showcase, one-hour workshops, and one day and week-long workshops (see Table 15). 
Additional descriptive statistics provided an overview of barriers for faculty funding, teaching awards, services and other support focused activities (see Table 15).

Table 15

Perceived Barriers to Faculty Participation

\begin{tabular}{|c|c|c|c|c|c|c|}
\hline \multirow{3}{*}{ Showcase } & \multicolumn{5}{|c|}{ Not } & \multirow[b]{2}{*}{ No Barriers } \\
\hline & $\begin{array}{l}\text { Unaware of } \\
\text { this Activity }\end{array}$ & $\begin{array}{c}\text { Not Relevant } \\
\text { to Me }\end{array}$ & $\begin{array}{c}\text { Encouraged to } \\
\text { Participate }\end{array}$ & $\begin{array}{c}\text { Scheduling } \\
\text { Conflicts }\end{array}$ & Too Busy & \\
\hline & $1 \%$ & $8 \%$ & $3 \%$ & $24 \%$ & $11 \%$ & $53 \%$ \\
\hline Online Boot Camps & $7 \%$ & $28 \%$ & $4 \%$ & $8 \%$ & $17 \%$ & $36 \%$ \\
\hline Accessibility Institute & $19 \%$ & $12 \%$ & $4 \%$ & $15 \%$ & $15 \%$ & $35 \%$ \\
\hline Diversity Workshops & $9 \%$ & $14 \%$ & $4 \%$ & $25 \%$ & $14 \%$ & $34 \%$ \\
\hline Faculty Writing Retreats & $2 \%$ & $29 \%$ & $4 \%$ & $24 \%$ & $18 \%$ & $23 \%$ \\
\hline
\end{tabular}

The faculty in this study indicated that available time (too busy) and scheduling conflicts (see Table 15) were perceived barriers limiting their participation in professional learning activities. A respondent to the online survey stated that they chose the too busy option for most of their responses because the "value of the PD didn't seem to overcome the effort it would take to get to the PD.” Twenty-nine percent of faculty responding to the survey ranked the faculty writing retreats as not being relevant and $27 \%$ indicated that the online course development boot camp was not relevant.

Crosstabulations were created in SPSS to further analyze and clarify the relationship between the variable years of teaching and the perceived barrier not relevant to me for these two professional learning activities (see Tables 16 and 17). 
Table 16

Years of Teaching and Relevancy of Faculty Writing Retreats

\begin{tabular}{|c|c|c|c|c|c|c|}
\hline & $<1$ year & $1-5$ years & $6-15$ years & $16-20$ years & $>20$ years & Totals \\
\hline Too Busy & 1 & 10 & 7 & 2 & 4 & 24 \\
\hline Not Relevant to Me & 3 & 7 & 11 & 7 & 12 & 40 \\
\hline Scheduling Conflicts & 4 & 16 & 10 & 1 & 2 & 33 \\
\hline Not Encouraged to Participate & 0 & 2 & 2 & 0 & 2 & 6 \\
\hline Unaware of this Activity & 1 & 1 & 1 & 0 & 0 & 3 \\
\hline No Barriers & 4 & 10 & 10 & 4 & 3 & 31 \\
\hline Totals & 13 & 46 & 41 & 14 & 23 & 137 \\
\hline
\end{tabular}

Twenty-seven percent of faculty teaching 6 to 15 years at the university, the midcareer timeframe after tenure, indicated that faculty writing retreats were not relevant to them. Fifty-two percent of faculty teaching more than 20 years at the university, or later-career faculty, indicated that faculty writing retreats were not relevant to them.

Table 17

Years of Teaching and Relevancy of Online Course Development

\begin{tabular}{|c|c|c|c|c|c|c|}
\hline- & $<1$ year & $1-5$ years & 6-15 years & $16-20$ years & $>20$ years & Totals \\
\hline Too Busy & 2 & 6 & 9 & 2 & 5 & 24 \\
\hline Not Relevant to $\mathrm{Me}$ & 4 & 9 & 10 & 5 & 9 & 37 \\
\hline Scheduling Conflicts & 0 & 7 & 3 & 1 & 0 & 11 \\
\hline Not Encouraged to Participate & 0 & 1 & 1 & 1 & 2 & 5 \\
\hline Unaware of this Activity & 1 & 5 & 0 & 1 & 2 & 9 \\
\hline No Barriers & 6 & 18 & 18 & 4 & 4 & 50 \\
\hline Totals & 13 & 46 & 41 & 14 & 22 & 136 \\
\hline
\end{tabular}

Twenty-seven percent of faculty teaching 6 to 15 years at the university, the midcareer timeframe after tenure, indicated that the online course development boot camp was not relevant to them. Twenty-four percent of faculty teaching more than 20 years at the university, or later-career faculty, indicated that online course development was not 
relevant to them. A review of the qualitative data provided an additional explanation for this when one research subject responded 'I'm not sure I WANT to participate ... I've heard that (online course development) is a lot of work."

When asked about perceived barriers to participation in professional learning activities, $19 \%$ of faculty indicated that they were unaware of the accessibility institute (see Table 15). This is inconsistent with the awareness question asked earlier in the survey where $31 \%$ of the research subjects responded that they had never heard of it for this particular professional learning activity (see Table 9). Nine percent of the survey respondents indicated they were unaware of the diversity workshops; this is consistent with the earlier question where $8 \%$ responded that they had never heard of the diversity workshops. Both of these professional learning activities, the accessibility institute and the diversity workshops, are newer activities being offered less than three years.

The curriculum grants and teaching awards are competitive activities with fewer than eight proposals or nominations submitted annually. Descriptive statistics indicate that $18 \%$ of faculty responding to this research study were too busy to apply for curriculum grants and $17 \%$ were too busy to apply for teaching awards; both of these activities are modeled after researched-based faculty scholar appreciation programs (Boyer, 1990/2016; Gillespie \& Robertson, 2010). Crosstabulations were created in SPSS to further analyze and clarify the relationship between the variable years of teaching and the too busy perceived barrier for these activities (see Tables 18 and 19). 
Table 18

Years of Teaching and Barriers for Curriculum Funding

\begin{tabular}{|c|c|c|c|c|c|c|}
\hline & $<1$ year & $1-5$ years & 6-15 years & $16-20$ years & $>20$ years & Totals \\
\hline Too Busy & 0 & 10 & 8 & 1 & 5 & 24 \\
\hline Not Relevant to $\mathrm{Me}$ & 2 & 2 & 4 & 2 & 5 & 15 \\
\hline Scheduling Conflicts & 0 & 2 & 1 & 0 & 0 & 3 \\
\hline Not Encouraged to Participate & 2 & 2 & 8 & 1 & 4 & 17 \\
\hline Unaware of this Activity & 2 & 10 & 2 & 2 & 2 & 18 \\
\hline No Barriers & 7 & 19 & 17 & 8 & 7 & 58 \\
\hline Total & 13 & 45 & 40 & 14 & 23 & 135 \\
\hline
\end{tabular}

Seventy-five percent of midcareer faculty, those teaching 6 to 20 years at the university, indicated that they were too busy to apply for curriculum funding offered by the faculty center. A review of the qualitative data provided an additional explanation for not applying for this funding when one research subject responded "it's easier to write a grant for big money for technology than it is to write a grant for effective pedagogical development."

Table 19

Years of Teaching and Barriers for Faculty Award Program

\begin{tabular}{rcccccc}
\hline & $<1$ year & $1-5$ years & $6-15$ years & $16-20$ years & $>20$ years & Totals \\
\cline { 2 - 7 } Too Busy & 0 & 8 & 7 & 3 & 5 & 23 \\
Not Relevant to Me & 1 & 3 & 5 & 3 & 3 & 15 \\
Scheduling Conflicts & 0 & 1 & 1 & 0 & 1 & 3 \\
Not Encouraged to Participate & 2 & 1 & 5 & 3 & 1 & 12 \\
Unaware of this Activity & 2 & 5 & 3 & 1 & 0 & 11 \\
Totals & 8 & 27 & 19 & 4 & 13 & 71 \\
No Barriers & 13 & 45 & 40 & 14 & 23 & 135 \\
\hline
\end{tabular}

Thirty-five percent of early-career faculty, teaching 1 to 5 years, indicated that they were too busy to apply for a faculty award program. These faculty are presumably working on 
being awarded tenue which is a higher priority. Forty-four percent of midcareer faculty, those teaching 6 to 20 years at the university, and $22 \%$ of later-career faculty indicated that they were too busy to apply for this type of faculty recognition program.

Qualitative data of perceived barriers from the online survey was coded into two categories of barriers for participation: cultural barriers and systems barriers. Cultural barriers are those based on perceived meanings for organizational operations and influential factors within the university (Bergquist \& Pawlak, 2008). Systems barriers are logistical factors that prohibit participation. Cultural barriers are embedded within an organization and cannot be changed by a single unit like the faculty center. Systems barriers, such as scheduling and delivery modalities, are conditions of a professional learning activity and can be controlled by the faculty center.

Perceived cultural barriers included lack of incentives, increased workloads, and scholarly teaching and professional learning not being tied to promotion and tenue processes. One research subject stated that they would like to enhance their teaching practice but was "so busy with teaching and advising that I do not have the time to dedicate to these professional learning activities." Faculty teaching in the colleges of Arts and Letters and Health and Human Services commented on the amount of time they spent on performing arts, community, and clinical work outside of the classroom and a typical 8 to 5 workday. An Arts and Letters assistant professor, teaching 1 to 5 years, shared that they had taught an overload every semester since coming to the university. They went on to say that with the additional work of rehearsals, performances, committee work, and student advising they felt "caught in a lose/lose situation as far as both my professional development and my mental and physical health are concerned." An 
instructor in the College of Education commented that the scope of their workload had changed since coming to the university to include teaching graduate courses and committee work. Even with the rank of instructor, some of the committees they served on were department hiring committees. They concluded by stating "I have been told by higher ups that instructors are considered the slave labor." A midcareer faculty from the College of Business stated they felt the university's focus was on recruiting and retaining students in order to increase revenue dollars and not in providing a quality education. This faculty went on to say that "the current system at Missouri State DOES NOT reward professional professors who provide quality education.”

Perceived systems barriers such as scheduling was a major concern for early and midcareer faculty, particularly those with young families; "for faculty with families, particularly young children, late afternoon/evening workshops are a significant hardship." It should be noted that the faculty center does not schedule evening workshops. Earlycareer faculty also listed the question of relevancy as a system barrier. One Instructor teaching less than a year at the university remarked, "It's hard to gauge how relevant each of these will be for me." Additional system barriers included location and parking. An instructor from the College of Health and Human Services commented that it required "a good chunk of time" to go from their office to the library where the faculty center is located. Another instructor from the College of Education added that "parking on campus is prohibitive of participating in activities that are provided on campus." It should be noted that the university maintains a campus-wide shuttle system that includes regular stops around campus as well as service to and from university locations around 
the city. The faculty center is located in the library which is a direct stop on the shuttle route with regularly scheduled stops.

Perceived barriers to seeking support services provided by the faculty center was also examined (see Table 20). While $47 \%$ of the total responses indicated there were no perceived barriers to utilizing support focused services provided by the faculty center, $17 \%$ of the total respondents indicated that they were too busy to seek out support for these activities.

Table 20

Perceived Barriers to Support Focused Activities

\begin{tabular}{|c|c|c|c|c|c|c|}
\hline \multirow[b]{3}{*}{ UDL (accessibility) } & \multicolumn{6}{|c|}{ Not } \\
\hline & $\begin{array}{r}\text { Unaware of } \\
\text { this Activity }\end{array}$ & $\begin{array}{c}\text { No Relevant } \\
\text { to } \mathrm{Me}\end{array}$ & $\begin{array}{c}\text { Encouraged to } \\
\text { Participate } \\
\end{array}$ & $\begin{array}{c}\text { Scheduling } \\
\text { Conflicts }\end{array}$ & Too Busy & No Barriers \\
\hline & $11 \%$ & $6 \%$ & $4 \%$ & $7 \%$ & $18 \%$ & $54 \%$ \\
\hline Instructional Design & $9 \%$ & $13 \%$ & $5 \%$ & $7 \%$ & $19 \%$ & $47 \%$ \\
\hline Inst. Technology & $9 \%$ & $9 \%$ & $5 \%$ & $9 \%$ & $21 \%$ & $47 \%$ \\
\hline Online Teaching & $6 \%$ & $28 \%$ & $2 \%$ & $3 \%$ & $16 \%$ & $45 \%$ \\
\hline MediaSite Studio & $19 \%$ & $13 \%$ & $6 \%$ & $7 \%$ & $14 \%$ & $41 \%$ \\
\hline
\end{tabular}

Research subject remarks during the focus group and the online survey frequently referenced efficiency of time for support received. One faculty member referenced that this type of support helped them with managing their online class and monitoring student progress. A common thread in the qualitative data was faculty view of support focused activities as help desk services; "things seemed seamless between open labs, help desk, and Blackboard people" and "I didn't have to go to several different places to get help." An additional perceived barrier collected through open response contributions of the online survey pertained to the availability of online resources; "there should be resources that I can access on my own time." A recommendation would be for the development of 
online and just-in-time resources increasing the availability of support focused activities for faculty.

\section{Remove Barriers to Participation}

Research subject were also asked, "What might be some ways to address these barriers to make it more likely for you to participate?" Qualitative data from the focus group and the online survey was coded into the following classifications: (1) schedule alternatives, including college outreach and combined university trainings; (2) location alternatives; (3) modality alternatives; (4) incentives; (5 relevancy, including the promotion of learning activities to intended audiences; and (6) workload or available time to participate. The classification and frequency of responses (see Table 16) were sorted by years of teaching at the university to visually represent changes needed to remove barriers for early, mid, and later-career faculty.

Table 21

Years of Teaching and the Classification and Frequency of Responses for Changes Needed to Remove Barriers

\begin{tabular}{ccccccc}
\hline Years Teaching & Schedule & Location & Modality & Incentive & Relevancy & Workload \\
\hline$<1$ year & 1 & 1 & 1 & & & \\
$1-5$ years & 3 & 4 & 2 & 1 & & 4 \\
$6-15$ years & & 2 & 2 & 3 & 3 \\
$16-20$ years & & & & & 1 & 3 \\
$>20$ years & & 5 & 5 & 3 & 5 & 11 \\
Totals & 4 & & & & & 1 \\
\hline
\end{tabular}


Reducing workload as a means for removing barriers for participation in professional learning activities was the most frequent qualitative response in the online survey. Research subjects made the following recommendations for how to remove barriers: (1) need dedicated time and space to focus on these activities; (2) align participation in professional learning activities to promotion and tenure processes; (3) use teaching assistants to periodically teach a class session creating time for faculty to participate in these activities; and (4) hire more faculty to reduce workloads.

\section{Summary of Findings}

\section{Effectiveness of Communication Processes}

In answering the research question of what communication processes informed faculty about professional learning activities; $29 \%$ of participating faculty indicated the weekly university e-newsletter Inside Missouri State was how they heard of these events and $25 \%$ indicated they learned about them from the monthly What's Happening email sent by the faculty center. Both of these communication tools are delivered through the university's email system and provide a steady flow of communication on a weekly and monthly basis.

In regard to faculty awareness of professional learning activities, faculty participants were most aware of recurring events such as the annual Showcase on Teaching and Learning. Seventy-three percent of those responding to the survey had previously attended Showcase. Professional learning activities that participants were least aware were events that had occurred for less than three years. The accessibility institute was one of these events with $31 \%$ of faculty responding they had never heard of this professional learning activity. 
Support services most utilized by participants were those that supported online teaching and the use of instructional technology. Twenty-six percent of faculty participates reported accessing support for online teaching while $27 \%$ participated in support for using instructional technology and 21\% reported using MediaSite video recording services.

\section{Perceived Value toward Professional Learning Activities}

In answering the question concerning faculty perceptions of value toward professional learning activities, expectant values and actual values of faculty that had participated in these activities were examined. Expectant values of faculty toward professional learning activities were comparatively positive. Forty-five percent of faculty perceived public forums and retreats for faculty writing to be very or extremely valuable. Support for online teaching and using instructional technology was also perceived valuable; $63 \%$ perceived support for online teaching to be very or extremely valuable and $68 \%$ perceived support for using instructional technology to be very or extremely valuable.

To answer the question of actual values held by faculty toward professional learning activities, qualitative and quantitate data of actual experiences was examined. Themes of support, impact/outcome, community, efficiency of time, or recognition were identified and faculty members' experiences were coded as positive or negative. Faculty experiences were overall positive commenting that support they received was

"impressive level of support when learning a new technology," "nice tips from staff," and “showed me some tools I could use." Experiences of impact or outcome were primarily positive statements of actual value received that helped faculty to improve their teaching, 
adopt formative assessment strategies, create and use of grading rubrics, universal design for learning, and online instruction.

\section{Perceived Barriers to Participation}

The final research question examined perceived barriers to faculty participation in professional learning activities. Faculty members indicated that available time (too busy) and scheduling conflicts were barriers that limited their participation in professional learning activities. Perceived cultural barriers that limited participation included lack of incentives, increased workloads, and scholarly teaching and professional learning not being tied to promotion and tenue processes. System barriers such as scheduling and parking on campus were also perceived barriers, particularly for early and midcareer faculty. When asked how these barriers could be removed, faculty members recommended reducing workloads, dedicating time and space for professional learning activities, and aligning participation to promotion and tenure processes.

\section{Recommendations}

The findings on faculty awareness of professional learning activities indicated that faculty, regardless if in their early, mid or later-career, were aware of professional learning activities provided at the university. The communication processes currently being used have contributed to this awareness but the findings of this study supports Braskamp and Wergin's (2008) theory that sharing information without focusing on relevancy and a call to the commitment of teaching, does not inspire faculty to pursue the advancement of their profession. 


\section{Improving Communication Processes of the Faculty Center}

In addressing the research question of how effective are the current communication processes being utilized by the faculty center; one recommendation is to focus on appropriate language in all communications that will support relevancy and expectant values for faculty. A second recommendation is to target groups of faculty with specific information about professional learning activities. One of these groups would be department heads who are responsible for the professional development plans of new faculty. Other faculty interest groups could be created from registration records stored in the university's organizational learning and management information system. This database provides documentation records of faculty members who have attended specific professional learning activities that can then be targeted to receive notifications of other upcoming events that may be of interest.

A final recommendation is to use mail merge features in the university's email system to send batch emails that are personalized for each recipient. Personalized messages will attract the receiver's attention to read the message and help them to see the relevancy of the activity. After these changes have been implemented, it is also recommended that the faculty center conducts a similar study to investigate and compare any changes in faculty awareness of professional learning activities.

\section{How best to meet Faculty Members' Expectant and Actual Values}

The second research question in this study examined the perceived and actual values of faculty toward professional learning activities. The findings on perceived expectant values of professional learning activities indicated that faculty in their early and midcareer had higher expectant values of professional learning activities than those in 
their later career. A reason for this is early and midcareer faculty are working on tenure or other advancement through the university's promotional process. Later career faculty are not as predisposed to making changes in their teaching and are not as likely to view professional learning as valuable to their teaching practice as early and midcareer faculty (Gillespie \& Robertson, 2010; Schroeder, 2011). A recommendation supported through the findings of this study is to align and promote professional learning activities to different stages of teaching careers at the university. Marketing these activities to early, mid, and later career faculty will provide more relevancy to the activity.

While this study was not intended to evaluate outcomes of individual professional learning activities, the findings indicated that a faculty member's actual value after participating in an activity was predominantly greater than those that did not participate in the activity. Additional evaluations would need to be conducted to determine outcomes and make recommendations based on quality, but a recommendation from this study is to use success stories and testimonials from participants to market the professional learning activities to future participants. After making these changes it is also recommended that the faculty center conduct a similar study to investigate and compare any changes in the expectant and actual values of faculty concerning professional learning activities.

\section{How the Faculty Center can contribute to the Removal of Barriers}

The final research question examined the perceived barriers of faculty toward their participation in professional learning activities. The findings in this study indicated that faculty workload was the most common barrier for not participation in professional learning activities provided by the university. Participants in this study indicated that 
additional faculty and teaching assistants were needed to reduce their teaching workloads. While this study does not provide quantitative evidence to support this phenomenon, it is a recommendation of this study that further research is conducted on the essential elements of faculty work at this university (Bergquist \& Pawlak, 2008; Bok, 2013; Kezar \& Maxey, 2016).

A recommendation of this study is to develop online and just-in-time resources increasing the availability of professional learning and support focused activities for faculty. An additional recommendation is for the university to dedicate time and space for faculty to participate in professional learning activities. The faculty center is housed in the academic library but when offering a technology workshop it requires reserving classroom space from the library or a computer lab from computer services. A recommendation is for the creation of a faculty lab located in the faculty center that includes collaborative furniture and computer workstations where faculty can come to learn about a new technology or engage in course development work. Another recommendation is that colleges increase course delivery through 'flipped' or inverted instruction providing more flexible class schedules, increased office hours, and additional time to participate in professional learning activities (Kezar \& Maxey, 2016). A final recommendation is for the university to form a strategic committee to investigate how select elements from institutional professional learning activities could be aligned to the university's promotion and tenure processes. This would provide an increased purpose for participating in these activities and also provide additional support for academic department heads (Schroeder, 2011). 
Section Five:

\section{Contribution to Scholarship}

To be submitted to: To Improve the Academy: A Journal of Educational

Development 


\title{
A DEVELOPMENTAL EVALUATION OF FACULTY ENGAGEMENT IN PROFESSIONAL LEARNING ACTIVTIES PROVIDED BY A FACULTY CENTER
}

\begin{abstract}
This study was a developmental evaluation of a faculty center at a state funded, public non-research university focused on undergraduate and graduate degree programs that is located in the Midwest United States. The purpose of the study was to investigate effective communication processes utilized by the faculty center, faculty perceptions of value placed on professional learning activities, and perceived barriers to participate in such professional learning activities. Effective communication processes were identified as well as frequent barriers for faculty participation.

Keywords: evaluation, motivation, communications, faculty development, organizational development
\end{abstract}

\section{Introduction}

Faculty centers have traditionally offered a cafeteria of services including: individual consultations, university-wide orientations, faculty workshops, intensive programs, grants and award programs, resources and publications, and specialized services (Sorcinelli, Austin, Eddy, \& Beach, 2006). As more external influences and pressures have been placed on higher education, the role of the faculty center has expanded beyond that of professional learning to one of integrating institutional goals and initiatives into their services and programs (Schroeder, 2011; Sorcinelli et al., 2006). These may include faculty training on the use of technology, workshops supporting the 
university's diversity mission and goals, or the expansion of online education in addition to the Scholarship of Teaching and Learning (SoTL). While the role of faculty support centers may have changed the core work of university faculty has essentially remained the same: teaching, research, and service. This shift can impact the perceived value and awareness of faculty concerning the type of professional learning activities offered through the university's faculty center and how these activities may relate to their essential work.

\section{Background}

This study took place at a state funded, public non-research university focused on undergraduate and graduate degree programs. The university is located in the Midwest United States and has a Carnegie classification of Community Engagement and a designated mission of public affairs framed through ethical leadership, cultural competence, and community engagement. These three pillars of public affairs define the profile for the university and are intended to frame what student expectations of learning experiences at the university.

In 2002 an academic development center was established providing an interdisciplinary academy for teaching and learning. Today the current enrollment at the university is over 24,000 undergraduate and graduate students and the faculty body consists of 753 full-time and 370 part-time faculty. Even with this growth, the faculty center has experienced cuts in funding and personnel and has been reorganized into a mixed-model support unit offering interdisciplinary programming on teaching and learning, technology support, and support with assessment and research. It is under the direction of the provost's office and many of its programs are shaped through the 
university's mission and long-range plans. These include diversity and inclusion, highimpact learning, accessible learning, and online education. The faculty center has an advisory council that is made up of faculty representatives from each academic college. A faculty fellow, which is selected by the advisory council, serves as advisory council chair. Additional faculty fellows, funded through the provost office, facilitate faculty lead programming such as diversity workshops and research writing retreats.

Professional staff consists of an administrative director, two instructional designers, one media staff, three classroom technicians, and two clerical staff.

The purpose of this developmental evaluation was to investigate effective communication processes utilized by the faculty center, faculty perceptions of value placed on professional learning activities, and perceived barriers to participate in such professional learning activities. Specific evaluation questions concerning faculty participation toward professional learning activities included: what communication processes inform faculty; what is the level of faculty awareness; what are the expectant values of non-participating faculty; what are the actual values of faculty participants; and what are the perceived barriers toward participation? In order to have a deeper understanding of faculty experiences at this university (Creswell, 2014), a mixedmethods approach was used surveying all faculty and conducting focus group interviews of faculty who had and those who had not participated in professional learning activities.

A total of 139 faculty responded to the online survey. The participants who completed the survey represented a cross-section of faculty ranks including full-time and part-time faculty. Of these 51 were Assistant Professors, 21 Associate Professors, 35 Professors, and 31 were instructors or part-time faculty. The sampling also provided a 
diverse representation of years teaching at the university representing early, mid, and later-career faculty.

Using registration data housed in the university's professional learning management system, a random sample group of 40 faculty that had participated in professional learning was invited to participate in a focus group interview. Seven participants attended the focus group discussion. A random sample group of 40 faculty that had not participated in professional learning activities were also invited to participate in a focus group interview. One participant agreed to a phone interview. Quantitative from the survey and qualitative data from focus group interviews were compared and analyzed to provide multiple experiences and perspectives of faculty.

\section{Communication Process that Inform Faculty}

Participants in this study ranked their awareness of twelve professional learning activities facilitated by the faculty center. Participants were most aware of the longest running program which began in 2002 when the center was established. Activities that they were least aware were offerings that had been held for less than three years.

When asked which university communication channels faculty used to inform themselves about upcoming professional learning activities, $29 \%$ of the respondents indicated the weekly university e-newsletter and $25 \%$ responded they learned about of these events from a monthly email sent by the faculty center. During the focus group, one faculty member responded that they were more likely to read these emails if it was forwarded to them by their department head. However, only $8 \%$ of those responding to the survey indicated that they learned of professional learning activities from emails sent by their dean or department head. One participant indicated that they would be more 
likely to read emails sent by the faculty center if it was personally addressed to them. Other participants provided feedback that they would like to see an increase in a social media presence used by the faculty center.

These findings are supported by Gratz and Salem's (1981) organizational communication theory for higher education which indicates that formal communication such as announcements and notices are more effective when delivered through channels appropriate for the purpose of the message and the intended audience. Faculty email along with social media that leverages community groups are appropriate channels for this type of communication. However, it is not clear whether or not the communication processes that lead to faculty awareness promotes or inhibits the decision-making processes regarding actual participation. The language of the message should focus on purpose and a calling to the commitment of teaching to be received as relevant and inspire faculty to pursue the advancement of their profession (Braskamp \& Wergin, 2008; Gratz \& Salem 1981).

\section{Value Placed on Professional Learning Activities}

Participants ranked their expectant value of professional learning activities using a Likert scale of (1) not at all valuable, (2) somewhat valuable, (3) very valuable, or (4) extremely

valuable. Basic frequencies of perceived expectant values were analyzed to determine the dominant perceived value for that particular professional learning activity (see Table 1). Activities with equal frequency distribution across two different values are represented with having two dominant perceived values. 
Table 1

Faculty Perceived Expectant Values of Professional Learning Activity

\begin{tabular}{ll}
\hline PL Activity & Dominant Perceived Value \\
\hline Faculty Recognition & Very Valuable/Extremely valuable \\
Grant Funding & Very valuable \\
Inst. Technology Support & Very valuable \\
Online Teaching Support & Very valuable \\
MediaSite Studio & Very valuable \\
UDL (accessibility) & Very valuable \\
Diversity Workshops & Somewhat valuable \\
Faculty Writing & Somewhat valuable \\
Public Forum & Somewhat valuable \\
\hline
\end{tabular}

Principles of the Scholarship of Teaching and Learning (SoTL) validate the practice of providing different means to acknowledge teaching and the other works of faculty (Boyer, 1990/2016). A comparison of the perceived expectant values of faculty participating in this study points to faculty recognition as the most dominant perceived value of any of these items public forums for the purpose of highlighting teaching practices and the research of those practices was ranked as somewhat valuable. The researcher recognizes that general terms were used in the wording of this question, public forum and recognition, and these terms may have different meanings to different individuals. Additional research would need to be conducted to more clearly understand the meaning placed on these terms by the population in this study. 
Diversity and inclusiveness is a major initiative in the university's strategic plan and also supports the public affairs mission of the university. Forty percent of the faculty participating in this study rated their perceived value toward diversity workshops as somewhat valuable. Further analysis indicated that early and mid-career faculty, those just prior to and following tenure award, were the largest segment of this population that perceived diversity workshops to be somewhat valuable (see Figure 1). This may indicate a misalignment of goals or lack of shared commitment toward university goals (Lencioni, 2002; Northouse, 2016). If these activities are important to the university and its public affairs mission, a good practice would be to emphasize the value of such activities through promotion and tenure processes.

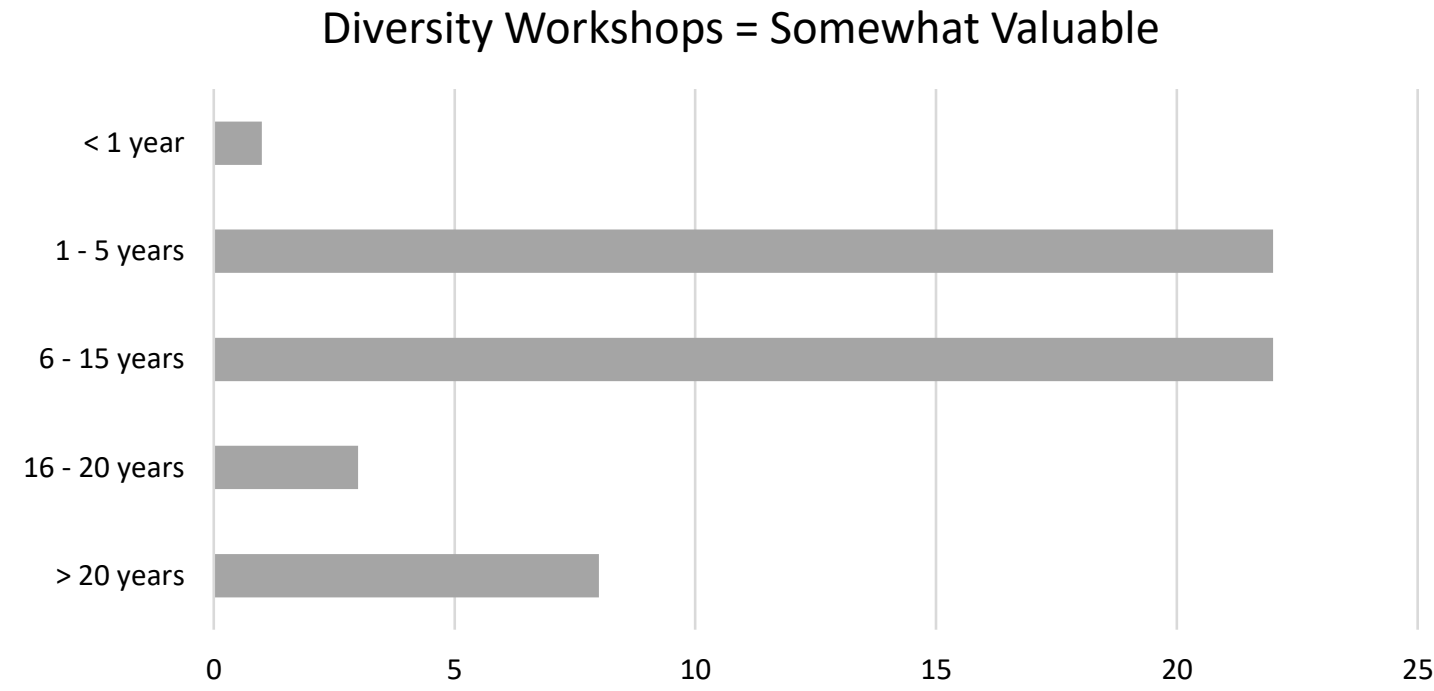

Figure 1. How Valuable are Diversity Workshops. This bar graph represents the percent of responses for the dominant somewhat valuable perceived value of early and mid-career faculty toward professional learning activities focused on diversity. 
Professional learning activities that research subjects indicated were valuable were those promoting accessible learning, online teaching, instructional technology, and grant funding for faculty. To further analyze and clarify the relationship between the ordinal variables years of teaching and perceived expectant value of instructional technology support, the categories of years of teaching were first collapsed and recoded to avoid small cells, and then a crosstabulation was created (see Table 2).

Table 2

Years of Teaching and Perceived Expectant Value of Inst. Technology Support

\begin{tabular}{|c|c|c|c|c|c|}
\hline & & \multicolumn{4}{|c|}{ Categories for years of teaching } \\
\hline & & $<1+1-5$ yrs. & $6-15 \mathrm{yrs}$. & $16-20+>20$ yrs. & Total \\
\hline \multirow[t]{2}{*}{ Not at all valuable } & Count & 4 & 2 & 5 & 11 \\
\hline & Expected Count & 4.7 & 3.3 & 2.9 & 11.0 \\
\hline \multirow[t]{2}{*}{ Somewhat valuable } & Count & 17 & 6 & 9 & 32 \\
\hline & Expected Count & 13.8 & 9.7 & 8.5 & 32.0 \\
\hline \multirow[t]{2}{*}{ Very valuable } & Count & 31 & 21 & 15 & 67 \\
\hline & Expected Count & 28.9 & 20.2 & 17.8 & 67.0 \\
\hline \multirow[t]{2}{*}{ Extremely valuable } & Count & 8 & 13 & 8 & 29 \\
\hline & Expected Count & 12.5 & 8.8 & 7.7 & 29.0 \\
\hline \multirow[t]{2}{*}{ Total } & Count & 60 & 42 & 37 & 139 \\
\hline & Expected Count & 60.0 & 42.0 & 37.0 & 139.0 \\
\hline
\end{tabular}

A Chi-square test was then calculated to compare years of teaching and the perceived expectant value of instructional technology. The Pearson chi-square test indicated no significant difference in years of teaching and perceived expectant value of support for instructional technology, $X^{2}(1, n=139)=8.584, p=.198$.

To further analyze and clarify the relationship between the ordinal variables years of teaching and perceived expectant value of MediaSite support, the categories of years 
of teaching were first collapsed and recoded to avoid small cells, and then a crosstabulation was created (see Table 3).

Table 3

Years of Teaching and Perceived Expectant Value of MediaSite Studio

\begin{tabular}{|c|c|c|c|c|c|}
\hline \multirow[b]{3}{*}{ Not at all valuable } & \multirow[b]{3}{*}{ Count } & \multicolumn{3}{|c|}{ Categories for years of teaching } & \multirow[b]{2}{*}{ Total } \\
\hline & & \multirow{2}{*}{$\begin{array}{r}<1+1-5 \mathrm{yrs} . \\
7\end{array}$} & \multirow{2}{*}{$\frac{6-15 \text { yrs. }}{5}$} & $16-20+>20$ yrs. & \\
\hline & & & & 7 & 19 \\
\hline & Expected Count & 8.2 & 5.7 & 5.1 & 19.0 \\
\hline \multirow[t]{2}{*}{ Somewhat valuable } & Count & 25 & 11 & 8 & 44 \\
\hline & Expected Count & 19.0 & 13.3 & 11.7 & 44.0 \\
\hline \multirow[t]{2}{*}{ Very valuable } & Count & 19 & 14 & 12 & 45 \\
\hline & Expected Count & 19.4 & 13.6 & 12.0 & 45.0 \\
\hline \multirow[t]{2}{*}{ Extremely valuable } & Count & 9 & 12 & 10 & 31 \\
\hline & Expected Count & 13.4 & 9.4 & 8.3 & 31.0 \\
\hline \multirow[t]{2}{*}{ Total } & Count & 60 & 42 & 37 & 139 \\
\hline & Expected Count & 60.0 & 42.0 & 37.0 & 139.0 \\
\hline
\end{tabular}

A Chi-square test was then calculated to compare years of teaching and the perceived expectant value for support of MediaSite video production. The Pearson chi-square test indicated no significant difference in years of teaching and perceived expectant value of MediaSite support, $X^{2}(1, n=139)=7.057, p=.316$.

\section{Barriers to Faculty Participation}

Participants in this study ranked perceived barriers to participating in professional learning activities by using a Likert scale of 1) too busy, 2) not relevant to me, 3) scheduling conflicts, 4) not encouraged to participate, 5) unaware of this activity, and 6) no barriers. They were also able to write-in other possible barriers as open responses. Descriptive statistics were sorted to provide an overview of barriers for professional 
learning activities delivered as one-hour workshops, half-day seminars or public forums, and one day or week-long workshops (see Table 4).

Table 4

\section{Perceived Barriers to Faculty Participation}

\begin{tabular}{|c|c|c|c|c|c|c|}
\hline \multirow[b]{2}{*}{ - } & & & Not & & & \\
\hline & $\begin{array}{l}\text { Unaware of } \\
\text { this Activity }\end{array}$ & $\begin{array}{c}\text { Not Relevant } \\
\text { to Me }\end{array}$ & $\begin{array}{c}\text { Encouraged to } \\
\text { Participate }\end{array}$ & $\begin{array}{c}\text { Scheduling } \\
\text { Conflicts }\end{array}$ & Too Busy & No Barriers \\
\hline Showcase & $1 \%$ & $8 \%$ & $3 \%$ & $24 \%$ & $11 \%$ & $53 \%$ \\
\hline Online Boot Camps & $7 \%$ & $28 \%$ & $4 \%$ & $8 \%$ & $17 \%$ & $36 \%$ \\
\hline Accessibility Institute & $19 \%$ & $12 \%$ & $4 \%$ & $15 \%$ & $15 \%$ & $35 \%$ \\
\hline Diversity Workshops & $9 \%$ & $14 \%$ & $4 \%$ & $25 \%$ & $14 \%$ & $34 \%$ \\
\hline Faculty Writing Retreats & $2 \%$ & $29 \%$ & $4 \%$ & $24 \%$ & $18 \%$ & $23 \%$ \\
\hline
\end{tabular}

The faculty in this study indicated that available time (too busy) and scheduling conflicts (see Table 4) were perceived barriers limiting their participation in professional learning activities. A research subject responding to the online survey stated that they chose the too busy option for most of their responses because the "value of the PD didn't seem to overcome the effort it would take to get to the PD." Twenty-nine percent of faculty responding to the survey ranked the faculty writing retreats as not being relevant and $27 \%$ indicated that the online course development boot camp was not relevant. Crosstabulations were created in SPSS to further analyze and clarify the relationship between the variable years of teaching and the perceived barrier not relevant to me for these two professional learning activities (see Tables 5 and 6). 
Table 5

Years of Teaching and Relevancy of Faculty Writing Retreats

\begin{tabular}{|c|c|c|c|c|c|c|}
\hline & $<1$ year & $1-5$ years & $6-15$ years & $16-20$ years & $>20$ years & Totals \\
\hline Too Busy & 1 & 10 & 7 & 2 & 4 & 24 \\
\hline Not Relevant to Me & 3 & 7 & 11 & 7 & 12 & 40 \\
\hline Scheduling Conflicts & 4 & 16 & 10 & 1 & 2 & 33 \\
\hline Not Encouraged to Participate & 0 & 2 & 2 & 0 & 2 & 6 \\
\hline Unaware of this Activity & 1 & 1 & 1 & 0 & 0 & 3 \\
\hline No Barriers & 4 & 10 & 10 & 4 & 3 & 31 \\
\hline Totals & 13 & 46 & 41 & 14 & 23 & 137 \\
\hline
\end{tabular}

Twenty-seven percent of faculty teaching 6 to 15 years at the university, the midcareer timeframe after tenure, indicated that faculty writing retreats were not relevant to them. Fifty-two percent of faculty teaching more than 20 years at the university, or later-career faculty, indicated that faculty writing retreats were not relevant to them.

Table 6

Years of Teaching and Relevancy of Online Course Development

\begin{tabular}{rcccccc}
\hline & $<1$ year & $1-5$ years & $6-15$ years & $16-20$ years & $>20$ years & Totals \\
\cline { 2 - 7 } Too Busy & 2 & 6 & 9 & 2 & 5 & 24 \\
Not Relevant to Me & 4 & 9 & 10 & 5 & 9 & 37 \\
Scheduling Conflicts & 0 & 7 & 3 & 1 & 0 & 11 \\
Not Encouraged to Participate & 0 & 1 & 1 & 1 & 2 & 5 \\
Unaware of this Activity & 1 & 5 & 0 & 1 & 2 & 9 \\
Totals & 6 & 18 & 18 & 4 & 4 & 50 \\
No Barriers & 13 & 46 & 41 & 14 & 22 & 136 \\
\hline
\end{tabular}

Twenty-seven percent of faculty teaching 6 to 15 years at the university, the midcareer timeframe after tenure, indicated that the online course development boot camp was not relevant to them. Twenty-four percent of faculty teaching more than 20 years at the university, or later-career faculty, indicated that online course development was not 
relevant to them. A review of the qualitative data provided an additional explanation for this when one research subject responded 'I'm not sure I WANT to participate ... I've heard that (online course development) is a lot of work."

The curriculum grants and teaching awards are competitive activities with fewer than eight proposals or nominations submitted annually. Descriptive statistics indicate that $18 \%$ of faculty responding to this research study were too busy to apply for curriculum grants and $17 \%$ were too busy to apply for teaching awards; both of these activities are modeled after researched-based faculty scholar appreciation programs (Boyer, 1990/2016; Gillespie \& Robertson, 2010). Crosstabulations were created in SPSS to further analyze and clarify the relationship between the variable years of teaching and the too busy perceived barrier for these activities (see Tables 7 and 8).

Table 7

Years of Teaching and Barriers for Curriculum Funding

\begin{tabular}{rcccccr}
\hline & $<1$ year & $1-5$ years & $6-15$ years & $16-20$ years & $>20$ years & Totals \\
\cline { 2 - 7 } Too Busy & 0 & 10 & 8 & 1 & 5 & 24 \\
Not Relevant to Me & 2 & 2 & 4 & 2 & 5 & 15 \\
Scheduling Conflicts & 0 & 2 & 1 & 0 & 0 & 3 \\
Not Encouraged to Participate & 2 & 2 & 8 & 1 & 4 & 17 \\
Unaware of this Activity & 2 & 10 & 2 & 2 & 2 & 18 \\
Total & 7 & 19 & 17 & 8 & 7 & 58 \\
\hline
\end{tabular}

Seventy-five percent of midcareer faculty, those teaching 6 to 20 years at the university, indicated that they were too busy to apply for curriculum funding offered by the faculty center. A review of the qualitative data provided an additional explanation for not applying for this funding when one research subject responded "it's easier to write a grant for big money for technology than it is to write a grant for effective pedagogical 
development." Additional research would be necessary to further understand how this population constructs meaning of this type of activity and perceptions of how it relates to the scholarship of teaching (Boyer, 1990/2016).

Table 8

Years of Teaching and Barriers for Faculty Award Program

\begin{tabular}{rcccccr}
\hline & $<1$ year & $1-5$ years & $6-15$ years & $16-20$ years & $>20$ years & Totals \\
\cline { 2 - 7 } Too Busy & 0 & 8 & 7 & 3 & 5 & 23 \\
Not Relevant to Me & 1 & 3 & 5 & 3 & 3 & 15 \\
Scheduling Conflicts & 0 & 1 & 1 & 0 & 1 & 3 \\
Not Encouraged to Participate & 2 & 1 & 5 & 3 & 1 & 12 \\
Unaware of this Activity & 2 & 5 & 3 & 1 & 0 & 11 \\
Totals & & 27 & 19 & 4 & 13 & 71 \\
\hline
\end{tabular}

Thirty-five percent of early-career faculty, teaching 1 to 5 years, indicated that they were too busy to apply for a faculty award program. These faculty are presumably working on being awarded tenue which is a higher priority. Forty-four percent of midcareer faculty, those teaching 6 to 20 years at the university, and $22 \%$ of later-career faculty indicated that they were too busy to apply for this type of faculty recognition program. This finding is inconsistent with the $76 \%$ of research subjects that indicated opportunities for faculty recognition were very or extremely valuable. A supposition for this phenomenon could be that recognition and time are both values (Fishbein \& Ajzen, 1975) and additional research would be necessary to further examine the significance placed on each of these values by this population.

Qualitative data of perceived barriers from the online survey was coded into two categories of barriers for participation: cultural barriers and systems barriers. Cultural barriers are those based on perceived meanings for organizational operations and 
influential factors within the university (Bergquist \& Pawlak, 2008). Systems barriers are logistical factors that prohibit participation. Cultural barriers are embedded within an organization and cannot be changed by a single unit like the faculty center. Systems barriers, such as scheduling and delivery modalities, are conditions of a professional learning activity and can be controlled by the faculty center.

Perceived cultural barriers included lack of incentives, increased workloads, and scholarly teaching and professional learning not being tied to promotion and tenue processes. One research subject stated that they would like to enhance their teaching practice but was "so busy with teaching and advising that I do not have the time to dedicate to these professional learning activities." Faculty teaching in the colleges of Arts and Letters and Health and Human Services commented on the amount of time they spent on performing arts, community, and clinical work outside of the classroom and a typical 8 to 5 workday. An Arts and Letters assistant professor, teaching 1 to 5 years, shared that they had taught an overload every semester since coming to the university. They went on to say that with the addition work of rehearsals, performances, committee work, and student advising that they felt "caught in a lose/lose situation as far as both my professional development and my mental and physical health are concerned.” An instructor in the College of Education commented that the scope of their workload had changed since coming to the university to include the teaching graduate courses and committee work. Even with the rank of instructor, some of the committees they served on were department hiring committees. They concluded by stating "I have been told by higher ups that instructors are considered the slave labor." A midcareer faculty from the College of Business contributed that they felt the university's focus was on recruiting and 
retaining students in order to increase revenue dollars and not in providing a quality education. This faculty went on to say that "the current system at Missouri State DOES NOT reward professional professors who provide quality education."

Perceived systems barriers such as scheduling was a major concern for early and midcareer faculty, particularly those with young families; "for faculty with families, particularly young children, late afternoon/evening workshops are a significant hardship." It should be noted that the faculty center does not schedule evening workshops. Earlycareer faculty also listed the question of relevancy as a system barrier. One Instructor teaching less than a year at the university remarked, "It's hard to gage how relevant each of these will be for me." Additional system barriers included location and parking. An instructor from the College of Health and Human Services commented that it required "a good chunk of time" to go from their office to the library where the faculty center is located. Another instructor from the College of Education added that "parking on campus is prohibitive of participating in activities that are provided on campus." It should be noted that the university maintains a campus-wide shuttle system that includes regular stops around campus as well as service to and from university locations around the city. The faculty center is located in the library which is a direct stop on the shuttle route with regularly scheduled stops.

The cultural and systems barriers identified in this study are consistent with external influences and trends occurring in higher education (Bok, 2013; Pazzanese, 2017). System barriers, particularly those impacting early and midcareer faculty like time, location, and question of relevancy should be considerations in the planning and 
delivery of professional learning activities. Further studies are necessary to identify the cultural values of midcareer faculty in this population.

Perceived barriers to seeking support services provided by the faculty center was also examined (see Table 9). While $47 \%$ of the total responses indicated there were no perceived barriers to utilizing support focused services provided by the faculty center, $17 \%$ of the total respondents indicated that they were too busy to seek out support for these activities.

Table 9

Perceived Barriers to Support Focused Activities

\begin{tabular}{rcccccc}
\hline & & \multicolumn{5}{c}{ Not } \\
& $\begin{array}{c}\text { Unaware of } \\
\text { this Activity }\end{array}$ & $\begin{array}{c}\text { No Relevant } \\
\text { to Me }\end{array}$ & $\begin{array}{c}\text { Encouraged to } \\
\text { Participate }\end{array}$ & $\begin{array}{c}\text { Scheduling } \\
\text { Conflicts }\end{array}$ & Too Busy & No Barriers \\
\cline { 2 - 7 } - & $11 \%$ & $6 \%$ & $4 \%$ & $7 \%$ & $18 \%$ & $54 \%$ \\
UDL (accessibility) & $9 \%$ & $13 \%$ & $5 \%$ & $7 \%$ & $19 \%$ & $47 \%$ \\
Instructional Design & $9 \%$ & $9 \%$ & $5 \%$ & $9 \%$ & $21 \%$ & $47 \%$ \\
Inst. Technology & $6 \%$ & $28 \%$ & $2 \%$ & $3 \%$ & $16 \%$ & $45 \%$ \\
Online Teaching & $19 \%$ & $13 \%$ & $6 \%$ & $7 \%$ & $14 \%$ & $41 \%$ \\
MediaSite Studio & & & & & & \\
\hline
\end{tabular}

Research subject remarks during the focus group and the online survey frequently referenced efficiency of time for support received. One faculty member referenced that this type of support helped them with managing their online class and monitoring student progress. A common thread in the qualitative data was faculty view of support focused activities as help desk services; "things seemed seamless between open labs, help desk, and Blackboard people" and "I didn't have to go to several different places to get help." The supposition that faculty seek this type of support when an issue arises rather than as a preemptive measure reinforces the perspective of not having available time (too busy) or not seeing how it may be relevant to them. An additional study concerning faculty 
perceptions of support services at the university would need to be conducted to further clarify this supposition. An additional perceived barrier collected through open response contributions of the online survey pertained to the availability of online resources; "there should be resources that I can access on my own time." A recommendation would be for the development of online and just-in-time resources increasing the availability of support focused activities for faculty.

\section{Remove Barriers to Participation}

Research subject were also asked, "What might be some ways to address these barriers to make it more likely for you to participate?" Qualitative data from the focus group and the online survey was coded into the following classifications: (1) schedule alternatives, including college outreach and combined university trainings; (2) location alternatives; (3) modality alternatives; (4) incentives; (5) relevancy, including the promotion of learning activities to intended audiences; and (6) workload or available time to participate. The classification and frequency of responses (see Table 10) were sorted by years of teaching at the university to visually represent changes needed to remove barriers for early, mid, and later-career faculty. 
Table 10

Years of Teaching and the Classification and Frequency of Responses for Changes Needed to Remove Barriers

\begin{tabular}{rcccccc}
\hline Years Teaching & Schedule & Location & Modality & Incentive & Relevancy & Workload \\
\hline$<1$ year & 1 & 1 & 1 & & & \\
$1-5$ years & 3 & 4 & 2 & 1 & & 4 \\
$6-15$ years & & 2 & 2 & 3 & 3 \\
$16-20$ years & & & & & 1 & 3 \\
$>20$ years & & 5 & 5 & 3 & 5 & 11 \\
Totals & 4 & & & & & 1 \\
\hline
\end{tabular}

Reducing workload as a means for removing barriers for participation in professional learning activities was the most frequent qualitative response in the online survey. Research subjects made the following recommendations for how to remove barriers: (1) need dedicated time and space to focus on these activities; (2) align participation in professional learning activities to promotion and tenure processes; (3) use teaching assistants to periodically teach a class session creating time for faculty to participate in these activities; and (4) hire more faculty to reduce workloads.

The core work of faculty is consistent across higher education; scholarship, teaching, research, and service (Boyer, 1990/2016). These essential elements of faculty work are also referenced in the faculty handbook for this university. An assumption might be that professional learning activates for faculty are for the purpose of advancing the teaching and learning profession. Academic faculty are professional members of 
their discipline, education, and other fields associated with their research or other areas of work. Promotion and tenure requirements set forth by the provost and the faculty member's academic department determine what documentation should be included in their dossier. It cannot be assumed that evidence of Scholarship of Teaching and Learning (SoTL) work or documentation of professional learning activities are equally represented across disciplines or even academic departments in promotion and tenue processes. An assistant professor stated that they were "expected to conduct significant research, and participate on committees at the department and college level - that leaves time for little to nothing else, including efforts to improve teaching." Future research is needed to better understanding how this university's administration and faculty regard the role of SoTL, in the advancement of teaching, and professional learning activities.

\section{Conclusions and Recommendations}

Communication process are critical to internal communication for an organization because it is often represents how that organization values employees, fosters employee empowerment, and supports employee ownership and acceptance of responsibility (Senge 1990). Braskamp and Wergin (2008) suggested that communication processes within a university cannot be effective in sharing information without focusing on its relevancy and a call to the commitment of teaching. They proposed that this does not inspire faculty in to pursue the advancement of their profession (Braskamp \& Wergin, 2008).

It is important that messages being communicated contain the appropriate language that supports relevancy and the expectant values of faculty. Universities are large organizations a many different types of messages are sent through communication channels each day. It is recommended that university units such as a faculty center target 
groups of faculty with specific information about professional learning activities. One of these groups would be department heads who are responsible for the professional development plans of new faculty. Universities often have an organizational learning and management information systems and the database from these systems provide documentation records of faculty members who have attended specific professional learning activities. These records could be used to create faculty interest groups activities that can then be targeted to receive notifications of other upcoming events. Email systems are often used passively by an organization to broadcast or forward high-level information only. However, these systems include functionality such as mail merge features that can be used to send batch emails that are personalized to the recipient. Personalized messages invites the receiver to read the message and also helps them to see the relevancy of the message or professional learning activity they are being invited to attend.

The findings on perceived expectant values of professional learning activities in this study indicated that faculty in their early and midcareer had higher expectant values of professional learning activities than those in their later career. A reason for this is early and midcareer faculty are working on tenure or other advancement through the university's promotional process. A reason for low expectant value of professional learning activities such as diversity workshops among early and mid-career faculty is it not being aligned to promotion and tenue processes. In addition, later career faculty are not as predisposed to making changes in their teaching and are not as likely to view professional learning as valuable to their teaching practice as early and midcareer faculty (Gillespie \& Robertson, 2010; Schroeder, 2011). A recommendation supported through 
the findings of this study is to align and promote professional learning activities to the promotion and tenue process as well as to the different stages of teaching careers at the university. Marketing these activities to early, mid, and later career faculty will provide more relevancy to the activity. In addition to providing an increased purpose for participating in these activities, it would also provide additional support for the role and responsibility of academic department heads (Schroeder, 2011).

Faculty workload was considered the most common barrier for not participation in professional learning activities among participants in this study. This is not an uncommon theme among higher education (Bok, 2013; Kezar \& Maxey, 2016). Participants in this study indicated a need for additional faculty and teaching assistants to reduce their teaching workloads. Future research is needed on the essential elements of faculty work in American universities (Bergquist \& Pawlak, 2008; Bok, 2013; Kezar \& Maxey, 2016). The growth of online and course delivery through flipped or inverted instruction can provide for more flexible class schedules, increased office hours, and additional time to participate in professional learning activities (Kezar \& Maxey, 2016). Recommendations from this study include the importance of developing online and justin-time resources that will increase the availability of professional learning and support services for faculty. Recommendations for this specific university include providing resources to dedicate time and space for faculty to participate in professional learning activities. There should be a faculty lab located in the faculty center that includes collaborative furniture and computer workstations where faculty can come to learn about a new technology or engage in course development work. 
According to Schroder (2011) there is no one singular process that will direct the most optimal organizational structure for faculty center on a university's campus. Professional learning activities must be aligned with the goals of the university and processes must be created that will support faculty's participation in these activities (Schroder, 2011). A final consideration is for higher education to employ strategic planning and investigate how select elements from institutional professional learning activities can be aligned to these goals and the university's promotion and tenure processes. 


\section{Acknowledgments}

The researcher would like to thank the faculty at Missouri State University and in particular her dissertation advisory committee; Dr. Cynthia MacGregor, Dr. Thomas Lane, Dr. Beth Hurst, and Dr. Tami Arthaud.

\section{Biography}

- Nancy Gordon, is Director for the Faculty Center for Teaching and Learning at Missouri State University. She earned an EdD in Educational Leadership and Policy Development from the University of Missouri. Her scholar interests include faculty as learners, adult learning theory, and educational technology.

\section{References}

Bergquist, W. H., \& Pawlak, K. (2008). Engaging the six cultures of the academy. San Francisco, CA: Jossey-Bass.

Bok, D. (2013). Higher education in America. Princeton, NJ: Princeton University Press. Boyer, E. L. (1990/2016). Scholarship reconsidered: Priorities of the professoriate. San Francisco, CA: Jossey-Bass.

Braskamp, L. A., \& Wergin, J. F. (2008). Inside-out leadership. Liberal Education, 94(1).

Creswell, J. W. (2014). Research design: Qualitative, quantitative, and mixed methods approaches (4th ed.). Los Angeles, CA: Sage.

Fishbein, M., \& Ajzen, I. (1975). Belief, attitude, intention, and behavior: An introduction to theory and research. Reading, MA: Addison-Wesley.

Gillespie, K. J., \& Robertson, D. L. (2010). A guide to faculty development (2nd ed.). San Francisco, CA: Jossey-Bass. 
Gratz, R. D., \& Salem, P. J. (1981). Organizational communication and higher education. American Association for Higher Education Research Report No. 10. (ED217826)

Kezar, A., \& Maxey, D. (2016). Recognizing the need for a new faculty model. In A. Kezar \& D. Maxey (Eds.), Envisioning the faculty for the 21st century: Moving to a mission-oriented and learner-centered model (pp. 23-42). New Brunswick, NJ: Rutgers University Press.

Lencioni, P. (2002). The five dysfunctions of a team: A leadership fable. San Francisco, CA: Jossey-Bass.

Northouse, P. G. (2016). Leadership: Theory and practice (7th ed.). Los Angeles, CA: Sage.

Pazzanese, C. (2017). The challenges facing higher education. Harvard Gazette, 4.

Schroeder, C. M. (2011). Coming in from the margins: Faculty development's emerging organizational development role in institutional change. Sterling, VA: Stylus Publishing.

Senge, P. M. (1990). The fifth discipline: The art and practice of the learning organization. New York, NY: Doubleday Publishing.

Sorcinelli, M. D., Austin, A. E., Eddy, P. L., \& Beach, A. L. (2006). Creating the future of faculty development: Learning from the past, understanding the present. Bolton, MA: Anker Publishing. 
Section Six:

Scholarly Practitioner Reflection 
A scholarly practice that new faculty are encouraged to undertake is the writing of a teaching philosophy. Writing such a philosophical statement requires them to reflect on their educational training and classroom experiences identifying their core beliefs about teaching and learning. Brookfield (1990a) advocated this process of critical reflection helps to establish a clear sense of purpose. According to Brookfield (1990a) if faculty only define themselves in terms of content experts "they effectively cut themselves off from some broader identity as change agents" (p. 17).

Doctoral students engaged in the dissertation process can expect similar consequences if they are unable to define their sense of purpose and how their research can influence them as a scholar and broaden their practice as an educational leader. The scholar-practitioner model of leadership incorporates an inquiry-based reflective practice that focuses on continuous improvement (Schultz, 2010). According to Schultz (2010) this model focuses on developing leaders that are reflective thinkers and have a focused commitment to their core values.

The practice of critical reflection is having an awareness of our own thoughts and actions and then examining how these relate to our current sense of reality (Brookfield, 1990b). It is through this reflective process that the scholar-practitioner is able to use new knowledge to inform their practice. A dissertation is the cumulative capstone of the doctoral journey and critical self-reflection of an individual's growth through this process deepens their understanding of how their research has influenced their practice as an educational leader and as a scholar. 


\section{How the Dissertation Process Influenced my Practice as an Educational Leader}

Level 5 leadership (Collins, 2005/2011) refers to leaders that build upon their fundamental skills to reach a higher capacity of leadership. Collins (2005/2011), believes these individuals have an innate capability and through self-reflection exhibit "an unwavering resolve to do whatever must be done to produce the best long-term results, no matter how difficult" (p. 127). This has certainly been true of my experiences during the dissertation process. My dissertation topic, Evaluation of Faculty Engagement in Professional Learning Activities: A Mixed-Methods Study on Communication Processes, Value, and Barriers, will contribute to the work of the university and to my completion of the EdD in Educational Leadership and Policy Analysis (ELPA). Level 5 leadership results in greater success for the leader and the organization because these individuals set aside their own needs to create something larger and more enduring than themselves (Collins, 2005/2011).

My dissertation was a developmental evaluation that focused on evaluating and improving communication processes and faculty engagement with programming developed or sponsored by the department under my direction. The study was mixedmethods and an evaluative inquiry framework allowed for the inclusion of dialogue which resulted in a deeper understanding of faculty experiences and supports community building (Patton, 2011; Preskill \& Torres, 1999). According to Patton (2011), "this framework begins by distinguishing beliefs from knowledge" and is an effective "in a situation where the action is heavily values-driven" (p. 233). The dissertation process was effective in allowing me to separate beliefs from knowledge and to deepen this 
knowledge concerning how the university functions as an organization, university leadership, faculty culture at the university, and my role as an educational leader.

Bruffee (1999) suggested engaging in conversations and granting authority to peers to collaborate with each other. Reflecting on this I understand even more the importance of engaging faculty in dialog concerning many of the professional learning activities that are delivered or sponsored by the faculty center. The critical reflection process helps individuals to identify assumptions, consider alternate points of view, and integrate new knowledge into their practice (Brookfield, 1990b). This reflective framework has served as a guide for how I have approached the dissertation process and applied it to my role as an educational leader. There are two scenarios I experienced during the dissertation process that are examples of this. The first was when sorting and analyzing data collected through the faculty survey it became obvious that since this was an anonymous survey some faculty took it as an opportunity to provide hostile comments. One faculty said they had never attended any of these activities and there was no purpose for the university to have such a unit; it should be closed and the money used for faculty raises. My description of these comments is much less hostile than the actual words this faculty used, but during my analysis it became clear that these particular comments were a type of outlier data. The other example was during a faculty interview when a faculty member said if communications from our department were personally addressed saying "I want you to know about this," they would be more likely to read the message. Reflecting on this, one of these individuals was wanting a connection with the faculty center and the other did not. I think these type of reflections have helped me to move more toward authentic leadership (Northouse, 2016). As an authentic leader I have 1) 
become more self-aware having better insights as a leader, 2) have grown in my ability to self-regulate guided by internal moral standards and values, 3) use balanced processing to analyze information objectively and explore other opinions, even those that may be outliers, and 4) exhibit relational transparency to be my true-self, open and honest, in order to build connections with others.

\section{How the Dissertation Process Influenced me as a Scholar}

The dissertation process has significantly influenced me as a scholar. First, earning a terminal degree and having the opportunity to publish research that contributes to the advancement of my practice extends my status not only at my university but also in my professional field. I have learned so much through this process that I know, even if my contribution to scholarship is not published, I have the knowledge, skills, and professional inspiration to publish other works in my field of practice.

The methodology for my research, Evaluation of Faculty Engagement in Professional Learning Activities: A Mixed-Methods Study on Communication Processes, Value, and Barriers, was mixed-methods in order to hear faculty dialogue as a part of this developmental evaluation (Creswell, 2014; Patton, 2011). I took this approach to have a better understanding of faculty experiences and the expectant values of faculty who had participated and those who had not participated in professional learning activities. One of the first challenges I had with this approach was getting faculty who had not participated in professional learning activities provided by the faculty center to respond to an invitation to participate in this study. I made an assumption if faculty were invited to provide input on this topic that they would agree to participate. I now believe that individuals not interested in participating in professional learning activities are also not 
interested in engaging in a discussion about these same professional learning activities. This is something I would change in the research design of similar research projects.

The analysis of both quantitative and qualitative data allows for a better understanding of the findings and also an increased confidence of the overall validity of the study (Creswell, 2014). However, as I was analyzing my data, I subconsciously did not feel this approach strengthened my study. I think as my first research design, I lacked confidence in designing a mixed-methods approach. I probably would have lacked the same confidence, questioning my research design if it was a quantitative or qualitative study. Throughout the dissertation process I was constructing knowledge, bridging my explicit and tacit knowledge of the research experience (Nonaka \& Takeuchi, 1995). According to Hart (2014), there are two distinct ways of knowing: categorical awareness and contact awareness. Categorical awareness (Hart 2014) is viewing something as if it is abstract or separate from ourselves. Contact awareness (Hart 2014) provides a broader view connecting ourselves to a world where we are attempting to create meaning. I was immersed in the dissertation process and the knowledge I gained through contact awareness was evolving through my own interactions and experiences. Reflecting at the conclusion of this process I am confident that this was the right approach; I just lacked confidence in my ability at the beginning of the process. However, I have gained confidence that will carry forward into my next research project and I would not hesitate to follow a mixed-methods design.

I am reminded of Brookfield's (1990a) advice that if we only define ourselves in terms of content experts, we are not growing, and isolating ourselves from a greater purpose. This is why, in the research process, it is important to not only discover a new 
theory, phenomenon, or practice; but to contribute those findings to our scholarly community. One of the phenomena I discovered during my research is faculty perceive time as a barrier to their participation in professional learning activities. Kezar and Maxey (2016) have researched the changing role of faculty work within the current and changing context of higher education. Evidence of this was present when a faculty member with the rank of instructor recounted they had "been told by higher ups that instructors are considered the slave labor." A future study might be to examine which activities are highly valued by the university and provide a benchmark evaluating faculty time spent on the activities that enhance the mission of the university. Whether or not the university undertakes such a study, I am confident that the dissertation process has equipped me to contribute to such an endeavor. 


\section{References}

Ambrose, S. A., Bridges, M. W., DiPietro, M., Lovett, M. C., \& Norman, M. K. (2010). How learning works: Seven research-based principles for smart teaching. San Francisco, CA: Jossey Bass.

American Educational Research Association. (2017). Professional ethics. Retrieved from http://www.aera.net/About-AERA/AERA-Rules-Policies/Professional-Ethics

Athapaththu, H. K. S. H. (2016). An overview of strategic management: An analysis of the concepts and the importance of strategic management. International Journal of Scientific and Research Publications, 6(2), 124-127.

Austin, A. E. (1990). Faculty cultures, faculty values. New Directions for Institutional Research, 1990(68), 61-74.

Austin, A. E. (2010). Supporting faculty members across their careers. In K. J. Gillespie \& D. L. Robertson (Eds.), A guide to faculty development (2nd ed.), (pp. 363378). San Francisco, CA: Jossey-Bass.

Austin, A. E., \& Trice, A. G. (2016). Core principles for faculty models and the importance of community. In A. Kezar \& D. Maxey (Eds.), Envisioning the faculty for the 21st century: Moving to a mission-oriented and learner-centered model (pp. 58-80). New Brunswick, NJ: Rutgers University Press.

Bahls, S. C. (2014). How to make shared governance work: Some best practices. Association of Governing Boards of Universities and Colleges. Trusteeship Magazine, 2(2).

Bain, K. (2004). What the best college teachers do. Cambridge, MA: Harvard University Press. 
Bain, K. (2012). What the best college students do. Cambridge, MA: Harvard University Press.

Baldridge, J. V. (1971). Models of university governance: Bureaucratic, collegial, and political. Stanford, CA: Stanford Center for Research and Development in Teaching.

Bauer, T., \& Erdogan, B. (2009). Organizational behavior. Boston, MA: Flat World.

Beach, A. L., Sorcinelli, M. D., Austin, A. E., \& Rivard, J. K. (2016). Faculty development in the age of evidence: Current practices, future imperatives. Sterling, VA: Stylus Publishing.

Bergquist, W. H. (1992). The four cultures of the academy. Essays on Teaching Excellence, 4(8).

Bergquist, W. H., \& Pawlak, K. (2008). Engaging the six cultures of the academy. San Francisco, CA: Jossey-Bass.

Bess, J. L. (1988). Collegiality and bureaucracy in the modern university: The influence of information and power on decision-making structures. New York, NY: Teachers College Columbia University.

Bess, J. L., \& Dee, J. R. (2008a). Understanding college and university organization: Theories for effective policy and practice. Volume I: The state of the system. Sterling, VA: Stylus.

Bess, J. L., \& Dee, J. R. (2008b). Understanding college and university organization: Theories for effective policy and practice. Volume II: Dynamics of the system. Sterling, VA: Stylus. 
Blumler, J. G., \& Katz, E. (1974). The uses of mass communications: Current perspectives on gratifications research. Beverly Hills, CA: Sage.

Bok, D. (2013). Higher education in America. Princeton, NJ: Princeton University Press.

Bolman, L. G., \& Deal, T. E. (2013). Reframing organizations: Artistry, choice, and leadership (5th ed.). San Francisco, CA: Jossey Bass.

Boyer, E. L. (1990/2016). Scholarship reconsidered: Priorities of the professoriate. San Francisco, CA: Jossey-Bass.

Braskamp, L. A., \& Wergin, J. F. (2008). Inside-out leadership. Liberal Education, 94(1).

Brinkerhoff, R. O. (2003). The success case method: Find out quickly what's working and what's not. Berkley, CA: Berrett-Koehler.

Brinkerhoff, R. O. (2005). The success case method: A strategic evaluation approach to increasing the value and effect of training. Advances in Developing Human Resources, 7(1), 86-101.

Brookfield, S. D. (1990a). The skillful teacher: On technique, trust, and responsiveness in the classroom. San Francisco, CA: Jossey-Bass.

Brookfield, S. D. (1990b). Using critical incidents to explore learners' assumptions. In J. Mezirow (Ed.), Fostering critical reflection in adulthood: A guide to transformative and emancipatory learning (pp. 177-193). San Francisco, CA: Jossey-Bass.

Bruffee, K. A. (1999). Collaborative learning: Higher education, interdependence, and the authority of knowledge. Baltimore, MD: Johns Hopkins University Press.

Caffarella, R. S., \& Daffron, S. R. (2013). Planning programs for adult learners: A practical guide (3rd ed.). San Francisco, CA: Jossey Bass. 
Carnegie Classification. (2017). Classification of institutions of higher education.

Retrieved from http://carnegieclassifications.iu.edu/lookup/

Carriveau, R. S. (2010). Connecting the dots: Developing student learning outcomes and outcome-based assessments. Denton, TX: University of North Texas.

Chalmers, D., \& Gardiner, D. (2015). An evaluation framework for identifying the effectiveness and impact of academic teacher development programmes. Studies in Educational Evaluation, 46, 81-91. doi:10.1016/j.stueduc.2015.02.002

Chrislip, D. D., \& Larson, C. E. (1994). Collaborative leadership: How citizens and civic leaders can make a difference. San Francisco, CA: Jossey Bass.

Chism, N. V. N., \& Szabo, B. (1997). How faculty development programs evaluate their services. Journal of Staff, Program, and Organizational Development, 15(2), 5562.

Collins, J. (2011). Level 5 leadership: The triumph of humility and fierce resolve. Harvard business review's 10 must reads: On leadership (pp. 115-136). Boston, MA: Harvard Business School Publishing. (Original work published 2005)

Condon, W., Iverson, E. R., Manduca, C. A., Rutz, C., \& Willett, G. (2016). Faculty development and student learning: Assessing the connections. Bloomington, IN: Indiana University Press.

Creswell, J. W. (2014). Research design: Qualitative, quantitative, and mixed methods approaches (4th ed.). Los Angeles, CA: Sage.

Debowski, S. (2017). Developing academics: The essential higher education handbook. New York, NY: Routledge. 
Dick, W., Carey, L., \& Carey, J. O. (2008). The systematic design of instruction (7th ed.). Boston, MA: Pearson.

Driver, M. (1983). Decision style and organizational behavior: Implications for academia. The Review of Higher Education, 6(4), 387-406. doi:10.1353/rhe.1983.0014

Egan, T. M. (2008). The relevance of organizational subculture for motivation to transfer learning. Human Resource Development Quarterly, 19(4), 299-322. doi:10.1002/hrdq.1243

Ettling, D. (2012). Educator as change agent: Ethics of transformative learning. In E. W. Taylor \& P. Cranton (Eds.), The handbook of transformative learnning (pp. 536551). San Francisco, CA: Jossey-Bass.

Fink, A. (2017). How to conduct surveys: A step-by-step guide (6th ed.). Los Angeles, CA: Sage.

Fink, L. D. (2013). Innovative ways of assessing faculty development. New Directions for Teaching and Learning [Special Issue]. The Breadth of Current Faculty Development: Practitioners' Perspectives, 133, 47-59.

Fishbein, M., \& Ajzen, I. (1975). Belief, attitude, intention, and behavior: An introduction to theory and research. Reading, MA: Addison-Wesley.

Fitzpatrick, J. L., Sanders, J. R., \& Worthen, B. R. (2004). Program evaluation: Alternative approaches and practical guidelines (3rd ed.). Boston, MA: Pearson.

Francis, J. B. (1975). How do we get there from here? Program design for faculty development. Journal of Higher Education, 46(6), 719-732. 
Gappa, J. M., Austin, A. E., \& Trice, A. G. (2005). Rethinking academic work and workplaces. Change: The Magazine of Higher Learning, 37(6), 32-39. doi:10.3200/CHNG.37.6.32-39

George, B., Sims, P., McLean, A. N., \& Mayer, D. (2011). Discovering your authentic leadership. Harvard business review's 10 must reads: On leadership (pp. 163177). Boston, MA: Harvard Business School Publishing. (Original work published 2007)

Gibbs, G., \& Coffey, M. (2004). The impact of training of university teachers on their teaching skills, their approach to teaching and the approach to learning of their students. Active Learning in Higher Education, 5(1), 87-100.

doi: $10.1177 / 1469787404040463$

Gill, S. J. (2010). Developing a learning culture in nonprofit organizations. Los Angeles, CA: Sage.

Gillespie, K. J., \& Robertson, D. L. (2010). A guide to faculty development (2nd ed.). San Francisco, CA: Jossey-Bass.

Gratz, R. D., \& Salem, P. J. (1981). Organizational communication and higher education. American Association for Higher Education Research Report No. 10. (ED217826)

Griffin, E. (2012). A first look at communication theory (8th ed.). New York, NY: McGraw Hill.

Guskey, T. R. (2000). Evaluating professional development. Thousand Oaks, CA: Sage. Hart, T. (2014). The integrative mind: Transformative education for a world on fire. London, United Kingdom: Rowman \& Littlefield. 
Hatch, M. J., \& Cunliffe, A. L. (2013). Organizational theory: Modern, symbolic, and postmodern perspectives (3rd ed.). Oxford, UK: Oxford University Press.

Helland, M. R., \& Winston, B. E. (2005). Towards a deeper understanding of hope and leadership. Journal of Leadership and Organizational Studies, 12(2), 42-54.

Herzberg, F. (1968/1987). One more time: How do you motivate employees? Harvard Business Review, 12(2), 42-54.

Hines, S. R. (2017). Evaluating centers for teaching and learning: A field-tested model. To Improve the Academy, 36(2), 89-100. doi:10.1002/tia2.20058

Hutchings, P., Huber, M. T., \& Ciccone, A. (2011). The scholarship of teaching and learning reconsidered: Institutional integration and impact. San Francisco, CA: Jossey Bass.

Ingersoll, R. M. (1993). Loosely coupled organizations revisited. Research in the Sociology of Organizations, 11, 81-112.

Institutional Review Board. (2017). IRB Guidebook. Retrieved from https://archive.hhs.gov/ohrp/irb/irb_chapter4.htm\#f7

Keeling, R. P., Underhile, R., \& Wall, A. F. (2007). Horizontal and vertical structures: The dynamics of organization in higher education. Liberal Education, 93(4), 2231.

Kezar, A. (2004). What is more important to effective governance: Relationships, trust, and leadership, or structures and formal processes? New Directions for Higher Education, 127, 35-46. 
Kezar, A., \& Lester, J. (2011). Enhancing campus capacity for leadership: An examination of grassroots leaders in higher education. Stanford, CA: Stanford University Press.

Kezar, A., \& Maxey, D. (2016). Recognizing the need for a new faculty model. In A. Kezar \& D. Maxey (Eds.), Envisioning the faculty for the 21 st century: Moving to a mission-oriented and learner-centered model (pp. 23-42). New Brunswick, NJ: Rutgers University Press.

Kirkpatrick, D. L., \& Kirkpatrick, J. D. (2006). Evaluating training programs: The four levels (3rd ed.). San Francisco, CA: Berrett-Koehler.

Kouzes J. M., \& Posner, B. Z. (2002). The leadership challenge (3rd ed.). San Francisco, CA: Jossey-Bass.

Krueger, R. A., \& Casey, M. A. (2015). Focus groups: A practical guide for applied research (5th ed.). Los Angeles, CA: Sage.

Kuh, G. D., \& Whitt, E. J. (1988). The invisible tapestry: Culture in American colleges and universities (ASHE-ERIC Higher Education Report No. 1). Washington, DC: Association for the Study of Higher Education. Retrieved from http://files.eric.ed.gov/fulltext/ED299934.pdf

Kuh, G. D., Kinzie, J., Schuh, J. H., \& Whitt, E. J. (2005/2010). Student success in college: Creating conditions that matter. San Francisco, CA: Jossey Bass.

Kuo, H. M. (2009). Understanding relationships between academic staff and administrators: An organizational culture perspective. Journal of Higher Education Policy and Management, 31(1), 43-54. 
Lencioni, P. (2002). The five dysfunctions of a team: A leadership fable. San Francisco, CA: Jossey-Bass.

Levi, D. (2014). Group dynamics for teams (4th ed.). Los Angeles, CA: Sage.

Lunenburg, F. C. (2010). Formal communication channels: Upward, downward, horizontal, and external. Focus on Colleges, Universities, and Schools, 4(1), 1-7.

MacGregor, C. J., \& Fellabaum, J. (2016). Dissertation redesign for scholarly practitioners in educational leadership: Increasing impact through disseminationready sections. In V. A. Storey \& K. A. Hesbol (Ed.), Contemporary approaches to dissertation development and research methods (pp. 53-69). Hershey, PA: IGI Global.

Madaus, G. F., \& Kellaghan, T. (2000). Models, metaphors, and definitions in evaluation. In D. L. Stufflebeam, G. F. Madaus, \& T. Kellaghan (Ed.), Evaluation models: Viewpoints on educational and human services evaluation (2nd ed.), (pp. 19-31). Rorwell, MA: Kluwer Academic Publishers.

Mallon, W. (2004). Disjointed governance in university centers and institutes. New Directions for Higher Education, 127, 61-74.

Maslow, A. H. (1943). A theory of human motivation. Psychological Review, 50(4), 370396. doi: $10.1037 / \mathrm{h} 0054346$

McKeachie, W. J., \& Svinicki, M. D. (2011/2014). McKeachie's teaching tips: Strategies, research, and theory for college and university teachers (14th ed.). Los Angeles, CA: Wadsworth, Cengage Learning.

Merriam, S. B., \& Bierema, L. L. (2013). Adult learning: Linking theory and practice. San Francisco, CA: Jossey-Bass. 
Merriam, S. B., \& Tisdell, E. J. (2016). Qualitative research: A guide to design and implementation (4th ed.). San Francisco, CA: Jossey Bass.

Mezirow, J. (2009). Transformative learning theory. In J. Mezirow \& E. W. Taylor, (Eds.), Transformative learning in practice: Insights from community, workplace, and higher education (p. 18-32). San Francisco, CA: Jossey-Bass.

Miller, K. (2009). Organizational communication: Approaches and processes (5th ed.). Boston, MA: Cengage.

Missouri State University. (2017a). Long-range plan 2016-2021. Retrieved from http://www.missouristate.edu/LongRangePlan

Missouri State University. (2017b). Fact book. Retrieved from http://www.missouristate.edu/oir/factbook.htm

Missouri State University. (2017c). Faculty handbook. Retrieved from https://www.missouristate.edu/provost/facultyhandbook/

Missouri State University. (2017d). What is public affairs? Retrieved from http://publicaffairs.missouristate.edu/About.htm

Missouri State University. (2017e). University committees handbook. Retrieved from https://www.missouristate.edu/committees/alc.htm

Missouri State University. (2017f). Office of the provost. Retrieved from http://www.missouristate.edu/provost/

Missouri State University. (2017g). Faculty senate. Retrieved from http://www.missouristate.edu/facultysenate/

Missouri State University. (2017h). Faculty center for teaching and learning: Advisory council. Retrieved from https://www.missouristate.edu/fctl/182773.htm 
Missouri State University. (2007i). History of the university. Retrieved from https://www.missouristate.edu/about/history.htm

Missouri State University. (2017j). Office of the President: Administrative Council. Retrieved from https://www.missouristate.edu/president/council.aspx Missouri State University. (2017k). My statement. Retrieved from http://blogs.missouristate.edu/mystatement

Missouri State University. (20171). Mission, vision and values. Retrieved from https://www.missouristate.edu/about/missionstatement.htm

Missouri State University. (2017m). Faculty center for teaching and learning: Mission. Retrieved from https://www.missouristate.edu/fctl/193860.htm

Missouri State University. (2017n). Policy library: Article XI. Retrieved from https://www.missouristate.edu/policy/G1_01_11_BoardsFacultyRelationship.htm Missouri State University. (2017o). Faculty constitution and bylaws. Retrieved from https://www.missouristate.edu/assets/facultysenate/ConstitutionandBylawsRevise d-July2017.pdf

Missouri State University. (2017p). 2016-21 long-range plan: Implementing the vision. Retrieved from https://www.missouristate.edu/longrangeplan/implementing-thevision.htm

Missouri State University. (2017q). 2016-21 long-range plans: Academic profile. Retrieved from https://www.missouristate.edu/longrangeplan/academicprofile.htm

Missouri State University. (2017r). Key performance indicators. Retrieved from https://www.missouristate.edu/fctl/193860.htm 
Missouri State University. (2017s). 2016-21 long-range plan: Student experience. Retrieved from https://www.missouristate.edu/longrangeplan/studentexperience.htm

Missouri State University. (2017t). Key performance indicators: Faculty and staff. Retrieved from https://mis.missouristate.edu/KeyPerformanceIndicators/kpi2016/index/5

Morrill, R. L. (2010). Strategic leadership: Integrating strategy and leadership in colleges and universities. Lanham, MD: Rowman \& Littlefield.

Newcomer, K. E., Hatry, H. P., \& Wholey, J. S. (2015). Handbook of practical program evaluation (4th ed.). Hoboken, NJ: Jossey Bass.

Nonaka, I. \& Takeuchi, H. (1995). The knowledge creating company: How Japanese companies create the dynamics of innovation. New York, NY: Oxford University Press.

Northouse, P. G. (2016). Leadership: Theory and practice (7th ed.). Los Angeles, CA: Sage.

Onwuegbuzie, A. J., \& Johnson, R. B. (2006). The validity issue in mixed research. Research in the Schools, 13(1), 48-63.

Ouellett, M. (2010). Overview of faculty development: History and choices. In K. J. Gillespie \& D. L. Robertson (Eds.), A guide to faculty development (2nd ed.), (pp. 3-20). San Francisco, CA: Jossey-Bass.

Patton, M. Q. (1981). Creative evaluation. Beverly Hills, CA: Sage.

Patton, M. Q. (2011). Developmental evaluation: Applying complexity concepts to enhance innovation and use. New York, NY: Guilford. 
Patton, M. Q. (2018). Facilitating evaluation. Thousand Oaks, CA: Sage.

Pazzanese, C. (2017). The challenges facing higher education. Harvard Gazette, 4. Retrieved from http://news.harvard.edu/gazette/2017/04

Perry, J. A. (2014). Changing schools of education through grassroots faculty-let change. Innovative Higher Education, 39, 155-168. doi:10.1007/s10755-013-9267-y

Preskill, H. S., \& Russ-Eft, D. (2005). Building evaluation capacity: 72 activities for teaching and training. Thousand Oaks, CA: Sage.

Preskill, H. S., \& Torres, R. T. (1999). Evaluative inquiry for learning in organizations. Thousand Oaks, CA: Sage.

Preskill, S., \& Brookfield, S. D. (2009). Learning as a way of leading: Lessons from the struggle for social justice. San Francisco, CA: Jossey-Bass.

Richmond, V. P., \& McCroskey, J. C. (2009). Organizational communication for survival: Making work, work (4th ed.). Boston, MA: Pearson.

Rogers, E. M. (2003). Diffusion of innovations (5th ed.). New York, NY: Free Press.

Sashkin, M. (2006). Leadership that matters: A new vision of leadership. In W. E. Rosenback \& R. L. Taylor (Eds), Contemporary issues in leadership (6th ed.). (pp. 7-20). Boulder, CO: Westview Press.

Schroeder, C. M. (2011). Coming in from the margins: Faculty development's emerging organizational development role in institutional change. Sterling, VA: Stylus Publishing.

Schultz, J. R. (2010). The scholar-practitioner: A philosophy of leadership. ScholarPractitioner Quarterly, 4(1), 52-64. 
Schumann, D. W., Peters, J., \& Olsen, T. (2013). Cocreating value in teaching and learning centers. New Directions for Teaching and Learning [Special Issue]. The Breadth of Current Faculty Development: Practitioners' Perspectives, 133, 3345.

Seidman, I. (2013). Interviewing as qualitative research: A guide for researchers in education and the social sciences. New York, NY: Teachers College Press.

Sell, G. R. (2004). Annual report of the SMSU academic development center for 2003-04. Springfield, MO: Missouri State University.

Senge, P. M. (1990). The fifth discipline: The art and practice of the learning organization. New York, NY: Doubleday Publishing.

Shuell, T. J. (1986). Cognitive conceptions of learning. Review of Educational Research, $56,411-436$.

Shulman, L. S. (2004). The wisdom of practice: Essays on teaching, learning, and learning to teach. San Francisco, CA: Jossey-Bass.

Shulman, L. S. (2010). Visions of the possible: Models for campus support of the scholarship of teaching and learning. In Andrews, M. L. \& Becker, W. E. (Eds.), The scholarship of teaching and learning in higher education: Contributions of research universities (pp. 9-23). Bloomington, IN: Indiana University Press.

Sorcinelli, M. D., Austin, A. E., Eddy, P. L., \& Beach, A. L. (2006). Creating the future of faculty development: Learning from the past, understanding the present. Bolton, MA: Anker Publishing.

Stufflebeam, D. L. (2000). The CIPP model for evaluation. In Stufflebeam, D. L., Madaus, G. F., \& Kellaghan, T. (Ed.), Evaluation models: Viewpoints on 
educational and human services evaluation (2nd ed.), (pp. 279-317). Rorwell, MA: Kluwer Academic Publishers.

Stufflebeam, D. L., \& Zhang, G. (2017). The CIPP evaluation model: How to evaluate for improvement and accountability. New York, NY: The Guilford Press.

Taylor, M. (2013). Shared governance in the modern university. Higher Education Quarterly 67(1), 80-94. doi:10.1111/hequ.12003

Tierney, W. G. (1988). Organizational culture in higher education: Defining the essentials. The Journal of Higher Education, 59(1), 2-21.

Tierney, W. G. (2008). The impact of culture on organizational decision making: Theory and practice in higher education. Sterling, VA: Stylus.

Von Krogh, G., Nonaka, I., \& Rechsteiner, L. (2012). Leadership in organizational knowledge creation: A review and framework. Journal of Management Studies, 49(1), 240-277.

Vroom, V. H. (1964). Work and motivation. San Francisco, CA: Jossey-Bass.

Walsh, L., \& Kahn, P. (2010). Collaborative working in higher education: The social academy. New York, NY: Routledge.

Wang, V. C. X. (2009). Assessing and evaluating adult learning in career and technical education. Hershey, PA: Zhejiang University Press.

Weick, K. (1978/1983). Educational organizations as loosley coupled systems. In J. V. Baldridge, \& T. Deal, The dynamics of organizational change in eduction (pp. 1536). Berkeley, CA: McCutchan Publishing.

Weick, K. (1995). Sensemaking in organizations. Thousand Oaks, CA: Sage. 
Wenger, E. (1999). Communities of practice: Learning, meaning, and identity. New York, NY: Cambridge University Press.

Wergin, J. F. (2001). Beyond carrots and sticks: What really motivates faculty. Liberal Education, 87(1), 50-53.

Wong, P. T. P. (2006). Is your organization an obstacle course or a relay team? A meaning-centered approach to creating a collaborative culture. In S. Schuman (Ed.), Creating a culture of collaboration (pp. 229-255). San Francisco, CA: Jossey-Bass.

Wright, D. B. \& London, K. (2013). First and second steps in statistics (2nd ed.). Thousand Oaks, CA: Sage.

Yin, R. K. (2000). Case study evaluations: A decade of progress? In D. L. Stufflebeam, G. F. Madaus, \& T. Kellaghan, (Eds.), Evaluation models: Viewpoints on educational and human services evaluation (2nd ed.), (pp. 185-193). Rorwell, MA: Kluwer Academic Publishers.

Yukl, G., \& Falbe, C. M. (1990). Influence tactics and objectives in upward, downward, and lateral influence attempts. Journal of Applied Psychology, 75(2), 132-140. 
Appendix A

Invitation Email and Reminders

\section{Invitation to Participate Email}

As a Missouri State University faculty member, you are invited to participate in an online survey in regard to professional learning activities at the university. This survey is part of a research study evaluating factors that impact faculty engagement in professional learning.

The survey is very brief and should only take 8 to 10 minutes to complete. This is an anonymous survey and no personal information will be collected through the online survey process. There is no compensation for participating in this study. However, your participation will be valuable to this research and the findings of this study will be used to improve professional learning activities at the university.

Surveys should be completed by [DATE]. If you have any questions please contact nancygordon@ missouristate.edu.

Thank you.

\section{Reminder Email}

A few days ago you were invited to participate in an online survey in regard to professional learning activities at the university. If you have already completed the survey, thank you for your valuable input. If not, please complete the survey by [DATE].

This is a very brief survey and should only take 8 to 10 minutes to complete. Your participation is valuable to this research and the findings of this study will be used to improve professional learning activities at the university.

If you have any questions please contact nancygordon@ missouristate.edu. 
Appendix B

Informed Consent Forms

CONSENT Form to ParticiPate IN A ReSEARCh StUdy: OnLINE SURVEY

Researcher's Name(s): Nancy Gordon

Project Number:

Project Title:

\section{INTRODUCTION}

This consent may contain words that you do not understand. Please ask the investigator or the study staff to explain any words or information that you do not clearly understand.

You are being asked to participate in a research study. This research is being conducted to understand faculty value placed on professional learning activities. When you are invited to participate in research, you have the right to be informed about the study procedures so that you can decide whether you want to consent to participation. This form may contain words that you do not know. Please ask the researcher to explain any words or information that you do not understand.

You have the right to know what you will be asked to do so that you can decide whether or not to be in the study. Your participation is voluntary. You do not have to be in the study if you do not want to. You may refuse to be in the study and nothing will happen. If you do not want to continue to be in the study, you may stop at any time without penalty or loss of benefits to which you are otherwise entitled.

\section{WHY IS THIS STUDY BEING DONE?}

The purpose of this research is to understand faculty value placed on professional learning activities and align processes that support such activities.

HOW MANY PEOPLE WILL BE IN THE STUDY?

About 200 people will take part in this study at Missouri State University.

WHAT AM I BEING ASKED TO DO?

You will be asked to participate because you are a faculty member at Missouri State University.

HOW LONG WILL I BE IN THE STUDY?

This study will extend over a four week period and your participation will take approximately 8 to 10 minutes to complete. You can stop participating at any time without penalty.

WHAT ARE THE BENEFITS OF BEING IN THE STUDY? 
Your participation will benefit the offerings and delivery of professional learning activities at Missouri State University.

\section{WHAT OTHER OPTIONS ARE THERE?}

You also have the option of not participating in this study, and will not be penalized for your decision.

\section{CONFIDENTIALITY}

Your responses to this survey are anonymous and no IP information will be captured. Information produced by this study will be stored in the investigator's file and identified by a code number only.

\section{WILL I BE COMPENSATED FOR PARTICIPATING IN THE STUDY?}

You will receive no payment for taking part in this study.

\section{WHAT ARE MY RIGHTS AS A PARTICIPANT?}

Participation in this study is voluntary. You do not have to participate in this study.

You will also be informed of any new information discovered during the course of this study that might influence your health, welfare, or willingness to be in this study.

\section{WHO DO I CONTACT IF I HAVE QUESTIONS, CONCERNS, OR COMPLAINTS?}

Please contact nancygordon@ missouristate.edu if you have questions about the research. Additionally, you may ask questions, voice concerns or complaints to the research team.

\section{WHOM DO I CALL IF I HAVE QUESTIONS OR PROBLEMS?}

If you have any questions regarding your rights as a participant in this research and/or concerns about the study, or if you feel under any pressure to enroll or to continue to participate in this study, you may contact the University of Missouri Campus Institutional Review Board (which is a group of people who review the research studies to protect participants' rights) at (573) 882-9585 or umcresearchcirb@ missouri.edu.

You may ask more questions about the study at any time. For questions about the study contact Nancy Gordon at 417-836-8396.

Clicking on the 'Agree' button indicates you have read the above information and voluntarily agree to participate in this study.

If you do not wish to participate, please decline by clicking on the 'Disagree' button.

Thank you. 


\section{CONSENT FoRM TO PARTICIPATE IN A RESEARCH STUDY: FocUs GROUP ONE}

Researcher's Name(s): Nancy Gordon

Project Number:

\section{Project Title:}

\section{INTRODUCTION}

This consent may contain words that you do not understand. Please ask the investigator or the study staff to explain any words or information that you do not clearly understand.

You are being asked to participate in a research study. This research is being conducted to understand faculty value placed on professional learning activities. When you are invited to participate in research, you have the right to be informed about the study procedures so that you can decide whether you want to consent to participation. This form may contain words that you do not know. Please ask the researcher to explain any words or information that you do not understand.

You have the right to know what you will be asked to do so that you can decide whether or not to be in the study. Your participation is voluntary. You do not have to be in the study if you do not want to. You may refuse to be in the study and nothing will happen. If you do not want to continue to be in the study, you may stop at any time without penalty or loss of benefits to which you are otherwise entitled.

\section{WHY IS THIS STUDY BEING DONE?}

The purpose of this research is to understand faculty value placed on professional learning activities and align processes that support such activities.

\section{HOW MANY PEOPLE WILL BE IN THE STUDY?}

About 200 people will take part in this study at Missouri State University.

\section{WHAT AM I BEING ASKED TO DO?}

You will be asked to participate because you are a faculty member at Missouri State University that has previously participated in professional learning activities sponsored through the Faculty Center for Teaching and Learning.

\section{HOW LONG WILL I BE IN THE STUDY?}

This study will extend over a four week period and your participation in this focus group will take approximately 90 minutes to complete. You can stop participating at any time without penalty. 


\section{WHAT ARE THE BENEFITS OF BEING IN THE STUDY?}

Your participation will benefit the offerings and delivery of professional learning activities at Missouri State University.

\section{WHAT OTHER OPTIONS ARE THERE?}

You also have the option of not participating in this study, and will not be penalized for your decision.

\section{CONFIDENTIALITY}

Your participation in this focus group discussion will not be identified with you personally. Information produced by this study will be stored in the investigator's file and identified by a code number only. The code key connecting your name to specific information about you will be kept in a separate, secure location. Information contained in your records may not be given to anyone unaffiliated with the study in a form that could identify you without your written consent, except as required by law.

In addition, any audiotapes created during the study that could identify you, then you must give special written permission for their use. In that case, you will be given the opportunity to view or listen, as applicable, to the photographs, audiotapes or videotapes before you give your permission for their use if you so request.

\section{WILL I BE COMPENSATED FOR PARTICIPATING IN THE STUDY?}

You will receive no payment for taking part in this study.

\section{WHAT ARE MY RIGHTS AS A PARTICIPANT?}

Participation in this study is voluntary. You do not have to participate in this study.

You will also be informed of any new information discovered during the course of this study that might influence your health, welfare, or willingness to be in this study.

WHO DO I CONTACT IF I HAVE QUESTIONS, CONCERNS, OR COMPLAINTS? Please contact nancygordon@missouristate.edu if you have questions about the research. Additionally, you may ask questions, voice concerns or complaints to the research team.

\section{WHOM DO I CALL IF I HAVE QUESTIONS OR PROBLEMS?}

If you have any questions regarding your rights as a participant in this research and/or concerns about the study, or if you feel under any pressure to enroll or to continue to participate in this study, you may contact the University of Missouri Campus Institutional Review Board (which is a group of people who review the research studies to protect participants' rights) at (573) 882-9585 or umcresearchcirb@ missouri.edu.

You may ask more questions about the study at any time. For questions about the study contact Nancy Gordon at 417-836-8396. 
A copy of this Informed Consent form will be given to you before you participate in the research.

\section{SIGNATURES}

I have read this consent form and my questions have been answered. My signature below means that I do want to be in the study. I know that I can remove myself from the study at any time without any problems.

Subject

Date 


\section{CONSENT FoRM TO PARTICIPATE IN A RESEARCH STUDY: FOCUS GROUP TwO}

Researcher's Name(s): Nancy Gordon

Project Number:

Project Title:

\section{INTRODUCTION}

This consent may contain words that you do not understand. Please ask the investigator or the study staff to explain any words or information that you do not clearly understand.

You are being asked to participate in a research study. This research is being conducted to understand faculty value placed on professional learning activities. When you are invited to participate in research, you have the right to be informed about the study procedures so that you can decide whether you want to consent to participation. This form may contain words that you do not know. Please ask the researcher to explain any words or information that you do not understand.

You have the right to know what you will be asked to do so that you can decide whether or not to be in the study. Your participation is voluntary. You do not have to be in the study if you do not want to. You may refuse to be in the study and nothing will happen. If you do not want to continue to be in the study, you may stop at any time without penalty or loss of benefits to which you are otherwise entitled.

\section{WHY IS THIS STUDY BEING DONE?}

The purpose of this research is to understand faculty value placed on professional learning activities and align processes that support such activities.

\section{HOW MANY PEOPLE WILL BE IN THE STUDY?}

About 200 people will take part in this study at Missouri State University.

\section{WHAT AM I BEING ASKED TO DO?}

You will be asked to participate because you are a faculty member at Missouri State University that has not participated in any professional learning activities sponsored through the Faculty Center for Teaching and Learning.

\section{HOW LONG WILL I BE IN THE STUDY?}

This study will extend over a two week period and your participation in this focus group will take approximately 90 minutes to complete. You can stop participating at any time without penalty. 


\section{WHAT ARE THE BENEFITS OF BEING IN THE STUDY?}

Your participation will benefit the offerings and delivery of professional learning activities at Missouri State University.

\section{WHAT OTHER OPTIONS ARE THERE?}

You also have the option of not participating in this study, and will not be penalized for your decision.

\section{CONFIDENTIALITY}

Your participation in this focus group discussion will not be identified with you personally. Information produced by this study will be stored in the investigator's file and identified by a code number only. The code key connecting your name to specific information about you will be kept in a separate, secure location. Information contained in your records may not be given to anyone unaffiliated with the study in a form that could identify you without your written consent, except as required by law.

In addition, any audiotapes created during the study that could identify you, then you must give special written permission for their use. In that case, you will be given the opportunity to view or listen, as applicable, to the photographs, audiotapes or videotapes before you give your permission for their use if you so request.

\section{WILL I BE COMPENSATED FOR PARTICIPATING IN THE STUDY?}

You will receive no payment for taking part in this study.

\section{WHAT ARE MY RIGHTS AS A PARTICIPANT?}

Participation in this study is voluntary. You do not have to participate in this study.

You will also be informed of any new information discovered during the course of this study that might influence your health, welfare, or willingness to be in this study.

WHO DO I CONTACT IF I HAVE QUESTIONS, CONCERNS, OR COMPLAINTS? Please contact nancygordon@missouristate.edu if you have questions about the research. Additionally, you may ask questions, voice concerns or complaints to the research team.

\section{WHOM DO I CALL IF I HAVE QUESTIONS OR PROBLEMS?}

If you have any questions regarding your rights as a participant in this research and/or concerns about the study, or if you feel under any pressure to enroll or to continue to participate in this study, you may contact the University of Missouri Campus Institutional Review Board (which is a group of people who review the research studies to protect participants' rights) at (573) 882-9585 or umcresearchcirb@ missouri.edu.

You may ask more questions about the study at any time. For questions about the study contact Nancy Gordon at 417-836-8396. 
A copy of this Informed Consent form will be given to you before you participate in the research.

\section{SIGNATURES}

I have read this consent form and my questions have been answered. My signature below means that I do want to be in the study. I know that I can remove myself from the study at any time without any problems.

Subject

Date 


\section{Appendix C}

Online Survey Instrument

Online Survey Questions

\begin{tabular}{|c|c|c|}
\hline Research Question & Survey Items & Response Choices \\
\hline $\begin{array}{l}\text { 1.a Communication } \\
\text { Processes }\end{array}$ & $\begin{array}{l}\text { How do you hear about FCTL } \\
\text { professional learning activities? }\end{array}$ & $\begin{array}{l}\text { Please select all that apply: } \\
\text { - What's Happening } \\
\text { email } \\
\text { - Inside Missouri State } \\
\text { - Provost Communique } \\
\text { - Calendar of Events } \\
\text { - FCTL Webpage } \\
\text { - Dean or Dept. Head } \\
\text { - Faculty/Colleague } \\
\text { - Other }\end{array}$ \\
\hline $\begin{array}{l}\text { 1.a Communication } \\
\text { Processes }\end{array}$ & $\begin{array}{l}\text { What do you think are the best } \\
\text { way to advertise professional } \\
\text { learning activities? }\end{array}$ & Open Response \\
\hline $\begin{array}{l}\text { 1.b Faculty } \\
\text { Awareness }\end{array}$ & $\begin{array}{l}\text { Are you aware that these } \\
\text { activities are available to faculty? } \\
\text { - Showcase on Teaching and } \\
\text { Learning } \\
\text { - Faculty Writing Program } \\
\text { - Accessibility Institute } \\
\text { - Diversity Mini-Workshops } \\
\text { - Online Course Development } \\
\text { Boot Camp (formally known } \\
\text { as DPA or Digital Professor } \\
\text { Academy) } \\
\text { - Curriculum Innovation Grants } \\
\text { - Teaching Awards } \\
\text { - Assistance with designing } \\
\text { online instruction } \\
\text { - Assistance with using } \\
\text { instructional technology } \\
\text { - Assistance with creating } \\
\text { course work that engages } \\
\text { students }\end{array}$ & $\begin{array}{l}\text { Likert Scale } \\
\text { 1. Have never heard of it } \\
\text { 2. Somewhat familiar } \\
\text { 3. Yes, I'm familiar with } \\
\text { this } \\
\text { 4. I have participated in } \\
\text { this }\end{array}$ \\
\hline
\end{tabular}




\begin{tabular}{|c|c|c|}
\hline & $\begin{array}{l}\text { - Assistance with making } \\
\text { course materials more } \\
\text { accessible to students with } \\
\text { disabilities } \\
\text { - Assistance creating lecture } \\
\text { capture using MediaSite }\end{array}$ & \\
\hline $\begin{array}{l}\text { 2.a. Expectant } \\
\text { Value }\end{array}$ & $\begin{array}{l}\text { To what extent would the } \\
\text { following professional learning } \\
\text { activities be helpful? } \\
\text { - A public forum to share } \\
\text { teaching practices } \\
\text { - A dedicated time and space to } \\
\text { focus on writing } \\
\text { - Resources to help to make } \\
\text { course materials more } \\
\text { accessible to students with } \\
\text { disabilities } \\
\text { - Faculty discussion on how to } \\
\text { integrate cultural diversity } \\
\text { into teaching practices } \\
\text { - Assistance with developing } \\
\text { online courses } \\
\text { - Assistance with using } \\
\text { instructional technology } \\
\text { - Walk-in studio where faculty } \\
\text { can record lectures } \\
\text { - Financial support or grant } \\
\text { money to revise curriculum } \\
\text { - The reward of teaching } \\
\text { excellence }\end{array}$ & $\begin{array}{l}\text { Likert Scale } \\
\text { 1. Not at all } \\
\text { 2. Somewhat } \\
\text { 3. Extremely }\end{array}$ \\
\hline 2.b Actual Value & $\begin{array}{l}\text { Please add any comments you } \\
\text { may have about the helpfulness of } \\
\text { these activities }\end{array}$ & Open Response \\
\hline 3. Barriers & $\begin{array}{l}\text { What barriers prohibit you from } \\
\text { participating in the following } \\
\text { professional learning activities? } \\
\text { - Showcase on Teaching and } \\
\text { Learning } \\
\text { - Faculty Writing Program } \\
\text { - Accessibility Institute } \\
\text { - Diversity Mini-Workshops }\end{array}$ & $\begin{array}{l}\text { Likert Scale } \\
\text { Please select all that apply: } \\
\text { 1. I'm too busy } \\
\text { 2. Not relevant } \\
\text { 3. Scheduling conflicts } \\
\text { 4. Other }\end{array}$ \\
\hline
\end{tabular}




\begin{tabular}{|c|c|c|}
\hline & $\begin{array}{l}\text { - Online Course Development } \\
\text { Boot Camp (formally known } \\
\text { as DPA or Digital Professor } \\
\text { Academy) } \\
\text { - Curriculum Innovation Grants } \\
\text { - Teaching Awards } \\
\text { - Assistance with designing } \\
\text { online instruction } \\
\text { - Assistance with using } \\
\text { instructional technology } \\
\text { - Assistance with creating } \\
\text { course work that engages } \\
\text { students } \\
\text { - Assistance with making } \\
\text { course materials more } \\
\text { accessible to students with } \\
\text { disabilities } \\
\text { - Assistance creating lecture } \\
\text { capture using MediaSite }\end{array}$ & \\
\hline 3. Barriers & $\begin{array}{l}\text { What might be some ways to } \\
\text { remove these barriers to make it } \\
\text { easier for you to participate? }\end{array}$ & Open Response \\
\hline 3. Barriers & $\begin{array}{l}\text { Would you be interested in } \\
\text { accessing professional learning } \\
\text { activities from your office } \\
\text { computer? }\end{array}$ & $\begin{array}{l}\text { Likert Scale and Open } \\
\text { Response: } \\
\text { 1. Not at all } \\
\text { 2. Somewhat } \\
\text { 3. Extremely }\end{array}$ \\
\hline
\end{tabular}




\section{Appendix D}

\section{Focus Group Interview Protocol}

The first focus group will be selected from a pool of approximately 200 faculty who have participated in professional learning activities through the Faculty Center for Teaching and Learning (FCTL). Attendance and participation is maintained using a database and 40 faculty members will be invited to participate in this focus group

The second focus group will be faculty who have not participated in professional learning activities through the faculty center. College distribution lists will be compared to the participant database to come up with potential 40 faculty members to take part in this focus group.

Participation in either focus group will be voluntary. Faculty will be informed about the purpose of the survey, why their input is being sought and how the data will be used (Seidman, 2013). The focus group will be recorded and the researcher will be taking notes during the session. Participants will receive an informed consent form that includes acknowledgment of the session being recorded, participants' rights and any potential risks for participating or not participating, possible benefits, confidentiality of records, dissemination of survey results, and contact information (Seidman, 2013).

\section{Focus Group Script}

I am the moderator for today's focus group. The purpose of our discussion today is to learn more about factors impacting faculty engagement in professional learning activities at Missouri State University. I am passing around a consent form and by signing this form you are agreeing to participate in the focus group. Our discussion here 
is confidential but if you feel uncomfortable for any reason, you are free to leave at any time. Please take a moment to read over the consent form.

Before we begin, I would like to go over a few ground rules for the focus group.

\section{Ground Rules}

- Confidentiality - please respect the confidentiality of your peers. The moderator will record all responses as anonymous with no identifying information

- One Speaker at a Time - I will be taking notes, so please only one person should speak at a time in order to be sure we can hear what everyone is saying.

- Open discussion - please openly express your opinions, viewpoints, and experiences. We only ask that you are respectful in your language and avoid any statements or words that may be offensive to other members of the group.

- Participation is important - you have been invited to be part of this focus group and it is important that you participate. We want to hear what you have to say!

\section{Questions}

- How do you hear about FCTL professional learning activities?

- What do you think are the best way to advertise professional learning activities?

- What FCTL professional learning activities are you familiar with?

- Can you comment on the helpfulness of any of the professional learning activities you've participated in?

- What professional learning activities would you find helpful?

- What might be some barriers that prohibit you from participating in professional learning activities? 
- What might be some ways to remove these barriers to make it easier for you to participate?

- Would you be interested in accessing professional learning activities from your office computer?

\section{Conclusion}

Thank you for participating in today's focus group. If you think of any additional thoughts or comments you would like to add after today, please contact me at [ ]. 


\section{Appendix E}

Perceived Cultural and Systems Barriers for Participation in Professional Learning Activities

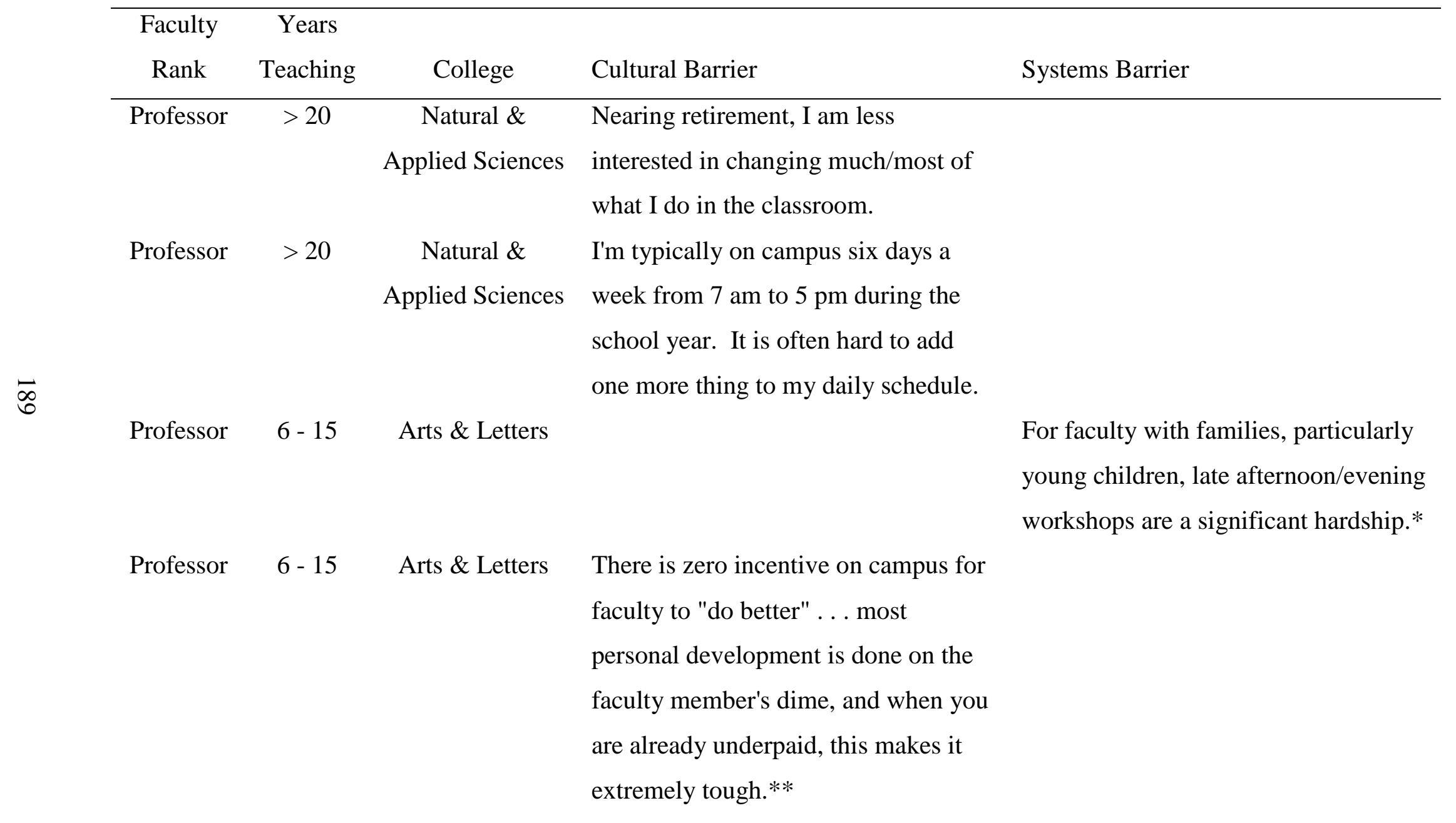




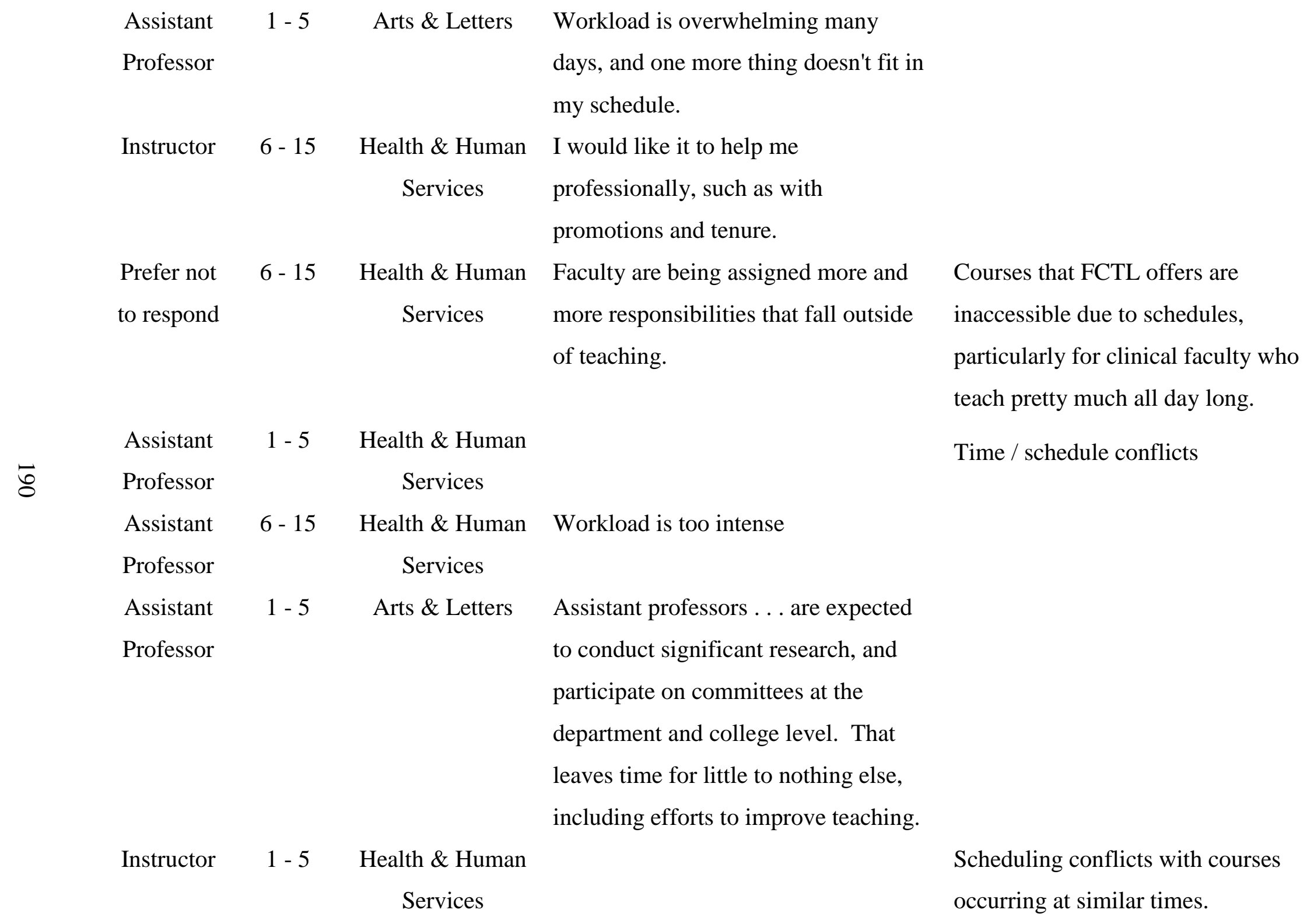




$\begin{array}{lll}\text { Instructor } \quad<1 \quad \text { Education } \\ \\ \text { Assistant } 1-5 \quad \text { Arts \& Letters } \quad \text { Dedicated time and space to focus on } \\ \text { Professor } & \text { writing - this is the one thing I wish I } \\ & \text { could have more than anything. But I } \\ & \text { have been asked to teach an overload } \\ & \text { every semester I've worked here, and . } \\ & \ldots \text { between rehearsals and classes ... } \\ & \text { meetings (both student meetings and } \\ & \text { committee meetings). I definitely feel } \\ & \text { like I am caught in a lose/lose } \\ & \text { situation as far as both my } \\ & \text { professional development and my } \\ & \text { mental and physical health are } \\ & \text { concerned. }\end{array}$

Instructor $\quad<1 \quad$ Humanities \&

Public Affairs
There are SO many opportunities available that it is impossible to take advantage of all of them in my first year.

It's hard to gage how relevant each of these will be for me. 


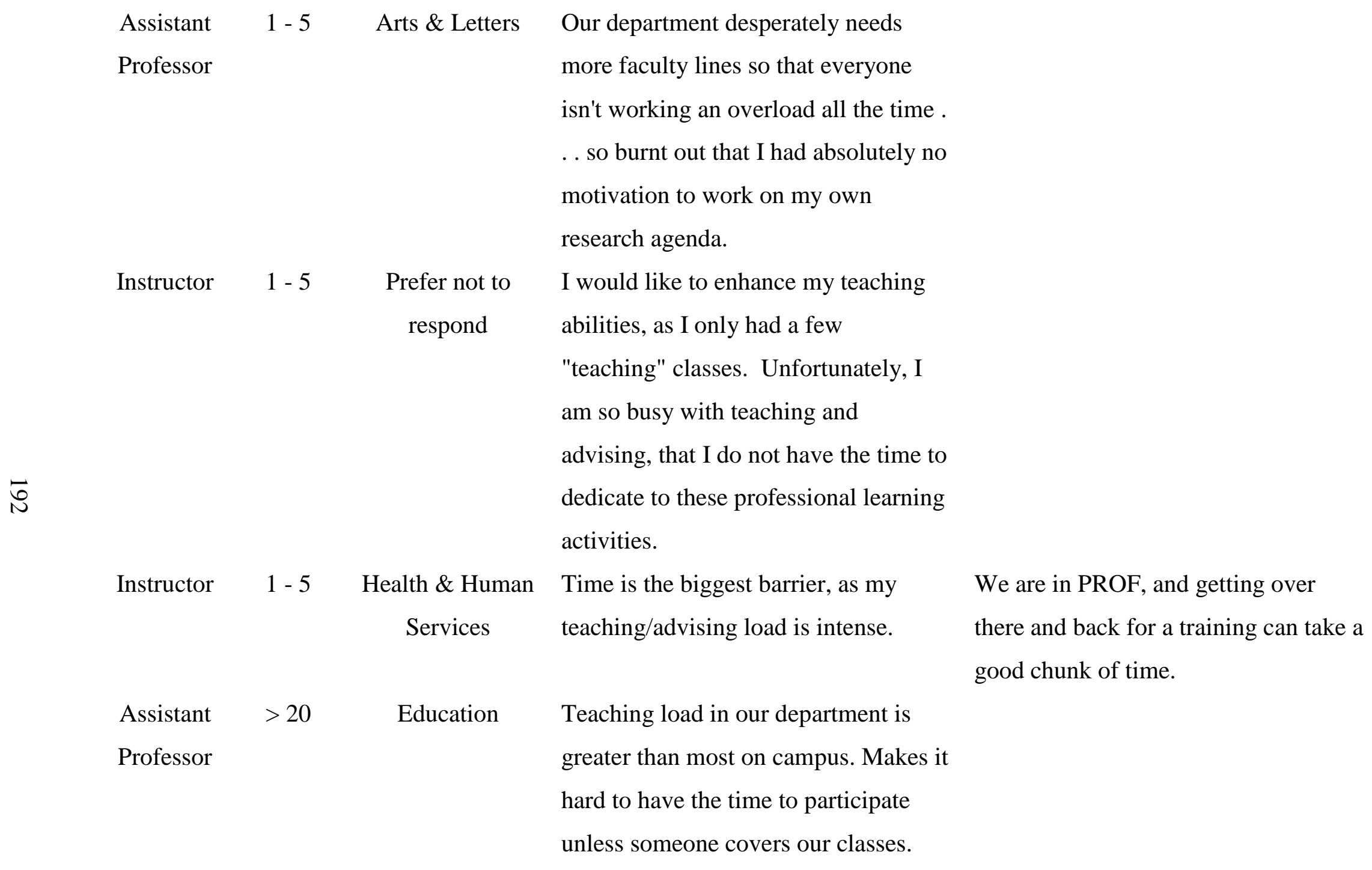




\begin{tabular}{|c|c|c|c|}
\hline $\begin{array}{l}\text { Associate } \\
\text { Professor }\end{array}$ & $6-15$ & $\begin{array}{c}\text { Health \& Human } \\
\text { Services }\end{array}$ & $\begin{array}{l}\text { Increasing service demands and } \\
\text { advising loads (as faculty retire and } \\
\text { are not replaced) has put a big strain } \\
\text { on faculty. }\end{array}$ \\
\hline $\begin{array}{l}\text { Assistant } \\
\text { Professor }\end{array}$ & $16-20$ & $\begin{array}{c}\text { Health \& Human } \\
\text { Services }\end{array}$ & \\
\hline Professor & $6-15$ & Arts \& Letters & $\begin{array}{l}\text { In my department we work 60-70 } \\
\text { hours a week. We are all overloaded. }\end{array}$ \\
\hline Instructor & $1-5$ & $\begin{array}{l}\text { Health \& Human } \\
\text { Services }\end{array}$ & $\begin{array}{l}\text { I want to do a lot of these things but I } \\
\text { am already grading and doing lecture } \\
\text { prep at home outside of my } 40+\text { hours }\end{array}$ \\
\hline & & & $\begin{array}{l}\text { I am in my office or the classroom. I } \\
\text { feel like the expectations to improve } \\
\text { are never ending and the resources to } \\
\text { actually do it are not available. }\end{array}$ \\
\hline $\begin{array}{l}\text { Assistant } \\
\text { Professor }\end{array}$ & $<1$ & Education & \\
\hline $\begin{array}{l}\text { Assistant } \\
\text { Professor }\end{array}$ & $<1$ & Education & \\
\hline
\end{tabular}

It seems that many of the offerings are during times that I have class.

Occasionally I have scheduling issues, but these are sometimes unavoidable For scheduling, sometimes it is the time of day and sometimes the time of the semester that is challenging. 


Associate $1-5 \quad$ Arts \& Letters
Professor

Education

Instructor

Arts \& Letters

Associate

$1-5$

Professor

(n)

$$
6-15
$$

I would like to know more about what FCTL can do for individual faculty members, but I almost never hear about that. A lot of the workshops, at least the large-scale ones, are at times when it is difficult for me to participate.

I'm not sure I WANT to participate in some of them. For example, I've heard that DPA (online course development) is a lot of work ...

Time is always a factor and at MSU, parking on campus is prohibitive of participating in activities that are provided on campus-
When hired as an instructor, I had the time to participate because my course load was 12 hours of lower case undergraduate classes Now my course load is 15 hours of higher level courses including graduate courses. In addition ... we are expected to serve 
on committees, including search committees. I have been told by

higher ups that instructors are

considered the slave labor.

$\begin{array}{ll}\text { Instructor } & <1 \quad \begin{array}{l}\text { Humanities \& } \\ \text { Public Affairs }\end{array}\end{array}$

Assistant

$<1$

Professor

vi

$\begin{array}{lll}\text { Instructor } & 6-15 & \text { Agriculture } \\ \text { Associate } & 6-15 & \text { Business } \\ \text { Professor } & & \end{array}$

Humanities \&

Public Affairs

For tenure, sadly but true, teaching is

not weighed as much as research.

Once tenured, professors have little

motivating them to be innovative in the classroom as pay and other

benefits are usually tied to research

production.

Really most of these barriers are just trying to find time to do things I know need to be done.

Admistrators focus $95 \%$ on getting and retaining more students because that equals increased REVENUE . . . administrators care very little about
There's all sorts of things going on and, furthermore, it's hard to gauge how relevant each of these will be for me. 
providing a quality education, and the

current system at Missouri State

DOES NOT reward professional

professors who provide quality

education.

$\begin{array}{ccc}\text { Assistant } & 6-15 & \text { Health \& Human } \\ \text { Professor } & & \text { Services }\end{array}$

Professor $16-20 \quad$ Libraries

๘ั

Assistant $\quad<1 \quad$ Arts \& Letters

Professor
Time is always a barrier, particularly as we expand our responsibilities as faculty numbers shrink.
As a clinical person, it is very difficult to take advantage of the many opportunities due to the need to be in the community or out of town when these are offered.

Some of these activities I just don't know much about, so it's difficult to decide whether I fit into the program.

Note. *Face-to-face professional learning activities are not offered during the evening. **Professional learning activities are not fee based nor does the faculty center charge for services. 


\section{VITA}

Nancy Gordon, is Director for the Faculty Center for Teaching and Learning at Missouri State University. She earned an EdD in Educational Leadership and Policy Development from the University of Missouri. Her scholar interests include faculty as learners, adult learning theory, and educational technology. 